Portland State University

PDXScholar

$5-22-2020$

\title{
Faculty Use of Collaborative Online International Learning (COIL) for Internationalization at Home
}

Sally Strand Mudiamu

Portland State University

Follow this and additional works at: https://pdxscholar.library.pdx.edu/open_access_etds

Part of the Higher Education Commons, and the International and Comparative Education Commons Let us know how access to this document benefits you.

Recommended Citation

Mudiamu, Sally Strand, "Faculty Use of Collaborative Online International Learning (COIL) for Internationalization at Home" (2020). Dissertations and Theses. Paper 5470.

https://doi.org/10.15760/etd.7342

This Dissertation is brought to you for free and open access. It has been accepted for inclusion in Dissertations and Theses by an authorized administrator of PDXScholar. Please contact us if we can make this document more accessible: pdxscholar@pdx.edu. 
Faculty Use of Collaborative Online International Learning (COIL) for

Internationalization at Home

by

Sally Strand Mudiamu

A dissertation submitted in partial fulfillment of the requirements for the degree of

Doctor of Education

in

Educational Leadership: Postsecondary Education

Dissertation Committee:

Karen Haley, Chair

Dilafruz Williams

Yoko Sakurauchi

Kimberley Brown

Portland State University

2020 
(C) Sally Strand Mudiamu 


\begin{abstract}
Universities are not preparing all of their students for $21^{\text {st }}$ century global work and citizenship. Internationalization of the Curriculum is critical to this preparation and equity in higher education. Over the past decades, universities have relied on outbound and inbound student mobility to internationalize their institutions, the curriculum, the faculty, and student learning. However, $90 \%$ of U.S. students neither study nor intern abroad. Of the $10 \%$ who do go abroad, very few are underrepresented, Pell-eligible, or post-traditional students. Universities need to shift their focus from student mobility to Internationalization at Home so that all students may have an internationalized education experience as part of their degree. This qualitative study examined faculty experience in teaching Collaborative Online International Learning courses as a pedagogical approach with curricular implications for Internationalization at Home. The interview data and analysis have implications for institutional internationalization strategy to equitably prepare all students for $21^{\text {st }}$ century global work and citizenship. Key findings include that Collaborative Online International Learning is a faculty-driven intervention for Internationalization at Home, giving all students opportunities for global learning and engagement.
\end{abstract}


Dedication

To my family:

Bernard N., Sarah, Aimée, Bernard M. \& Lukusa Mudiamu

For my parents:

Larry \& Harriet Strand 


\section{Acknowledgements}

My deepest thanks goes to my advisor, Karen J. Haley, for taking me on as an advisee and shepherding me through the dissertation journey. Her calm and patient guidance was critical to this endeavor. Her generosity of time spent with me thinking through the study and reading endless drafts will make me forever grateful.

I want to thank my dissertation committee: Dilafruz Williams, Yoko Sakurauchi and Kimberley Brown. It is an honor for me to have you share your tremendous breadth and depth of knowledge around global learning in higher education. Thank you for the time you have invested in me.

I also want to recognize my cohort, who were my "brain trust" for this dissertation. Their unwavering support and solidarity made this learning experience the best of my life. Thank you for being such amazing colleagues.

My family's support and sacrifices made it possible for me to be a doctoral student. For my husband, Bernard: Thank you for believing in me. Sarah, Aimée, Bernard and Lukusa: This degree is for you. I hope you will be inspired to pursue lifelong learning to develop your gifts so as to share them with the world.

For my parents Larry and Harriet Strand: They laid the foundation for every accomplishment and success I've ever had. I wished they had lived to see this day. They spent their lives lifting up others. May I do the same in my work as a scholarpractitioner. 


\section{Table of Contents}

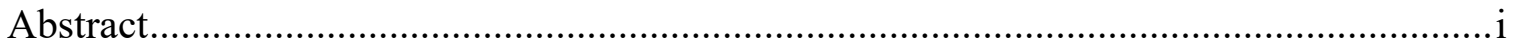

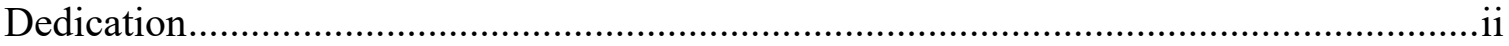

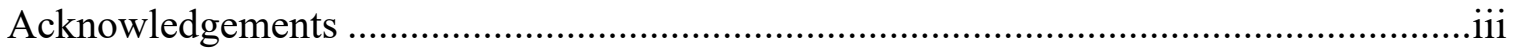

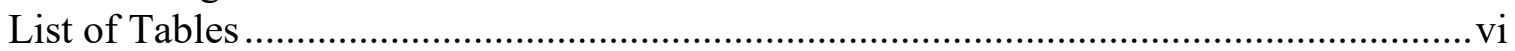

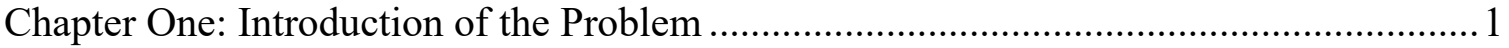

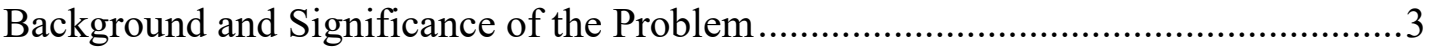

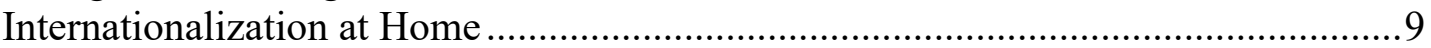

Statement of the Research Problem...................................................................... 11

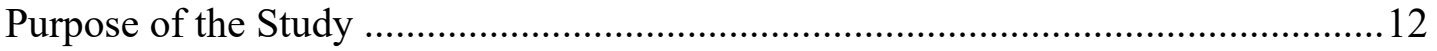

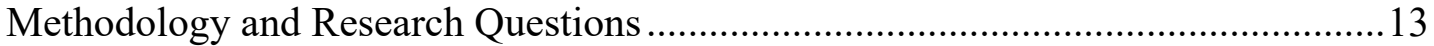

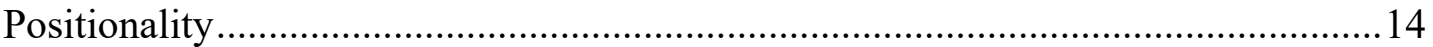

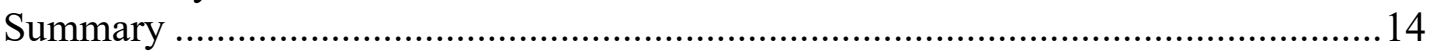

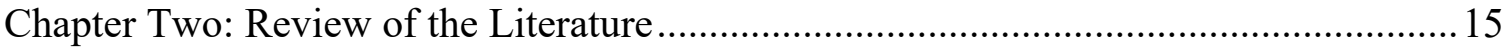

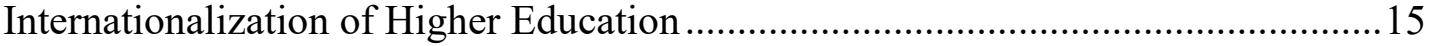

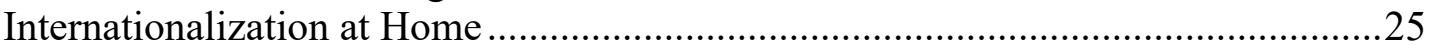

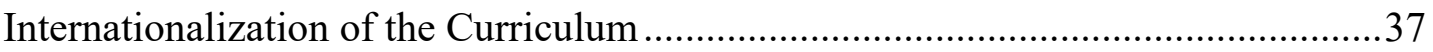

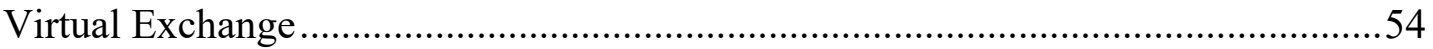

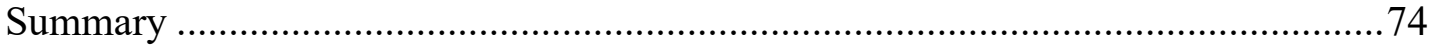

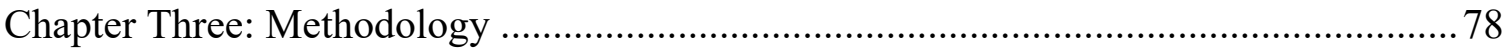

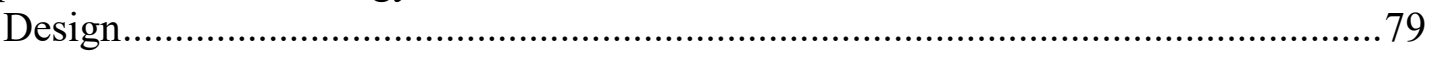

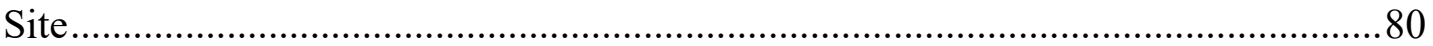

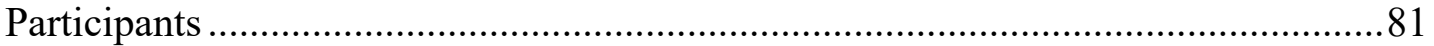

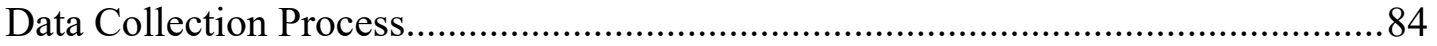

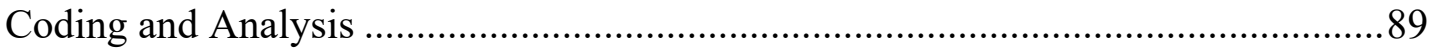

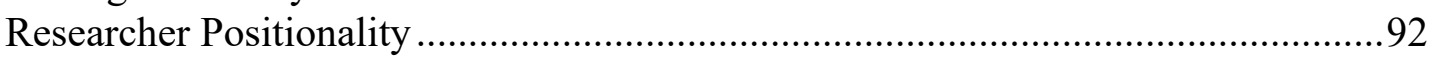

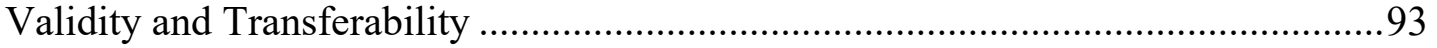

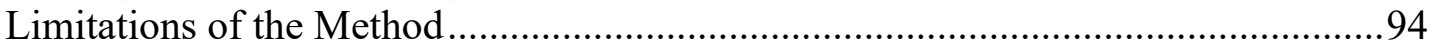

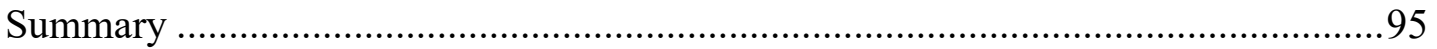

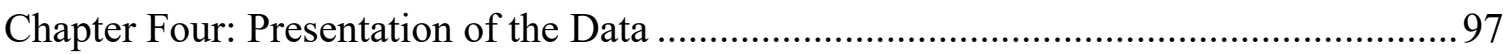

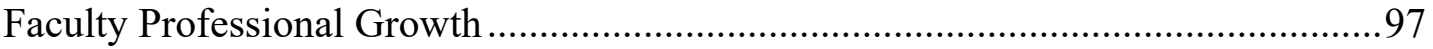

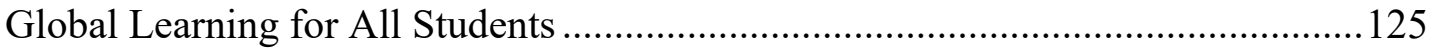

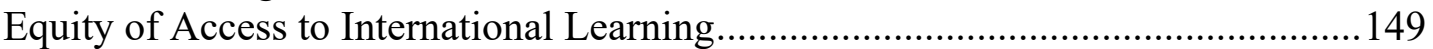

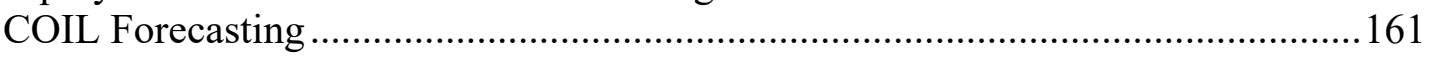

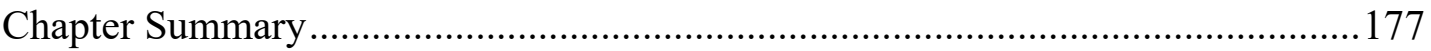


Chapter Five: Discussion and Implications for Practice ........................................... 181

COIL is a Faculty Intervention for Internationalization at Home ........................... 182

Faculty Use COIL to Prepare Students for $21^{\text {st }}$ Century Life ..................................186

Faculty Experienced Benefits to Teaching COIL ..................................................189

COIL Integrates UN Sustainable Development Goals into the Curriculum .............193

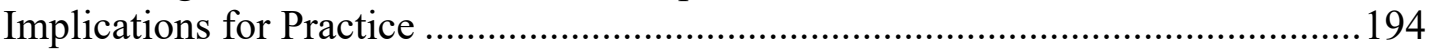

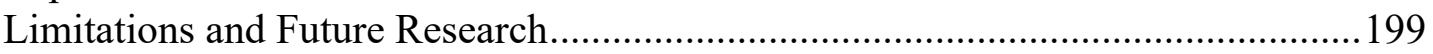

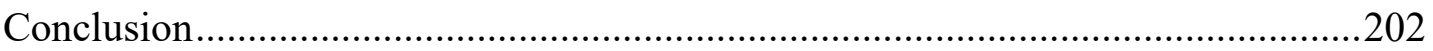

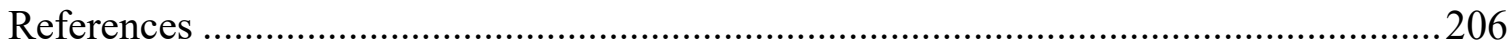

Appendix A: Interview Questions \& Protocol .................................................... 244

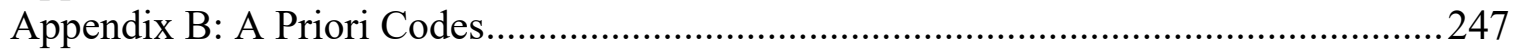

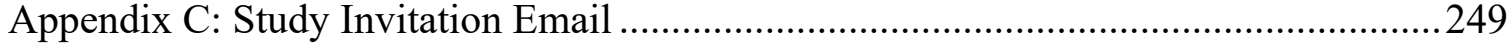

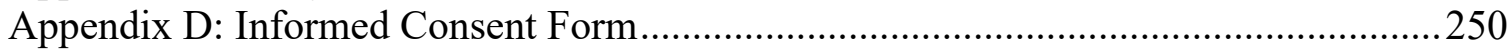

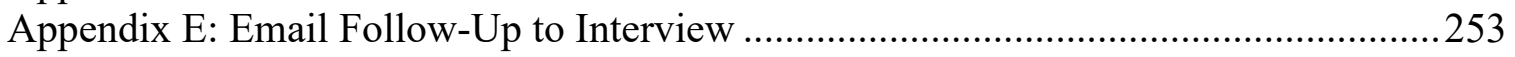




\author{
List of Tables
}

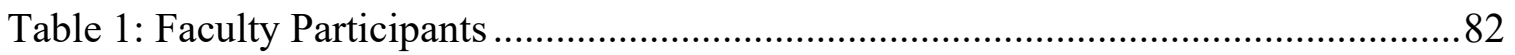


Chapter One: Introduction of the Problem

Universities are not preparing students, especially underrepresented students, for global work and citizenship in the $21^{\text {st }}$ century. This failure perpetuates structural social and economic inequalities for college graduates. First-generation and Pell-eligible students pursue higher education as a way of joining the middle class through professional mobility. However, those not prepared through a formal international education experience to participate in the global workforce will find that their bachelor's degrees worth less in the job marketplace. Lack of a global learning experience can also make students vulnerable to civic tribalism and nationalism, undermining the foundations of a liberal education.

Employers are asking for "career ready" graduates (World Economic Forum [WEF], 2016, 2020), especially those who have intercultural problem-solving skills. The Future of Jobs report by the World Economic Forum (2016) and UN 2030 Sustainable Development Goals (United Nations, 2015) both call for higher education that prepares students to work in a globally networked and globally sourced work environments. Nearly $80 \%$ of knowledge workers currently work on global virtual teams (Ferrazzi, 2014) and most jobs in the future will require the ability to do so. Therefore, practicing intercultural communication and problem solving virtually and collaboratively will be an important "career ready" preparation for all college graduates.

Possessing a sense of global citizenship (Andreotti, 2006; Banks, 2008; WEF, 2019) is vital to enhance students' critical thinking skills and informed action when 
navigating difference in their local communities as well as in the workplace. Global awareness fosters accountability towards learning with "the other," which is necessary prerequisite to sustain a pluralistic society (Andreotti, 2006; Banks, 2008; WEF, 2019) as well as to perform $21^{\text {st }}$ century work. Therefore, global competency is both skill and attitude which must be cultivated as part of a university education.

Universities are internationalizing themselves in response to the pressures of globalization. Indeed, internationalization has become ancillary to the mission of higher education. Institutions have adopted a holistic institutional approach to internationalization that is referred to as "Comprehensive Internationalization" (American Council on Education [ACE], 2015; Hudzik, 2011) or "pervasive internationalization" (Association of Public and Land-Grant Universities [APLU], 2017). The Center for International and Global Engagement at the American Council for Education has recommended six strategic areas for institutions to align their institutional priorities to become more "globally orientated and internationally connected institutions" (ACE, 2015). The foundation is an articulated institutional commitment to internationalization, such as a mission statement linked to internationalized learning outcomes, student mobility targets, and faculty research. There also must be adequate support from administrative leadership to create staffing structures to support internationalization goals. The curriculum, co-curriculum, and student learning outcomes should be informed by international learning for global citizenship and work. Faculty policies and practices, such as promotion and tenure, should be linked to Internationalization of the Curriculum and international joint research and publication. Outbound student mobility (study 
abroad) should receive the same resources as recruiting inbound international students. Finally, collaboration through public/private and international partnerships must be pursued to help universities better understand and respond to the needs of their communities and local employers.

These six focus areas of internationalization have been adopted by most universities in their mission statements, but there is uneven engagement in them (Hudzik, 2014). This uneven engagement can undermine institutional mandates that $100 \%$ of graduates leave with an international learning experience as part of their undergraduate degree (Landorf, Doscher, Hardrick, \& Musil, 2018; Waseda University, 2012). For example, many universities look at internationalization as a way to increase revenue to benefit local students through international student enrollments and international special programs. However, there is little articulation on how revenue generated from international student enrollments is to be invested or reallocated at the university to provide an international learning experience for all students (Hudzik, 2014). Similarly, universities pursue internationalization to increase their rankings and "brand" recognition (Hudzik, 2014) as a way to attract the most talented and motivated students (Astin, 2016). Again, there is a lack of clarity on how an improved world university ranking and bringing more "talented" students improves teaching and learning outcomes for all students (Hudzik, 2011).

\section{Background and Significance of the Problem}

Underrepresented students, who are pursuing higher education, are most vulnerable to the forces of globalization (Applegate, 2018; Morey, 2004). Wages are 
already lower for bachelor's degree holders raised on low incomes (Herschbein, 2016). Contemporary higher education inequalities are exacerbated for students at open access institutions, where notions of education for public good are undermined by neoliberal differentiation of disciplines and degrees (Altbach, 2013). A lack of an international learning experience as part of their degree will further hinder underrepresented graduates in a globally networked society.

Conversely, while lack of an international experience can lessen the value of a degree, the intentional addition of such an experience can mitigate structural disadvantages for underrepresented students. An international learning experience as part of the undergraduate curriculum is increasingly identified with social mobility and professional employment (Department of Education [DoE], 2012). Participation in international learning also improves the quality of undergraduate learning outcomes (Soria \& Troisi, 2014) and the perceived value of the baccalaureate degree by future employers (Bondi \& Matthews, 2017; Paige, Fry, Stallman, Josić \& Jon, 2009; Streitwieser, 2014). Finally, it empowers underrepresented students by defining themselves in a global community (Acquaye \& Crewe, 2012).

While universities have widened the overall scope of their international activities, they have continued to rely almost exclusively on Education Abroad programming to deliver global learning experiences to their students (Farrugia \& Sanger, 2017). Work to overcome the barriers of the "four F's"-faculty, finances, family and fears (Cole, 1991) — to Education Abroad has been unceasing at the institutional level. Universities participate in a national advocacy campaign, called Generation Study Abroad, through 
the Institute for International Education. They negotiate external non-profit Education Abroad providers to bring down instructional costs and offer scholarships. Where possible, grants have replaced traditional financial aid to get underrepresented students, fearful of incurring more debt, to study abroad (Whatley, 2017). General education and disciplinary curriculum have been articulated through Education Abroad programming, some of which are led by home institution faculty and based on a course that is already offered (Hamir \& Gozik, 2018).

Despite the efforts outlined above, overall participation in Education Abroad in the United States has remained very low at 10\% (Institute of International Education [IIE], 2018) and benefited only an elite few. Of the students who do study or intern abroad, underrepresented students are disproportionately absent, making up a fraction of overall U.S. study abroad participation (NAFSA, 2017). The Open Doors report (IIE, 2018) shows that while Latino students make up 19\% of the undergraduate population, they made up only $10 \%$ of those studying abroad. Similarly, African-American students make up $14 \%$ of the U.S. undergraduate population while just $6 \%$ studied abroad. IIE Open Doors contrasts this to $72 \%$ of Education Abroad students self-identifying as white while making up $57 \%$ of the U.S. undergraduate population.

Universities are mandated to educate all of their students for global work and citizenship. Universities are therefore challenged to provide an international learning experience on the home campus that benefits the $90 \%$ or more of students who will not participate in Education Abroad programs. Universities who equate mobility with internationalization are conflating it with notions of competitiveness, excellence, and 
quality of education (Ackers, 2008). Student mobility is not an end in itself and international engagement should be viewed as a range of strategies, with the expectation that all students will have an internationalized learning experience regardless of whether they travel (Ackers, 2008).

Some universities see global learning opportunities for domestic students through increasing the enrollments of their international students. Currently, over one million international students study in the United States (IIE, 2018). The majority come from China, India, South Korea, Saudi Arabia and Canada (IIE, 2018). Universities have believed that dramatically increasing international student enrollments will help internationalize their institutions, their students and improve academic quality and competitiveness (Altbach \& Knight, 2007). In addition, public institutions have come to depend on international student tuition to make up for the decline in public funding (McMurtrie, 2011). Much is invested in the presence of international students on campus, but few international students are actively engaged by faculty or the university as a curricular or co-curricular resource (Urban \& Palmer, 2014). This gap between aspiration and reality has to do with student and faculty backlash over the numbers of international students on campus, the reframing of higher education as an individual investment and pursuit, discomfort with other academic cultures, and the insistence that foreign students "assimilate" (Fischer, 2019). While many universities have touted the presence of international students on their campus as an asset, few have focused on creating a shared community, leaving international students feeling like "cash cows" (Cantwell, 2015). Domestic students lose out on authentic global learning and 
engagement when their international student peers are not engaged by faculty and alienated by the campus climate (Fischer, 2019).

Outbound and inbound student mobility therefore has its limits on what it can deliver for global learning success for domestic students. Universities are not preparing all of their students for global work and citizenship because they are not exploring the most effective elements of internationalization. A joint study by Kinzie, Helms, \& Cole (2017), using data from the National Survey of Student Engagement and Mapping Internationalization Survey, showed that most institutions are emphasizing outbound and inbound student mobility through Education Abroad and International Partnerships to internationalize their student bodies, curricula, and campuses. The initial findings from the study show that institutions should be focusing on Internationalization at Home-in particular, on faculty pedagogical and curricular professional development-in order to have a positive effect on student learning and career outcomes (Kinzie et al., 2017).

In the past decade, Collaborative Online International Learning (hereinafter COIL) and the use of global collaborative virtual teams have emerged as innovators of curriculum internationalization at many urban open-access institutions in Europe and the United States (SUNY, 2018). COIL, also called telecollaboration or virtual exchange (O’Dowd, 2018), is part of a larger Internationalization at Home movement (Beelen \& Jones, 2015). Internationalization at Home formed in response to the challenge of providing non-mobile students with international experiences in the curriculum, especially those experiences that develop the soft skills valued by employers (Jones, 2013). 
Scholars have asserted that COIL is a new teaching and learning paradigm rather than a technology or technology platform (Helm \& Guth, 2010; Rubin, 2017). Choice of digital technology is to be considered last when designing a COIL course (Rubin, 2017; Tuke, 2019). Of primary consideration in designing a course are activities that develop cross-cultural awareness across shared multicultural learning environments (Rubin, 2017). COIL is a pedagogical approach because it is a collaboration established in an institutional context and because collaborative tasks are assigned by the faculty participating (Helm \& Guth, 2010). Scholars say that COIL's ultimate value is in how it engages and internationalizes instructors as much as it does students (Rubin, 2017).

While much has been studied about the individual components of internationalization and how they are evolving (ACE, 2015; APLU, 2017; Hudzik, 2011), less is known about faculty experience of internationalization in the classroom. Since faculty are considered the major drivers and innovators of COIL (Helm 2015; Rubin \& Guth, 2015; Rubin, 2017), it is important to understand better their experience of teaching COIL for personal development, curricular development, and pedagogical development. Understanding how faculty experience internationalization through the teaching of a COIL course can help scholar-practitioners who implement the university's internationalization agenda in several ways. First, understanding how faculty experience the teaching of a COIL course can shed light on what is sustainable in internationalizing the curriculum and what is not. Second, having deeper knowledge of faculty experience in teaching COIL can inform instructional designers and faculty workshop facilitators in creating training and materials that reflect faculty priorities in teaching over institutional 
mandates around internationalization. Lastly, learning better how faculty in all disciplines utilize Web 2.0 technology, especially the use of global virtual teams, may further innovate how universities prepare their graduates for $21^{\text {st }}$ century work.

Scholars (Lee \& Cai, 2018; Starke-Meyerring, 2010) recommend that three areas be explored in virtual exchange (such as COIL): the assumptions on which the courses are based, the pedagogies that challenge locally situated ways of knowing and thinking about a topic, and the methodologies for studying teaching and learning in the virtual exchange environment. One area that is starting to be researched in COIL is the use of global virtual teams in coursework (O’Dowd, 2018). This is particularly important to explore because COIL is often employed as a prescriptive institutional intervention by administrators without understanding how it is in fact enacted by faculty.

\section{Internationalization at Home}

Internationalization at Home can be a lens by which to study faculty use of COIL. It was chosen for this study because it reframes internationalization from a mobilitydependent activity to one that calls upon all international and global resources in a domestic setting to give students an international learning experience. Internationalization at Home also emphasizes global learning in an interdisciplinary and general studies course context over specified knowledge of area studies or foreign languages. It invites faculty who have not seen their work as globally connected or amenable to intercultural learning, to reconsider traditional ways of thinking about internationalized curriculum. Internationalization at Home was initially conceptualized by faculty in the Netherlands and Sweden who were concerned that European higher education policy 
investing in increasing student mobility would leave out the non-mobile majority of university students. They feared that internationalization efforts based on mobility would create unequal learning and career outcomes between those who studied abroad and those who did not (Nilsson, 2003; Wächter, 2003). In addition, they believed that local multicultural and international assets and diversity could and should be mobilized to inform the university curriculum and to teach students how to live, work and thrive in a globally connected world.

Internationalization at Home is defined most broadly as "the purposeful integration of international and intercultural dimensions into formal and informal curriculum for all students within domestic learning environments" (Beelen \& Jones, 2015, p. 69). Internationalization at Home is also described as a "significant means of internationalizing higher education, looking beyond the mobility of a minority of students, emphasizing instead the delivery to all students of an internationally focused curriculum and the embedding of cultural communication in culturally diverse settings" (Wächter, 2003, p. 6). Internationalization at Home activities include course redesign with international content, co-curricular activities on the campus or a COIL course (Rubin, 2017, p. 31).

Internationalization at Home has been embraced by faculty and practitioners (Baldassar \& McKenzie, 2016; Jon, 2013; Soria \& Troisi, 2014). Firstly, it is seen as an "epistemology of equity" (Almeida, Robson, Morosini, \& Baranzeli, 2019) by shifting international learning benchmarks from quantitative measurements (mobility) to qualitative measurements (what is learned). It implies not only accessibility of 
internationalized learning but inclusion of internationalized learning in higher education

for all. It gives educators a tool to examine the purpose of higher education internationalization for student learning beyond market-driven imperatives (Robson, Almeida, \& Schartner 2018). Educators see Internationalization at Home as a way to link diversity, sustainability and global citizenship (Kowalska, 2016). It is also seen as a way to intentionally integrate international students' knowledge and experience in the formal curriculum (Jones \& Reiffenrath, 2018). In terms of the community, Internationalization at Home engages students with "cultural others" in their local community and allows them to look at the effects of globalization, migration and diversity on campus and beyond. For the institution, Internationalization at Home can provide congruency (Bartell, 2003) between the mission of "global excellence" and educating students for $21^{\text {st }}$ century work and citizenship.

\section{Statement of the Research Problem}

Universities must innovate through pedagogy, curriculum, local resources, and internet communication technology to give all students adequate preparation to live and work in a global society. In order to find sustainable and effective ways to supply an international learning experience to all students, we need to better understand the faculty role in institutional internationalization. COIL is a faculty-initiated and faculty-developed international activity that benefits student global learning. However, we don't know very much about the faculty experience of enacting COIL in their classes and on their campuses. First, little is known about how faculty view COIL in the context of Internationalization at Home. Secondly, many open-access institutions are investing in 
COIL as a primary method to provide more global learning opportunities for all students, irrespective of their mobility. Administrators need to know how to best support faculty who choose to use COIL as a pedagogy in their courses, including the use of global virtual teams for collaborative project-based teaching and learning. We need to understand how faculty are innovating pedagogy and curriculum through COIL to understand whether it has potential to be a high-impact practice within Internationalization at Home.

\section{Purpose of the Study}

Though COIL is viewed and being adopted as an Internationalization at Home strategy, we know little about how its effectiveness and sustainability. At open access institutions with limited resources, it is critical that practitioners know what Internationalization at Home efforts work, their effectiveness on internationalization goals, and their impact on faculty who are charged with the front-line work of Internationalization of the Curriculum.

Faculty are particularly important to understanding how internationalization is understood and implemented at higher education institutions worldwide, which are increasingly pressured to adapt to the forces of globalized markets and internet communication technologies. Both bottom-up and top-down institutional initiatives are focused on increasing student intercultural skills to make them career-ready graduates and professionally successful alumni. Faculty are at the nexus of these imperatives. Faculty engagement is critical to counter the growing inequitable outcomes of the 
undergraduate degree, leaving our students unprepared to take their place in the $21^{\text {st }}$ century.

Internationalization of higher education needs to happen on the home campus if it is to be equitable for students. My study seeks to understand how Internationalization at Home is achieved through COIL. In particular, my study examines how COIL is being understood and implemented by faculty in their courses as an Internationalization at Home strategy.

\section{Methodology and Research Questions}

A basic qualitative design is best suited to an exploratory study. In particular, a basic qualitative method allows me to explore the thoughts and feelings of my participants to enable an understanding of the meaning they assign to their experience. My study will explore individual faculty members' experiences with teaching COIL and explore how faculty make meaning of their participation in this modality. In particular, my study seeks to understand what motivates faculty to participate in COIL at their institution.

The research question that guides this study is: What is the motivation and experience of faculty who create and teach a COIL course? The sub-questions include:

- Why do faculty participate in a COIL course?

- What do faculty see as significant in their experience in preparing for and teaching a COIL course?

- How do faculty experience COIL through the lens of Internationalization at Home?

- What is the experience of faculty using global virtual teams in a COIL course? 


\section{Positionality}

My international education and international lived experience has helped me create opportunities for growth and achievement that my degrees on their own would not have afforded. It has been also of significant advantage to me in challenging stereotypes around class, race, tribe, and cosmopolitanism. I was a need-based scholarship student at an elite liberal arts college as an undergraduate and did not possess the same social capital and co-curricular experiences as my peers. Engaging in international learning on the home campus and abroad transformed my undergraduate experience and the structural inequities that I faced. And now in my role as a director of university international partnerships, I want to ensure that students at open access institutions benefit from the opportunities that are generated through the internationalization of higher education. We must provide curriculum that helps them be prepared to fully participate in a global context as a citizen and professional.

\section{Summary}

Chapter One introduced the problem of practice, its impact on higher education internationalization, and the purpose and implications of the study. Chapter Two reviews the relevant literature on the concepts of Internationalization of Higher Education and Internationalization at Home. Chapter Three restates the research questions and how they are addressed through a general qualitative study using a semi-structured interview protocol. Chapter Four presents the analysis of the data collected to answer the research questions. Chapter Five discusses the results and implications of the study for higher education leaders and suggests areas for future research. 
Chapter Two: Review of the Literature

The following review of the literature examines the Internationalization of Higher Education from U.S. and European perspectives in order to provide context for the study research questions. The literature on Internationalization at Home is then examined as both an institutional approach to internationalization and a way to offer the advantages of intentional global learning to place-bound students. Internationalization of the Curriculum for undergraduates is presented as part of the institutional response to internationalization. It then turns to faculty as agents of innovation in internationalization of pedagogy through Internationalization of the Curriculum. Virtual Exchange as an innovation is then introduced. COIL as a form of Internationalization at Home and Virtual Exchange is presented as an individual-faculty-driven innovation of, and institutional approach to, curriculum integration and innovative pedagogy. Increased student global learning and acquired global competencies via virtual global teamwork are then addressed as desired outcomes of COIL courses identified by faculty and administration. The literature review concludes by looking at how scholars link Internationalization of the Curriculum to employability, through globally networked learning and virtual global teams.

\section{Internationalization of Higher Education}

The literature on what internationalization means in a higher education context addresses several areas of concern. First, there is discussion about whether the phenomenon of pressure to adapt should be called globalization or internationalization, 
and what distinguishes one from the other. Second, the definition of internationalization in a higher education context is regularly revised. Third, there are different approaches to how internationalization is embodied and assessed at the institutional level. The literature also highlights disagreement about the main purposes or goals of the internationalization of higher education for institutions, faculty and students. Finally, scholars question internationalization of higher education as a tool of equity and inclusiveness.

\section{Globalization and Internationalization Definitions}

Scholars have debated the use of the term globalization or internationalization in the higher education context (Altbach \& Knight, 2007; Brandenburg \& De Wit, 2015; Jones \& De Wit, 2012; Knight, 2004; Maringe, 2010), but the consensus is that internationalization of higher education is a response to globalization of the economy (Altbach \& Knight, 2007; Brandenburg \& De Wit, 2015; De Wit, 1999; Zha, 2003). Institutions seeking to use internationalization as a strategy for development rely on an economic rationale situated in neo-liberalism to build support for initiatives (Gopal, 2011). Jane Knight (2004), a preeminent scholar in the field, distinguishes the terms thus: "Internationalization is changing the world of higher education, and globalization is changing the world of internationalization" (p. 5). There is much diversity of thought around globalization shaping the internationalization of higher education. Some say that internationalization of higher education occurs around elements that academic institutions do not control, such as the world economy, English as a lingua franca, and ongoing innovations in information and communications technology (Altbach, Reisberg, \& 
Rumbley, 2010). Internationalization is therefore an institutional adaptation to the forces of globalization. Others describe internationalization as a push-back against the forces of globalization — especially against the commodification of higher education — where practitioners steer the conversation towards the pursuit of higher goals, such as world peace and understanding (Brandenburg \& De Wit, 2015).

The definition of internationalization in the context of higher education has been regularly updated by scholars over the past three decades (Brandenburg \& De Wit, 2015; Buckner \& Stein, 2019; De Wit, 1999; Hudzik, 2011; Killick, 2012, 2017; Knight, 1994, 2003, 2004, 2008, 2012; Pashby \& Andreotti, 2016; Robson, 2011; Rumbley, Altbach, \& Reisberg, 2012; van der Wende, 2007; Vavrus \& Pekol, 2015). The most frequently cited and foundational definition in the literature is Knight's 2004 definition of internationalization as "the process of integrating an international, intercultural, or global dimension into the purpose, functions, or delivery of post-secondary education" (Knight, 2004, p. 11).

In order to further elaborate on Knight's (2004) definition, scholars (De Wit, 2011; Knight, 2011) have gone on to detail what internationalization is not in order to describe better what it is. They agree that it is not a sum of activities usually undertaken by universities, such as offering degree programs in English (for those in non-nativespeaking countries), requiring study abroad as part of the curriculum, having a global studies major, enrolling large numbers of degree-seeking international students on the home campus, creating an international marketing plan (as equivalent to an internationalization plan), racking up accreditations by international bodies, enhancing 
brand reputation, or accumulating more international partners. Rather, it is a process seen through the activities responding to forces of globalization, such as rapid innovations in information and communications technology, increased labor mobility, free trade, the creation of a knowledge economy and its emphasis on lifelong learning, an increase in private investment in higher education, and a decrease in public support of education as a common good (Knight, 1997, p. 7). Knight's (2004) definition of internationalization is the one I've chosen to guide my study as it emphasizes internationalization as a process where curriculum, teaching, and learning at the university are innovated through global engagement using local resources and assets.

\section{Development of Internationalization in Higher Education}

Scholars discuss how internationalization is embodied at higher education institutions to illustrate how its development may affect its future trajectories (Hudzik, 2011; Knight, 2012; Rumbley et al., 2012). In the 1950s and 1960s, internationalization revolved around incoming foreign students, student exchange, development projects in the Third World, and foreign language study (Knight, 2012). In the 1970s and 1980s, it expanded to large-scale study-abroad programming, cross-disciplinary studies, and binational cooperative-education programs (Knight, 2012). Starting in the 1990s, it expanded further to include third-party service providers, international quality-assurance certifications, university-to-university institutional partnerships, overseas branch campuses, international academic faculty, and the awarding of dual degrees (Knight, 2012). Globalization is also seen in the rise of the worldwide ranking system for 
universities and the development of corporate-style branding for universities (Knight, 2012).

Internationalization has evolved into a complex phenomenon (Rumbley et al., 2012). Multiple simultaneous and ongoing activities must be managed by higher education institutions. They include the increased number of internationally mobile students and scholars, pressure to offer degree programs entirely in English, and the rapid increase in dual degrees articulated with foreign institutions. There is growing pressure to be a "world class" university through rankings and branding. Fiscal dependence grows on the private sector and foreign institutions to offset the decline in public funding for education. Accommodating disruptions through innovations in digital technology, big data management and export control puts new burdens on university infrastructure (Rumbley et al., 2012).

Senior leadership responsible for guiding the university through internationalization confirm the complexity of managing its activities. A 2017 survey of senior international officers by the Association of Public and Land Grant Universities (APLU, 2017) identified seven areas of particular focus for public institutions through 2022. Their institutional priorities for internationalization were driven by increasing international student recruitment for revenue and prestige while managing global risk on outbound mobility of faculty and students. Priorities were also propelled by development of public/private partnerships for research and revenue along with demand that global competencies and skills be integrated in the general curriculum. Finally, priorities were shaped by growing digital technology to foster virtual collaboration and exchange in the 
face of concerns about sustainability and access in education abroad. Greater internationalization of the faculty was highlighted as a priority to accomplish all of the international activities (APLU, 2017, p. 23). The survey revealed that institutions intended to budget more resources for the promotion of international research, internationalizing the curriculum, faculty engagement in international activities, creation of global administrative units, and students' overall internationalization (APLU, 2017, p. 22). Institutional priorities were shifting to provide more international learning opportunities for local students while they sought to increase enrollments from abroad.

\section{Comprehensive Internationalization}

A prescriptive approach to internationalization of higher education institutions which can sustain multiple ongoing internationalization efforts is called "Comprehensive Internationalization.” Comprehensive internationalization, as defined by Hudzik (2011, 2014), argues for a holistic, meta-level, institutional approach to internationalization:

comprehensive internationalization is a commitment, confirmed through action, to infuse international and comparative perspectives throughout the teaching, research, and service missions of higher education... It is an institutional imperative, not just a desirable possibility. Comprehensive internationalization not only impacts all of campus life but the institution's external frames of reference, partnerships and relations. (Hudzik, 2011, p. 6)

The American Council on Education's (ACE) Center for Global and International Engagement has another definition of comprehensive internationalization that is more strategic and based on measurable outcomes (ACE, 2015). They include faculty promotion and tenure guidelines, an institutional mission statement, a dedicated Senior International Officer, a technology infrastructure, and a clearly defined internationalized curriculum (ACE, 2015). Others see comprehensive internationalization as focused on 
pedagogy. Ping (1999) has argued for universities to see comprehensive internationalization as a transformation of disciplines, freeing faculty from the intellectual traditions of their respective academic cultures. While there are many opinions about how comprehensive internationalization can be achieved, it is clear that strategy driven by outcome measurements is not sufficient to internationalize higher education.

\section{Purposes of Internationalization in Higher Education}

Scholars also debate the key purpose and goals of the internationalization of higher education for students by faculty and the institutions themselves. Some believe that the goal of internationalization is to prepare students for the global workforce and that internationalization and employability are indivisible (Beelen, 2011; Watkins \& Smith, 2018). Others say the goal is to create global citizens who will counter the forces of xenophobia and nationalism (Green, Marmolejo, \& Egron-Polak, 2012). Some scholars take this further, arguing that internationalization empowers students as local citizens to "challenge opinions based on multiple hierarchies of ethnicity, gender, race, class, and citizen status. Domestic students can face specific challenges in this area, particularly in face of an increasingly prevalent antimigrant political discourse" (Watkins \& Smith, 2018, p. 218). This is supported by Landorf et al. (2018), who argue, "how can people develop a sense of identity or seek equitable treatment if they don't understand their relationship to others or are presented with a distorted view of themselves" (p. 5)? Some scholars embrace both narratives (Beelen \& Jones, 2015; Green, 2012), while 
others say the debate points to larger underlying competing paradigms of the purpose of higher education (Harrison, 2015, p. 420).

The primary aims and purpose of internationalization to benefit faculty themselves are discussed in the literature. For some faculty, the goal of internationalization is to incorporate an inclusive, less Western-centric international perspective in their teaching and scholarship (Hudzik, 2011). Others say that incorporating international perspectives into the academic disciplines is a necessity, not an option (Leask, 2015). Still others see faculty as the key actors in internationalizing the curriculum (Niehaus \& Williams, 2016). Lastly, internationalization gives power back to faculty, as "the shift towards mainstreaming internationalization in teaching and learning means... academics now take centre stage rather than the international office" (Beelen \& Jones, 2015, p. 8).

For higher education institutions, internationalization is existential. As Hudzik (2011) states, "the business of universities is ideas," and "with the increasing flow of students and scholars worldwide, it becomes easier to talk about the free trade of minds" (p. 7). Scholars continue to debate whether internationalization of higher education emancipates students or reinforces the institutional status quo. Brandenburg and De Wit (2015) argue that internationalization, intended as a force for good in the face of globalization, itself has been coopted:

...activities more related to the concept of globalization (higher education as a tradeable commodity) are increasingly executed under the flag of internationalization, as the increasing commercialization illustrated at the conferences of NAFSA: Association of International Educators, the Asia Pacific Association for International Education, and the European Association for International Education. (p. 3) 
Scholars also question whether higher education is already inherently international and whether efforts to internationalize it are therefore misplaced (Altbach \& De Wit, 2015). Concerns about quality assurance, funding, and accreditation have fueled nationalism in the internationalization of higher education (Knight, 2007), even as e-learning has made geographic borders of less consequence.

In Globalization of Internationalization (2017), Marmolejo \& Egron-Polak argue that internationalization has become another form of colonialism. They believe that institutions should tie their individual internationalization agenda to the 2030 Agenda for Sustainable Development (UN, 2015), which promotes equality, mobility and cooperation. The Sustainable Development Goals, or SDGs, are seventeen goals to guide efforts to solve the world's most pressing challenges (Egbelakin \& Jiang, 2020). They build on previous work of the United Nations in the Global South by shifting to a shared global agenda for all nations to aspire to. These include setting different national targets around ending poverty, social inclusion, environmental sustainability and good governance (Egbelakin \& Jiang, 2020). The 2030 Agenda is shaped by the five "Ps": People, planet, prosperity, peace and partnerships and these inform the 17 goals (UN, 2015). The 2030 Agenda is unique in that it makes all countries collaborative partners in enacting the goals, and they have already been adopted in government, academia, business and civil society (Egbelakin \& Jiang, 2020). Scholars (Sachs, 2015) argue that universities are well positioned to integrate the SDGs into their curricula for the common good:

We can use the global network of universities, your university, my university, a thousand-and-more universities around the world, to be an active "solutions 
network" to help governments, business, and civil society to chart out the pathways to successful sustainable development. (p. 61)

Most importantly scholars argue that the SDGs break the Global North and Global South dichotomy by making sustainable development the business of all (Egbelakin \& Jiang, 2020).

Finally, the literature shows a growing concern for the inequalities inherent in the process of internationalization. The Association of Public \& Land Grant Universities report on internationalization (2017) calls for a "pervasive internationalization," one that requires institutional strategic plans around internationalization with specific deliverables, while also recognizing the growing inequality of this pursuit: "While significant progress has been made, much work lies ahead in making internationalization pervasive and democratic" (APLU, 2017, p. 17). Internationalization of higher education is described as a "multifaceted palette of opportunities" (Wihlborg \& Robson, 2018. p. 10) that is also loaded with pitfalls. Killick $(2012,2017)$ and Pashby \& Andreotti (2016) have warned that there are contradictions in trying to create one approach to internationalization which combines the development of employable global professionals — an instrumental approach—with the development of intercultural practitioners — an ethical approach. Harrison (2015) refers to this as: "The conflict between 'global worker' and 'global citizen' approaches” (p. 413).

The literature on the internationalization of higher education addresses several areas. It debates whether to call the global phenomenon affecting universities globalization or internationalization. Both terms are used interchangeably, which causes confusion. The literature looks at how internationalization is embodied, enacted, and 
assessed at the university as a way to further define its perimeters. The purposes and goals of internationalization of higher education are also debated widely. As summarized by Rumbley, Altbach, and Reisberg (2012):

internationalization is affecting what, how, where and from whom students learn; how higher education institutions and systems conceive of their mission and roles; how research is carried out and disseminated; and how fundamental paradigms of cooperation and competition in higher education are understood and elaborated. (p. 22)

Within the discussion of purposes and goals comes concern on whether internationalization is a tool of educational equity or a force that creates unequal learning outcomes for students.

Internationalization mandates and initiatives must be implemented thoughtfully and intentionally by higher education institutions. Unless consciously used as a tool of educational equity, internationalization can undermine equitable degree outcomes and students' professional mobility trajectories, which in turn can negatively impact their global civic engagement. Therefore, university internationalization efforts which focus on the majority of non-mobile students and faculty have the most potential to achieve equitable internationalization in higher education and transform institutions, teaching, and the curriculum.

\section{Internationalization at Home}

The concept of "Internationalization at Home" was a faculty-driven innovation in higher education (Beelen \& Jones, 2015). Reframing internationalization from a mobility-dependent activity to a location/context-dependent activity challenged prevailing ideas on how students could benefit from internationalization. The shift in 
focus also emphasized internationalization as iterative process over discrete outcomes. Internationalization at Home was created through necessity to reconcile competing pressures. Students needed to have the skills and knowledge to work in a globalized economy, but the majority would not travel as part of their formal education. Classrooms were more diverse with first generation and migrant students who carried unique and unmined cultural capital. Globalization was fostering social unrest and begged locally sourced solutions.

A pivotal policy development in the internationalization of higher education was the enactment of the ERASMUS (European Region Action Scheme for the Mobility of University Students) program by the European Union in 1987. This program allowed students to move freely between institutions, much as goods traveled freely through the customs union. It also included a mandate to have 1 out of every 10 students study abroad (Wächter, 2003), which forced innovation and adaptation in the areas of curriculum, teaching, and higher education administration.

One of these innovations was Internationalization at Home, which was conceptualized by faculty in the Netherlands and in Sweden. They were concerned that European higher education internationalization efforts based on mobility would exclude the majority of students undertaking a degree and create unequal education benefits of internationalization for students (Nilsson, 2003; Wächter, 2003). They argued for an internationalization concept that went "beyond mobility" (Wächter, 2003, p. 6). Beyond mobility was not clearly defined at this point, except to imply that all local, place-bound assets should be leveraged for international learning (Nilsson, 2003). Scholars believed 
that "beyond" did not mean "instead of" or "in place of," but was instead a call to redefine what Internationalization of the Curriculum meant and looked like (Beelen \& Jones, 2015). Rather than something added, it was a way to teach, to learn, to "do" higher education in any core subject, including math, writing, and the sciences (Beelen \& Jones, 2015). Students would not sign up for an international class; all of their courses would be internationalized, similar to the International Baccalaureate curriculum in the $\mathrm{K}-12$ system (Beelen \& Jones, 2015). The following is an examination of Internationalization at Home, seen through its foundations, alternatives, elements and transformational impact on higher education.

\section{Foundations of Internationalization at Home}

Internationalization at Home was inspired by the work of Mestenhauser and Ellingboe (1998) who introduced the concept of an "international mindset" in higher education. Paige and Mestenhauser (1999) developed the framework further by articulating that an international mindset is "metacognitive and epistemological in nature; it focuses on the ways in which individuals organize their thinking, construe their experiences, and make sense out of their world" (p. 504). While they acknowledge that internationalization involves global forces acting on education, including the mobility of people and ideas, they argue that looking at internationalization as a movement neglects a central issue: what students and faculty are doing with the knowledge and experiences they already possess (Paige \& Mestenhauser, 1999).

Paige \& Mestenhauser (1999) described seven dimensions of knowledge construction which combined to form an international mindset. The first dimension was 
“integrative," focused on knowledge produced from diverse settings within/without national boundaries. The second was "intercultural," especially as related to issues of inclusion, democracy, and human rights. The third was "interdisciplinary," drawing on the knowledge of all disciplines to create more holistic ways of understanding. The fourth was "comparative," especially in the ability to transfer educational ideas practice from one setting to another as a method to understand them better. The fifth was the "transfer of knowledge-technology" dimension, with the ideal being not the simple borrowing of knowledge but the creation of new knowledge. The sixth was the "contextual" dimension, where professionals can analyze the context of knowledge well. The seventh and final was the "global" dimension, where global trends were understood and informed practice and curriculum.

The concept of international mindset, along with its "integrative," "intercultural," and "transfer of knowledge" dimensions (Paige \& Mestenhauser, 1999, pp. 504-505), inspired the Internationalization at Home movement (EAIE, 2015). Mestenhauser (2006) later endorsed Internationalization at Home "as a system of international education [that] offers the possibility of finding a new way in which higher education mainstreams the international dimension in all segments of the universities, reforms the curriculum, mobilizes community resources, institutionalizes international education and focuses on relevance to the global job market" (Mestenhauser, 2006, p. 70). Internationalization at Home therefore became the embodiment of an international mindset. 


\section{Alternative to Education Abroad}

The initial touted benefits of Internationalization at Home did not focus on it as an alternative to study abroad, though it was acknowledged as a factor (Nilsson, 2003; Wächter, 2003). Instead, Internationalization at Home positioned cultural diversity as a general resource and a source of enrichment, at a time when Intercultural Communication was seen as inadequate to address the problems of societies being transformed by migration (Crowther, Joris, Otten, Nilsson, Teekens, \& Wächter, 2001). Nilsson argued for Internationalization at Home as a necessity that would address community xenophobia by "inoculating" local students against racism and nationalism at home; this would then attract more international students, who would feel welcome and valued (Nilsson, 2003). Other benefits were intentional, genuine, intercultural learning in the curriculum, where mobility programs focused on travel often fell short (Baldassar \& McKenzie, 2016; Kinzie et al., 2017; Soria \& Troisi, 2014). Other scholars hoped that it could expand the Organization for Economic Cooperation and Development's (OECD, 1996) definition of the internationalized curriculum, which focused on inbound and outbound students only and ignored domestic intercultural opportunities (Beelen \& Jones, 2015). Up to that time, the OECD definition had been the driver of international higher education policy in the developed world.

Internationalization at Home offered a different perspective/framework on Internationalization of the Curriculum and co-curriculum from that established by the OECD (Leask, Beelen, \& Kaunda, 2013). Its name implied that opportunities could be found "at home" for students to gain an intercultural learning experience through 
leveraging the permanent and transient local/global diversity in their communities. It was meant to empower faculty and students to engage with their local communitiesincluding international students — on global and multicultural issues, as part of the curriculum and co-curriculum (Leask, Beelen \& Kaunda, 2013). It was also intended to encourage faculty and students think about local diversity and internationalization as deeply connected. Scholars in the field started to explore international and intercultural as one and the same. Jones (2013) called for "further exploration of the intercultural context as a vehicle for a kind of transformational learning evidenced through international mobility" (p. 8). In fact, Internationalization at Home was coined to "signal a new way of thinking about internationalization" as an institutional as well as pedagogical imperative (Leask, Beelen, \& Kaunda, 2013, p. 191).

Internationalization at Home became formally defined by scholars of praxis. Crowther et al. (2001) defined Internationalization at Home as "any internationally related activity with the exception of outbound student and staff mobility" (p. 8). Beelen and Jones (2015) updated the definition of Internationalization at Home to be more specific about its content and perimeters. They said Internationalization at Home was "the purposeful integration of international and intercultural dimensions into the formal and informal curriculum for all students within domestic learning environments" (Beelen \& Jones, 2015, p. 69). The updated definition emphasized the inclusion of international and intercultural elements in an intentional way. It also mandated that Internationalization at Home applied to all students in all academic programs, even those who studied abroad (Beelen \& Jones, 2015). Noticeably, the definition did not require 
the presence of international students on campus, which was included in the first definitions (Nilsson, 2003; Wächter, 2003).

\section{Elements of Internationalization at Home}

Internationalization at Home activities are varied and entrepreneurial. They include course redesign with international content, a co-curricular international activity on the campus or in the community, or a collaborative online international learning course (European Union, 2019). They may include a travel abroad seminar over a weekend for students in Europe (Beelen \& Jones, 2015). Many activities involve preprofessional experiential training for students (Baldassar \& McKenzie, 2016; MarcilloGomez \& Desilus, 2016; Skagen, McCollum, Morsch \& Shokoples, 2018). Still others focus on foreign language acquisition and communication (O’Dowd, 2018). Finally, Internationalization at Home has created a service provider market. An example is Soliya Connect, a non-profit which provides professional facilitators to lead discussions between student groups located in different countries or in areas plagued by sectarian violence (Helm, 2015).

Discussion of what the elements of Internationalization at Home can include preoccupies scholars. They debate whether it includes travel abroad, the co-curriculum, inbound international students, or virtual exchange, a form of virtual international mobility (Soria \& Troisi, 2014). The initial concept of Internationalization at Home was that only elements considered local or "at home" were necessary or to be used to achieve internationalization (Beelen \& Jones, 2015). Other scholars advocated that study abroad should not be intentionally excluded, because one of Internationalization at Home's goals 
was to eventually get students to go abroad (Wächter, 2003). Similarly, there was concern that Internationalization at Home would be more widely adopted through the cocurriculum by institutions (because it was easier to accomplish), therefore undermining its fundamental power in transforming the curriculum (Beelen \& Jones, 2015). In-bound international students also had their own personal agendas for foreign study and trying to include them in the Internationalization at Home curriculum would be very difficult (Harrison, 2015). Lastly, virtual exchange was in its infancy in the early 2000s and was seen as a tool of foreign language teaching (O’Dowd, 2018).

The ideal conditions to achieve Internationalization at Home are also discussed in the literature. Scholars have come up with a list of discrete elements required to fully realize Internationalization at Home at the university (Beelen, 2013; Beelen \& Jones, 2015; Mak \& Barker, 2013). The university achieving full Internationalization at Home would have: locally-based curriculum providing a global perspective independent of mobility; internationalized, disciplinary content courses embedded in core degree requirements; the co-curriculum designed around the internationalized curriculum; classroom diversity and multicultural community partners intentionally used as a curricular resource; faculty interests leading in design of the internationalized curriculum; lingua franca (English) neutral; and virtual mobility utilization.

Of particular concern is whether study abroad strengthens or weakens the further conceptualization and implementation of Internationalization at Home (De Wit, 2018). Some believe that the challenge for institutions is to mine the cultural diversity residing at home, augmented with the use of virtual exchange, to make it possible for students to 
gain the skills that they would acquire through study abroad (Standley, 2015). These scholars believe that "for Internationalization at Home, international and intercultural teaching and learning on a domestic campus is the main aim, irrespective of whether the student experience is enhanced by mobility" (Beelen \& Jones, 2015, p. 63). As the focus of internationalization shifts from inputs/outputs to outcomes, location has become less salient to its process (Aerden, 2014; Leask 2015).

\section{Transforming Higher Education}

Internationalization at Home's potential to transform higher education has animated discussion and debate in the literature on the purposes of internationalization. This includes faculty and student intercultural learning and competencies, graduate employment, teaching of transversal skills, equity in educational outcomes, and challenging the postwar North-South divide in international higher education. Some scholars (Soria \& Troisi, 2014) advocate that Internationalization at Home interventions in the curriculum and co-curriculum are superior to study abroad in achieving intercultural competence:

Results suggest that participating in some on-campus global/international activities may benefit students' development of GII competencies more than participating in study abroad; specifically, enrolling in global/international academic coursework and attending international/globally theme lectures, symposia, or conferences were activities positively predictive of students' selfreported development of global/international competencies and intercultural competencies, respectively. (Soria \& Troisi, 2014, p. 273)

Other scholars (Van Gaalen \& Gielesen, 2014, 2016) similarly posit that the goal of creating internationally and interculturally competent graduates can be best achieved "if institutions consciously create controlled situations that lead to intercultural collaboration 
and the utilization of students' specific international knowledge" (Van Gaalen \& Gielesen, 2014, p. 16). Institutions needed to recalibrate their internationalization efforts to Internationalization of the Curriculum and campus culture.

Internationalization at Home can transform how universities prepare their students for professional work. Jones $(2013,2016)$ made a strong case for Internationalization at Home to enhance the employability of non-mobile students, saying that "it is clear that domestic environments could play an equivalent role in offering opportunities for experiential learning in an intercultural context, taking people beyond their comfort zones" (Jones, 2013, p. 101). De Wit (2018) posits that Internationalization at Home will be adopted as a de facto method to prepare students for global work:

The rationale is that all graduates will live and work in an increasingly interconnected and globalized world as professionals - economic actors - and as citizens - social human beings. The need by the labor market for global professionals and by society for global citizens cannot be addressed solely by mobility. International, intercultural and global learning outcomes are important elements of the modern curriculum. (De Wit, 2018, p. 9)

Indeed, according to Standley (2015), “employers are primarily looking for the transversal skills developed through international experience (e.g., openness and curiosity about new challenges), rather than the international exposure per se...” (p. 4). Transversal skills are skills that "are not specifically related to a particular job, task, academic discipline or area of knowledge, but can be used in a wide variety of situations and work settings" (UNESCO IBE Glossary, 2013, p.58). Transversal skills are in high demand by employers and are a tool of lifelong learning for the knowledge economy (UNESCO IBE, 2013). Examples of transversal skills are critical thinking, teamwork, 
self-motivation, enthusiasm, global citizenship, and digital media and information literacy (UNESCO Bangkok, 2014).

Internationalization at Home can change how universities respond to internationalization by making it a tool of educational equity in higher education (De Wit, 2012; Watkins \& Smith, 2018). Internationalization at Home is seen to do this by shifting the focus from student mobility to domestic core curriculum redesign and student learning outcomes (Egron-Polak \& Hudson, 2014). In fact, some scholars say that the primary intention of Internationalization at Home is to "deliver to all students an internationally focused curriculum" (Watkins \& Smith, 2018, pp. 210-211) wherever teaching occurs. Teekens (2013) says that the primary concern of Internationalization at Home is the supermajority of students who are not exposed to the intercultural learning that comes from an international experience. Beelen and Jones (2015) take this further by pointing out that "Internationalization at Home operates on the assumption that not all students will have mobility opportunities and that, while mobility can bring additional benefits for the mobile few, this should not be at the expense of internationalization for all” (p. 68). This argument is augmented by studies (European Union, 2014; Jones, 2013; Leask, 2015) that tie internationalized learning in a domestic setting to the employability of graduates. Bruhn (2017) emphasized this point by arguing that the focus on students puts an emphasis on the wrong thing: The question should be whether learning environments have been internationalized, not whether students have been. Others support the focus on learning environment over travel as a way to blur divisions between those who are mobility privileged over those who are not (Almeida et al., 2019). 
Scholars also discuss Internationalization at Home as a tool to create more equality between global North-South educational institutions. Some see Internationalization at Home as a way for institutions in the global South to build capacity in teaching and learning and to break the hegemony of elite western universities (Almeida et al., 2019; De Wit, 2017). Internationalization at Home is even described as an "epistemology of equity" (Almeida et al., 2019, p. 200). However, others are concerned about Internationalization at Home relying too much on the English language, further reinforcing its linguistic hegemony and affording native speakers an unfair advantage in the classroom (Harrison, 2015). In addition, some scholars argue that Internationalization at Home is paternalistic in assuming that students want to have an international experience or be prepared for global jobs as part of their education: "In short, not all home students enter higher education expecting, wanting or valuing intercultural experiences (Ippolito, 2007), yet many educators believe that they are vital in terms of education and/or future employment" (Harrison, 2015, p. 418). Finally, there is concern that Internationalization at Home is not being examined in a wider context of inequality, social mobility, and class transmission for all students (Harrison, 2015). While there are valid concerns about Internationalization at Home reinforcing structural inequity in higher education, its power to create more equitable outcomes in higher education locally and globally is a powerful argument in its favor.

The literature around Internationalization at Home discusses it as a substitute for student mobility, a movement of educational equity for mobile and non-mobile students, a rationale for career preparation as part of the university curriculum, and a way to utilize 
diversity and multicultural assets on the home campus. The literature even describes Internationalization at Home as an "epistemology of equity" (Almeida et al., 2019). Of all of the elements of Internationalization at Home, Internationalization of the Curriculum has been a particular area of interest to scholars.

Internationalization at Home has emerged as a movement to directly link student learning and the goals of higher education to university internationalization efforts. Most institutions have focused their internationalization activities around increasing the numbers of international students on campus or the numbers of home students that study abroad. This has been ineffective in benefiting all students and in some cases, has even been counterproductive to global learning and engagement on the home campus. Internationalization at Home promises to offer a framework and set of activities for leaders, practitioners and faculty to implement that allows all students to benefit from internationalization of higher education.

\section{Internationalization of the Curriculum}

Internationalization at Home has come to imply Internationalization of the Curriculum in higher education vernacular (Beelen \& Jones, 2015; Leask, 2015). There is a slow but growing emphasis by scholars to see "international" and "intercultural" as one and the same (Deardorff \& Jones, 2012), and this provides new opportunities to internationalize the curriculum in a local context (Olson \& Peacock, 2012). Jones (2013) calls for "further exploration of the intercultural context as a vehicle for a kind of transformational learning evidenced through international mobility" (p. 8). Some believe that the impetus for internationalizing the curriculum must come up through the academic 
disciplines (Leask, 2015), while others say it must happen at the individual faculty level, but with institutional support (Neihaus \& Williams, 2016; Schuerholz-Lehr, Caws, Van Gyn, \& Preece, 2007). Neihaus and Williams (2016) argue that "Internationalizing the Curriculum is also therefore an exercise in transforming faculty members' perspective and increasing their global competence" (p. 60). Whether Internationalization of the Curriculum can be sustained better through the academic disciplines (Leask, 2015), through interdisciplinary cooperation (Paige \& Mestenhauser, 1999), or through individual faculty engagement (Rubin, 2017) remains an issue of debate.

Internationalization of the Curriculum is embedded in the Internationalization at Home movement. In fact, Leask (2015) posits that there can be no Internationalization at Home without Internationalization of the Curriculum. Some scholars even assert (Beelen \& Jones, 2015) that Knight's (2004) seminal definition of internationalization of higher education "undervalues the fundamental role of the curriculum in the enterprise of Internationalization at Home, and that it is neither a 'related factor,' nor an 'activity,' but it is at the heart of the concept" (Beelen \& Jones, 2015, p. 61). This section examines Internationalization of the Curriculum through the literature of global learning, inclusive excellence and inclusive internationalization. It explores faculty roles in Internationalization of the Curriculum including faculty motivation and engagement, and adoption of the concept of cultural humility. It concludes with discussion of faculty as the preeminent actors in internationalization of higher education through Internationalization of the Curriculum. 


\section{Global Learning and Inclusive Excellence}

Internationalization of the Curriculum has been linked in the literature to global learning (Agnew \& Kahn, 2014, 2017; Landorf et al., 2018). Agnew and Kahn (2014) state that:

institutions of higher education are engaging in multiple strategies to provide students with global competencies that are aligned with new professional requirements and heightened citizenship expectations... there are, however, increasing demands that institutions look inward to renew curricula and cocurricular programming to reflect new paradigms for global knowledge production and learning. (p. 31)

They see Internationalization of the Curriculum encouraging "conversations around difference" (Agnew \& Kahn, 2014, p. 33). Indeed, they argue that curricular transformation depends also on the diversity of the local students. This is supported by De Vita (2007) who said that diverse student populations were catalysts for "activating processes of international connectivity, social connectivity and intercultural learning”, (De Vita, 2007, p. 165). Global learning may be accessed through local diversity and multiculturalism.

Internationalization of the Curriculum has also been connected in the literature to "Inclusive Excellence," a concept proposed by American Association of Colleges and Universities (Williams, Berger \& McClendon, 2005) defined as "the cultural differences learners bring to the educational experience and that enhance the enterprise," and "a community that engages all of its diversity in the service of student and organizational learning" (p. vi). Whitehead (2015) has put forward the term "Global Inclusive Excellence," asserting that: 
Global learning is also a 'high-impact practice' - an educational practice that benefits all students, particularly those from historically underserved groups, through increased engagement. And as higher education becomes more equitable, inclusive, and reflective of the American population, it is essential that all students have access to the most powerful forms of learning. (p. 6)

From this perspective, Internationalization of the Curriculum is mandated to build equity in access to global learning and the benefits global learning provides.

Internationalization of the Curriculum is also addressed in the context of “Inclusive Internationalization" (De Wit \& Jones, 2018). De Wit \& Jones (2018) argue that a double paradox lies at the heart of internationalization:

first, while we may be striving to increase internationalization and global engagement, in many countries isolationist and nationalist trends result in a disconnect between the local and global as part of curriculum internationalization. Second, while credit and degree mobility is increasing globally, this billion-dollar industry reaches only a small student elite, leaving 99 percent of the world's student population behind. (p. 17)

Therefore, Internationalization of the Curriculum is for all students "at home," supports that the system to internationalize education for all must be changed, rather than arguing that students must try to fit a system (Gillespie, 2002).

\section{Impact on Teaching}

Attention has shifted from course content to faculty engagement as the key to successful curriculum internationalization. Pedagogy is the new area of curricular internationalization. As Rubin and Guth (2015) observe about Internationalization of the Curriculum, "whereas many large universities collaborate on research, very few universities or colleges have significant experience with collaborative working in the area of pedagogy" (p. 25). Indeed, Rubin (2017) goes on to state that "engaging in the deep intercultural re-examination of why and how each class does what it does, can be a 
potentially radical and revealing intervention for students, instructors and staff" (p. 33). Ping (1999) wrote that "internationalization is a radical transformation of academic disciplines, freeing of both teaching and research from the dominance of the acceptance of and training in the intellectual traditions of a particular culture" (p.18).

The dilemma for administrators is the ownership of curriculum by faculty, whose primary focus is to teach in their area of expertise and not necessarily internationalize the curriculum (Edwards \& Teekens, 2012). Edwards and Teekens (2012) posit that infusing an intercultural dimension into a course, when the subject or coursework is not explicitly designed for it, adds a great burden to the instructor. They go on to state that it is difficult to "mandate, reward or even monitor" an internationalized curriculum (Edwards \& Teekens, 2012, p. 2). Therefore, successful strategies to internationalize the curriculum must come through faculty incentives. Incentives would include institutional support and encouragement in the areas of classroom management around culture and language differences and the utilization of Web 2.0 tools to enhance learning (Edwards \& Teekens, 2012). Changes in faculty culture are necessary to free faculty to teach differently. Austin's (2003) work on faculty cultures describes how faculty allegiances are shaped by the academic profession, their discipline, the academy, and their specific institutional type (public, private, research, graduate). Austin advocates for a broader conceptualization of scholarship and an effort to bring teaching back to the core of the profession.

As part of internationalizing the curriculum, faculty have been asked to engage their students through a more internationalized pedagogy. For instance, faculty were 
encouraged to develop local curriculum that could offer the same high impact practice (Kuh, Schneider, \& Association of American Colleges \& Universities, 2008) benefits as study abroad (Edwards \& Teekens, 2012). Faculty were asked to instill global attitudes in their students in order to make the students better prepared for professional employment (Deardorff, 2009). Faculty were encouraged to open up to alternatives to U.S. classroom culture (Edwards \& Teekens, 2012) by creating universal design style classroom cultures. These mandates have been too conceptual with too few faculty involved (Stohl, 2007). Internationalization directives at the university have failed to "convince faculty that their scholarship and teaching would benefit from these efforts by considering the risk and reward structures within our institutions and faculty cultures" (Stohl, 2007, p. 359). Scholars hoped that the innovation in faculty pedagogy through Internationalization of the Curriculum would gain momentum: "Opportunities grow for new dialogues within the classroom, among instructors across the globe, and among administrators seeking to encourage pedagogical innovation on their own campus" (Edwards and Teekens, 2012, p. 14). Therefore, there was recognition that Internationalization of the Curriculum involved much more than inserting global content in a course.

\section{Faculty Engagement and Motivation}

Faculty experiences of learning and discovery are considered paramount in successful and sustainable Internationalization of the Curriculum. Stohl (2007) warns that it is short-sighted and counter-productive to measure outcomes if the goal is to internationalize the curriculum, and that efforts to create targets and policy would undermine international educators' ability "to capture the faculty's interest in, and 
commitment to, internationalization" (p. 369). Stohl (2007) refers to the work of Simcock (1989) to suggest how faculty engagement could be cultivated along a continuum. In the first stage, the excitement would be around novelty of difference. The second stage would support faculty in thinking about how to appreciate and adapt other pedagogy and systems into their own teaching. The third stage would move from transaction of knowledge to creation of knowledge, where "one learns with the other and learns how to produce and work jointly with others with multiple ways of knowing and doing" (Stohl, 2007, p. 369).

The Association of American Colleges and Universities rubric on international competencies (AAC\&U, 2017) emphasizes the attitude of curiosity as key to faculty engagement in internationalization. Indeed, their rubric asserts that intercultural competence is rooted in cognitive and affective lenses which help faculty build selfempathy and flexibility as they approach unfamiliar ways of being in the classroom. Faculty intellectual curiosity is therefore a foundational pre-requisite to designing and implementing curricular internationalization, and must be considered in any institutional strategy around internationalization.

Scholars have therefore examined how critical institutional support is necessary to engaging faculty in internationalization. Childress (2010) has argued that most of the barriers to Internationalization of the Curriculum are due to a lack of faculty engagement. This lack of engagement is due to a lack of institutional support (Childress, 2010). This lack of support can be redressed through institutional implementation of what Childress (2010) calls the "Five I's": intentionality, information, involvement, institutional 
networks and incentives (p. 18). Intentionality means aligning any directives to internationalize the curriculum to align with departmental goals. Information means sharing information formally and informally with faculty when creating institutional policy to internationalize the curriculum. Involvement means both lightening faculty load so they can become involved in curriculum integration and signaling inclusiveness, communicating that all are desired to be involved in curriculum internationalization. Institutional networks are required to share information and to recruit faculty; therefore, a campus-wide internationalization council is strongly recommended. Incentives, financial or for scholarship, are necessary for faculty to engage in Internationalization of the Curriculum (Childress, 2009, 2010; Dewey \& Duff, 2009). Of the five I's, involvement and incentives undergird the foundation for institutional networks, information sharing, and intentionality to work.

Motivating faculty goes beyond the institution and involves the larger academic culture. As Jones and Killick (2013) write, "while academics may be "happy to "tinker around the edges' of their course content and classroom pedagogy" they still frequently ask, "What does it really mean for me and my classroom?" (p. 167). Social interaction and inter-professional experience are necessary keep faculty motivated to innovate their pedagogy: "They need extrinsic motivation to build their commitment to teaching, educational rigor in order to innovate, and ICT skills to keep up the quality of their teaching" (Killick, 2018, p. 14). This also implies going outside of their discipline. As Childress believes, "given the interdisciplinary nature of the infrastructural support and networks that facilitated faculty engagement in internationalization, institutions with an 
ethos of interdisciplinarity may be at an advantage to develop a foundation for faculty engagement in internationalization" (Childress, 2009, p. 20). Childress' findings suggest that it is critical to provide opportunities for faculty to challenge each other's thinking across disciplinary, national, and cultural boundaries (Childress, 2009).

Faculty like challenges that ask them to demonstrate autonomy, mastery and purpose; their motivation is driven by a desire to exercise all three (Merriam \& Bierema, 2013; Pink, 2009). Scholars go on to say therefore that faculty can be seen to be motivated through a desire for agency, a drive for expertise, an enthusiasm for learning, and the wish to be culturally responsive (Merriam \& Bierema, 2013). Indeed, Blackmore and Kandiko (2011) believe that these motivations are linked to "academic prestige" (p.408) and that faculty motivation is about "intellectual positioning rather than financial gain, [supporting] the idea of intellectual leadership — taking the lead in the generation of ideas" (p.408). Furthermore, such drives and motivations are seen as part of the internationalization of higher education (Webster-Wright, 2009).

Faculty must access their personal agency to find the motivation to respond to a variety of growing demands in their profession (Austin \& Sorcinelli, 2013). These demands include being held more accountable to student learning outcomes, teaching to increasingly diverse student populations, incorporating technological innovation in their pedagogy, and orientating more towards interdisciplinarity (Austin \& Sorcinelli, 2013). In order to meet these challenges, faculty will need to find an increased sense of agency and collegial support through faculty development programs that are more decentralized, 
collaborative and faculty community driven (Austin \& Sorcinelli, 2013; Nyangau, 2020) and more embedded within their professional lives (Webster-Wright, 2009).

Faculty need their institutions to tap into their motivation and sense of agency to improve their praxis (Austin \& Sorcinelli, 2013). This motivation includes the willingness to take on risk in order to fulfill their "cardinal responsibility...to be the primary innovators and initiators of change in academe" (Camblin \& Steger, 2000, p. 1). Risk can involve self-assessment of teaching efficacy or acknowledgement that their current teaching practice warrants revitalization (Camblin \& Steger, 2000, p. 5). Motivating faculty to take on risk to further their professional growth requires frequent interaction, collaboration and sense of community among the faculty themselves (Feldman \& Paulsen, 1999). This sense of community offers them a place to also selfreflect and self-determine the strengths and competencies they want to develop (Feldman \& Paulsen, 1999, p.76).

Feldman and Paulsen (1999) talk about the importance of a supportive teaching culture for faculty motivation, especially other faculty's involvement in giving feedback, shared academic values and a sense of ownership (p. 72). They also discuss the importance of frequent collaboration and community among faculty (p.73). This includes communities of practice (Steinert, 2010) and university structure to support a sense of community and shared learning with other faculty (Niehaus \& Williams, 2016). This sense of community could nurture faculty sense of agency which was important to participate in faculty development related to internationalization at their universities (Nyangau, 2020, p. 74). 
While personal faculty agency was linked to faculty communities of practice, the literature also looks at transformation of faculty as a cohort through internationalization. Faculty should engage much more intentionally with international students in their classrooms (Lemke-Westcott \& Johnson, 2013; Teekens, 2003) and create an internationalized curriculum that reflects classroom student diversity (Gopal, 2011; Mak \& Kennedy 2012). Faculty transformation around their course content and pedagogy is thus a precondition for curriculum internationalization (Niehaus \& Williams, 2016). Niehaus and Williams (2016) wrote that, "internationalizing curriculum/a is therefore also an exercise in transforming faculty members' engagement in international curriculum transformation" (p. 60). To accomplish curricular and teaching internationalization, faculty professional development programs are necessary (Childress, 2010; Landorf et al., 2018).

Some scholars examine how internationalization affects faculty as constituent stakeholders at the university. One study (Bedenlier \& Zawacki-Richter, 2015) concluded that further exploration was necessary regarding the individual impact of curricular internationalization on faculty. This is supported by both Green (2012) and Deardorff (2006), who argue further that assessing individual faculty experience and outcomes of internationalization will take on greater importance as internationalization becomes more central to defining the quality of teaching, research, and faculty engagement.

Scholars agree that there is a lack of adequate professional development provided by higher education institutions for faculty (Beelen, 2018; Egron-Polak \& Hudson, 2014; 
van Gaalen et al., 2014). Beelen (2018) argues that the paucity of programming is compounded by the disconnect between course developers and curriculum designers to faculty in Internationalization of the Curriculum. Beelen (2018) says this is because at most universities, "internationalization and education are still perceived as separate entities" (p. 67). Faculty professional development programming has not kept pace with internationalization (Beelen, 2018). It is critical therefore, that internationalization efforts at the university support individual faculty agency as well as support faculty community through professional development that is driven by faculty interests and needs.

\section{Campus Internationalization and Students' Global Learning}

The relationship between campus internationalization efforts, faculty engagement, Internationalization of the Curriculum and students' perceptions of global learning gains has been studied (Kinzie \& Helms, 2019). Two reports, one on campus internationalization and the other on student internationalization, were compared. The ACE 2017 Mapping Internationalization Survey (ACE, 2017) looked at institutional selfreported gains around the ACE six pillars of comprehensive internationalization: articulated institutional commitment; administrative leadership, structure, and staffing; curriculum and co-curriculum, and learning outcomes; faculty policy and practice; student mobility; and collaboration and partnerships (ACE, 2015). The 2018 National Survey of Student Engagement (NSSE, 2017) examined student self-reported gains in international awareness and skills. It was the first time that the National Survey of Student Engagement included a global learning module and it wanted to assess 
coursework and student experience around internationalization. The comparative analysis looked at how internationalization efforts by campuses actually synced with students' global learning (Kinzie \& Helms, 2019).

In comparing institutional internationalization efforts against students' gains in global perspective and global learning, the study found a mismatch. What institutions reported as most important to improve students' global learning was not the same as what students attributed their gains in global learning to (Kinzie \& Helms, 2019). Institutions had prioritized their internationalization activities from most to least important as (1) increasing study abroad, (2) recruiting international students to the home campus, (3) creating more international institutional partnerships, (4) internationalizing the curriculum and co-curriculum, and (5) investing in faculty development (Kinzie \& Helms, 2019). Students had attributed their gains in global learning and intercultural skills from most to least important as (1) faculty engagement in internationalization, (2) an internationalized curriculum and co-curriculum, (3) institutional commitment to internationalization, (4) university leadership commitment to internationalization, and (5) study abroad (Kinzie \& Helms, 2019). The authors found that faculty travel and development, along with Internationalization of the Curriculum, had a stronger impact on student gains in global learning and intercultural skills than inbound or outbound student mobility (Kinzie \& Helms, 2019; Kinzie et al., 2017). Therefore, faculty were paramount in successful internationalization of universities and curriculum internationalization yet did not receive commensurate institutional recognition or support. 


\section{Cultural Humility}

Faculty engagement with cultural humility is seen by scholars (Murray-Garcia \& Tervalon, 2017) as a prerequisite to intercultural competency (p.25). This is particularly applicable in educational settings were there faculty could have "high knowledge but low humility" (Hook, Davis, Owen, Worthington \& Utsey, 2013) around different cultural backgrounds and experience (p. 353). Especially in the context of a globally interdependent and connected society, cultural humility is advocated as a more useful term than cultural competency when looking at diversity and power imbalance in higher education (Foronda, Baptiste, Reinholdt \& Ousman, 2016, p.210). Indeed, this power imbalance seen through the internationalization of higher education requires that scholars and practitioners practice cultural humility to avoid reproducing geo-political inequality (Stein, 2016).

Cultural humility was first developed in the allied health fields (Tervalon \& Murray-Garcia, 1998). It was defined as a "lifelong commitment to self-evaluation and critique, to redressing power imbalances... and to developing mutually beneficial and non-paternalistic partnerships" (Tervalon \& Murray-Garcia, 1998, p.123). Cultural humility emphasized that it was not enough to be knowledgeable about other cultures; it also required a self-aware and a respectful orientation towards difference in order to be competent in navigating and learning from difference (Tervalon \& Murray-Garcia, 1998). Cultural humility was seen as a foundation for collaborative learning in international and intercultural settings (Foronda et. al., 2016). Cultural humility also implied faculty equity work. As Foronda et al. (2016) posited: 
In a multicultural world where power balances exist, cultural humility is a process of openness, self-awareness, being egoless, and incorporating self-reflection and critique after willingly interacting with diverse individuals. The results of achieving cultural humility are mutual empowerment, respect, partnerships... and lifelong learning (p. 21).

Therefore, scholars posit cultural humility as a guiding principle for faculty who teach in diverse and constantly evolving education settings (Nomikoudis \& Starr, 2016).

Scholars suggest that faculty embrace cultural humility as a tool when teaching in contexts where they do not have area studies or intercultural communication expertise (Murray-Garcia \& Tervalon, 2017). While it might not be possible for faculty to have cultural expertise in all areas and contexts, especially in interdisciplinary teaching, it was possible to adopt an attitude of humility and openness to learning that could mitigate barriers to communication and learning (De la Garza, 2019). Scholars advocate that faculty could model cultural humility for their students in order for them to learn in diverse settings where power imbalances exist by (Hook et al., 2013). It could help reinforce for students the notion that life-long learning involved cycles of discomfort and adaptation (Foronda et al., 2016). Therefore, faculty could both model and implement cultural humility as a value and a tool to navigate difference in an internationalized context.

\section{Globally Networked Learning}

Pedagogy informed by digital technology drives Internationalization of the Curriculum. In particular, scholars see globally networked learning environments as a way for faculty to transform their pedagogy through technology (O’Dowd, 2018; Rubin, 2016; Starke-Meyerring, 2010). Globally networked learning environments are described 
as partnered learning (Starke-Meyerring, 2010), where faculty, students and communities collaborate to make new knowledge that is of benefit to all, especially for groups most disadvantaged by globalization. Globally networked learning was conceived as independent of digital technology, but with the inclusion of digital technology, faculty became more central to internationalization of higher education (Starke-Meyerring, 2010):

Importantly, they [globally networked learning environments] have also led to institutions beginning to recognize the value of globally networked learning environments as pedagogical innovations by faculty, with some institutions beginning to develop a significant infrastructure in support of faculty innovation in globally networked learning, such as, most notably, the Center for Collaborative Online International Learning (COIL) at the State University of New York. (p. 127)

Institutions conceived of faculty international engagement going beyond traditional areas of study abroad or area studies to any course in any classroom through virtual exchange made possible by digital technology. Virtual exchange in higher education implies an activity where students in different countries collaborate on joint projects under the guidance of faculty as part of a formal university course (Virtual Exchange Coalition, 2019, para.1).

Studies have shown that faculty find teaching virtual exchange courses strongly benefits their teaching (De Castro, Dyba, Cortez, \& Pe Benito, 2018; Lee \& Cai, 2018). One study found that "faculty reported greater benefits from the Internationalization at Home course for their teaching...faculty most strongly endorsed the courses in prompting their reflection on their own pedagogical practices and expanding their experience of international education" (Lee \& Cai, 2018, p. 17). Another study (Edwards \& Teekens, 
2012) concluded that faculty recognize that their students will need preparation to live in a globalized world yet won't have the means or possibility to travel. Faculty are therefore inspired to innovate their pedagogy with digital tools (Edwards \& Teekens, 2012):

Increasingly, students are making decisions about higher education that are dominated by their understanding of themselves as global actors as well as members of local communities. As use of communication technologies grows... opportunities grow for new dialogues within the classroom, among instructors across the globe, and among administrators seeking to encourage pedagogical innovation on their own campus. (p. 14)

Internationalization of the Curriculum has been explicitly linked to digital learning by the European Union (European Commission, 2013). They have mandated that their members must adopt education policies which must increasingly focus on the integration of a global dimension in the design and content of all curricula and teaching/learning processes (sometimes called "internationalization at home"), to ensure that the large majority of learners, the $80-90 \%$ who are not internationally mobile for either degree or credit mobility, are nonetheless able to acquire the international skills required in a globalised world. (European Commission, 2013, p. 6)

The literature explores the intersection of pedagogical innovation with technology (Edwards \& Teekens, 2012; Lee \& Cai, 2018) and concludes that while it has become a priority for governments and institution, too few studies have measured its impact on Internationalization of the Curriculum (Altbach \& Knight, 2007; Leask, 2015). This is particularly true in the area of virtual exchange (Lewis \& O’Dowd, 2016; Rubin, 2017).

While many scholars agree that academic faculty are critical to successful internationalization of higher education (Childress, 2010; Knight, 1994; Stohl 2007), there is little research on how faculty experience internationalization as both participants 
and recipients (Bedenlier \& Zawacki-Richter, 2015; So \& Kim, 2009).

Internationalization of the Curriculum through faculty engagement needs further exploration as institutions discern how to best support faculty in the process of curricular and pedagogical internationalization. While strong interest by faculty is considered the single most important organizational factor to support internationalization at universities (Association of Universities and Colleges of Canada, 2008) little is known about how faculty perceive their role in the process of internationalization and what their motivations for doing so are (Friesen, 2013). We need to know about the faculty member experience in internationalization of the curriculum in particular if we are to understand its relevance to them. Without this understanding, it will not be possible to sustain internationalization efforts on campus that benefit all students.

\section{Virtual Exchange}

Virtual exchange is a generic term describing international mobility through technology instead of physical travel (Virtual Exchange Coalition, 2019). It is described as a way to allow geographically distant people to interact and communicate for educational purposes (Virtual Exchange Coalition, 2019). It is also described as "the engagement of groups of learners in online intercultural interactions and collaboration projects with partners from other cultural contexts or geographical locations" (O'Dowd, 2018, p. 5). Forms of virtual exchange include Telecollaboration (Belz, 2002; Warschauer, 1996), COIL (Rubin, 2016; Moore, \& Simon, 2015), Virtual Mobility (De Wit, 2017), Virtual Exchange (Helm, 2015), Virtual Transnational Education (Teekens, 2015), Global Virtual Teams (Jarvenpaa \& Leidner, 1999), Globally Networked Learning 
Environments (Starke-Meyerring \& Wilson, 2008), E-tandem (O’Rourke, 2007) and Online Intercultural Exchange (O’Dowd, 2007; O’Dowd \& Lewis, 2016). These forms and their names were generated independently but can reflect a disciplinary orientation (O’Dowd, 2018). "Telecollaboration" is used by foreign language teachers, while "virtual mobility" was coined by the European Union, and "globally networked learning" is used by the National Endowment for the Humanities (Rubin \& Guth, 2015, p. 16).

While all of these forms continue to be in use, the term "virtual exchange" has displaced "telecollaboration" in the literature (O’Dowd, 2018). This reflects a shift in emphasis from technology-enhanced foreign language learning to development of cultural knowledge and intercultural communication skills (O’Dowd, 2018). In addition, more emphasis is now on the faculty member as facilitator in class-to-class partnerships over individual exchanges outside of the classroom (O’Dowd, 2018).

O'Dowd (2018) states that what is common to all forms of virtual exchange is engagement online for a set time, collaborating with other learners under faculty guidance, as part of the curriculum. He defines virtual exchange thus:

virtual exchange involves the engagement of groups of learners in extended periods of online intercultural interaction and collaboration with partners from other cultural contexts or geographic locations as an integrated part of their educational programmes, and under the guidance of educators and/or expert facilitators. (O’Dowd, 2018, p. 5)

All forms of virtual exchange share an educational approach committed to experiential learning, collaborative critical inquiry, and cross-cultural learning (O’Dowd, 2018). In addition, all forms of virtual exchange share the same educational goals of transversal skill development, digital literacy, intercultural awareness, and the ability to live and 
work together with people of different backgrounds (Helm \& Guth, 2010). Shared challenges exist as well, especially in attempts to scale up and benefit more students (Aspen Institute, 2019). These include limited access to technology among students and faculty, faculty's limited digital competency, time-difference and its effect on synchronous communication, and faculty resistance to the interdisciplinary nature of virtual exchange (O’Dowd, 2018; Starke-Meyerring \& Wilson, 2008, p. 223).

As another perspective on virtual exchange, Bruhn (2017) builds on Knight's (2004) definition of internationalization by adding "virtual" to it, to create the concept of virtual internationalization: "Virtual internationalization at the national, sector, and institutional levels is defined by the process of introducing an international, intercultural, or global dimension to the delivery, purpose, or functions of higher education with the help of internet communication technology" (Bruhn, 2017, p. 2). Web 2.0 technologies will exponentially expand virtual mobility, to include even "international virtual experiences that are not necessarily grounded in collaboration, but provide other forms of virtual travel, including virtual field trips and internships" (Bruhn, 2017, p. 6). Virtual exchange is therefore a possible precursor to other forms of international learning experience achieved through digital technology.

\section{Web 2.0}

Web 2.0 made virtual exchange possible (Guth \& Helm, 2010). The term Web 2.0 was coined by O'Reilly Media in 2004 (O'Reilly, 2005) to reference to the secondgeneration development and capacity of the World Wide Web through software and technology innovations. Examples of innovations available through Web 2.0 include 
blogs, video-sharing sites, wikis, social networks, and web applications (Murugesan, 2007). Web 2.0 is often discussed in the context of the social web (Anderson, 2007). The social web refers to online platforms where users share their opinions, experiences, and perspectives (Anderson, 2007). Scholars say that there is a mindset engendered by Web 2.0, which is "a willingness to explore, learn and participate in online networks, collaborate with others, share ideas, knowledge, media and contribute to the collective construction of knowledge" (Guth \& Helm, 2010, p. 81). The New London Group (2000) advocates for a "Pedagogy of Multiliteracies" to help learners manage the complexity of culturally and linguistically diverse societies now accessible through multimedia technologies (New London Group, 2000, p. 9).

Web 2.0 has impacted the scholarship of teaching and learning. For example, Bloom's Taxonomy (Anderson \& Krathwohl, 2001; Bloom, Engelhart, Furst, Hill, \& Krathwohl, 1956) has been extended with technology and renamed Bloom's Digital Taxonomy (Churches, 2008). Bloom's Digital Taxonomy adds digital activities to the functional skills of doing, connecting, applying, conceptualizing, evaluating, and creating (Churches, 2008). A new functional level at the top of higher-level thinking skills, called sharing, was added (Common Sense Media, 2015). Sharing is defined functionally as publicly sharing, publishing, and broadcasting. Activities include contributing to open social networks, publishing, broadcasting, and networking. The aim of Bloom's Digital Taxonomy is to highlight not the digital tools themselves but how they can be used to transform learning and therefore teaching (Common Sense Media, 2015). 


\section{Limitations of Virtual Exchange}

Virtual Exchange, however, has not been widely adopted in the curriculum, even in online courses (Rubin \& Guth, 2015). Rubin \& Guth (2015) observe that "attempts to exploit technology for online intercultural exchange have remained limited until very recently and have rarely been institutionalized with the curriculum...rarely has intercultural dialogue or learning been a key component of online courses" (p. 15). That said, a shared curricular format has been adopted by virtual exchange practitioners (Helm \& Guth, 2010; Rubin \& Guth, 2015).

The desire for internationalized curriculum along with the advances of Web 2.0 has led institutions to seek a way to scale virtual exchange for regular classroom learning. In addition, student group project-based learning has emerged as a practical method of teaching and engagement in the virtual sphere. Institutions have started to embrace a scalable form of virtual exchange called COIL. Of particular interest for institutions is the innovative use of global virtual teams as part of a COIL course.

\section{Collaborative Online International Learning (COIL)}

Institutional support and implementation of virtual exchange through COIL has led to COIL to being widely used to infer virtual exchange (O'Dowd, 2018). COIL was developed within the State University of New York (SUNY) system in the early 2000s by Professor Jon Rubin. After having had a transformative international experience in Belarus on a Fulbright, he wanted his film and media studies students at SUNY Purchase to have the chance to collaborate with students abroad (Labi, 2011). COIL garnered initial institutional support because it was developed by faculty in the humanities with 
limited experience of technology (Moore \& Simon, 2015). COIL allowed faculty to use simple digital tools and applications to customize how they wished to internationalize their courses (Labi, 2011).

COIL is considered a pedagogy for international experiential learning (De Castro et al., 2018; Magnier-Watanabe et al., 2017; Marcillo-Gomez \& Desilus, 2016). It is a way to use digital technology to provide experiential international learning without travel abroad (De Castro et al., 2018; Marcillo-Gomez \& Desilus, 2016; Soria \& Troisi, 2014). It has been used by faculty in professional programs to internationalize their courses (De Castro et al., 2018; Magnier-Watanabe et al., 2017). COIL is seen as addressing three problems in higher education simultaneously: students needing to be prepared for $21^{\text {st }}$ century global work, place-bound students having access to an international experiential education experience, and students achieving equitable degree outcomes whether or not they can travel (Patterson, Carrillo \& Salinas, 2012).

COIL came out of the development of the internet and the field of educational technology. Educational technology is defined by the Association of Educational Communications and Technology as "the study and ethical practice of facilitating learning and improving performance by creating, using and managing appropriate technological processes and resources" (Richey, Silber \& Ely, 2008, p. 24). Initially, universities adopted learning management systems such as Blackboard or Canvas to create online courses that would disseminate information outward from the institution to students. Then, with the creation of social networks and collaborative online tools in the 
2000s such as Facebook, YouTube, Google Docs, and MOOCs, the landscape changed (Garrison, 2011).

COIL utilizes digital learning environments that are synchronous and asynchronous (Garrison, 2011). Synchronous learning may include face-to-face discussions in class or remote videoconferencing, and it requires all participants to be present. Asynchronous learning relies on Learning Management Systems such as Desire to Learn or Canvas, email, and web 2.0 social networking platforms such as Snapchat, WeChat, or Facebook (Garrison, 2011). Both higher education and human resources use synchronous and asynchronous e-learning through learning management systems to deliver curriculum to students and to provide training to employees (Frehywot et al., 2013).

COIL is unique in the world of e-learning because it requires co-teaching and brings together at least two classroom cohorts in different geographic locations to collaborate on a project or activity (De Castro et al., 2018; Rubin \& Guth, 2015). COIL courses have five signature elements (De Castro et al., 2018). First, faculty in different countries and at different institutions co-create, co-teach, and co-manage a course together. This may be for the entire course, or it may occur only in a segment where the respective institutional academic calendars overlap. Second, the course enrolls students from different countries, but grading and granting of credit are determined by the student's home institution. Third, learning objectives for each group of students may differ, though the assignments may be the same. Fourth, students' engagement with each other is designed around highly interactive problem-solving projects and exercises. 
Lastly, the course communication and delivery are not dependent on institutionally determined internet communication technologies but on what is accessible at low cost to the participating students (De Castro et al., 2018).

Examples of COIL. A typical course involves two faculty in two different geographic locations who want to teach a course together because of the perspective their respective classrooms will bring to the material (Rubin, 2017). Usually, the COIL course is cross-disciplinary and has a joint syllabus for 4-10 weeks of the respective courses (Rubin, 2017; Tuke, 2019). The faculty identify the technologies they want to use for the course based on what is available to their students (Rubin, 2017; Tuke, 2019). Collaborative student activities are designed on a course-by-course basis (Rubin, 2017). Some COIL faculty will design collaboration around asynchronous assignments where global student groups will post videos to each other for comment. Other faculty will implement a synchronous activity, either inside or outside of class as an icebreaker and at wrap up. Most COIL student groups are made up of students from both classrooms (Tuke, 2019).

Practitioners have developed course designs for other faculty to use, based on the collective experience of COIL faculty cohorts (Doscher \& Rubin, 2019; SUNY COIL Center, 2014; Tuke, 2019). Activities are sequenced to build on each other to result in a culminating project (Tuke, 2019). They start with a faculty and student icebreaker, a country/cultures activity, a team leader selection, a team-building activity, a low-stakes test task, a collaborative project, a reflection piece and presentation of a final project or 
product that benefits the learning outcomes for each class (Doscher \& Rubin, 2019; Rubin, 2017).

An example of a COIL course collaboration was "Gender Violence \& the Law: Global Perspectives" at a U.S. university and "Digital Games" at a Brazilian university (Doscher \& Rubin, 2019). Over a period of six weeks, students analyzed the representation of violence against women in different media forms. The final group project aimed to create an awareness campaign to educate peers about online violence. The faculty members were able to borrow from each other's courses to create more content and then discuss how the students' work could be used in their local context:

The aim of this COIL project is to analyze the representation of violence against women in different media forms (video games, commercials, music videos). While FIU students will share and apply their knowledge of causes and consequences of gender violence, FATEC students will share and apply their knowledge of gaming, game creation, and virtually created cultures. At the end of this project you will create an awareness campaign to educate your peers, your community, or your society, locally and globally, about online violence, and think about ways to take action. (Doscher \& Rubin, 2019)

Examples of other COIL courses include Rights of the Handicapped, Education Interventions for Exceptional Students, and Analysis of GMO impacts (Doscher \& Rubin, 2019). Propriety software applications used in COIL include Moodle and Voicethread (Doscher \& Rubin, 2019). Open-source applications used in COIL include: Bluejeans, Adobe Connect, Zoom, email, Google Drive, Padlet, Flipgrid, WhatsApp, Cahoot, Facebook, Instagram, Dropbox, Line, PowerPoint, Duolingo, Google Translate, and WeChat (Doscher \& Rubin, 2019).

Faculty role in COIL. Institutional COIL workshops for faculty are relatively new but are expanding (Doscher \& Rubin, 2019). Workshops focus on course 
development and classroom activities (SUNY COIL, 2014). Workshops cover include setting learning objectives, creating student icebreaker activities, creating collaborative assignments, learning about online technology tools, making language considerations, setting common readings for both courses, setting common expectations for student work, and a agreeing on a method to survey student learning (Doscher \& Rubin, 2019; Tuke, 2019). Ongoing critical reflection by faculty on their teaching as well as students on their learning is emphasized (Tuke, 2019). Also recommended is a formal closure to the course and the groups at the end of the "COILed" part of the respective courses (Tuke, 2019).

COIL emphasizes class-to-class partnering and the key role of the instructor in facilitating the exchange (O’Dowd, 2018):

Once connected, the instructors in the partner universities design course modules in a way that the two different student populations will engage in communication and collaboration together. Often, the two groups of students have to work together to discuss course materials, solve a problem of practice, or produce another type of grade-able product. (p. 14)

Each faculty member serves as a guide to helping students understand how their personal, cultural and national experiences affect their interpretation of the subject content (O’Dowd, 2018).

Influences on COIL. Scholars have referred to Allport's (1954) Intergroup Contact Theory as an inspiration for the curriculum design of COIL (Langdorf et al., 2018; Taras et al., 2013). Intergroup Contact Theory (Allport, 1954) states that lack of interaction between self-identified distinct racial groups leads to prejudice and conflict between them. Therefore, racism could be alleviated through intentional intergroup 
contact (Allport, 1954) designed around four conditions: equal status at point of contact, cooperation between group leaders, common goals and institutional support. Pettigrew \& Tropp (2006) built upon Intergroup Contact Theory to show that it could be applied to groups divided by politics, religion and views on gender and sexuality. Intergroup Contact Theory (Allport, 1954; Pettigrew \& Tropp, 2006) inspired the work of the Soliya Connect Program (2019) which uses virtual exchange between youth in the Middle East and the West to build world peace and global citizenship.

Murphy's (2014) six stages of collaboration have also informed the curriculum design of COIL (Patterson et al., 2012). These include having social presence, articulating individual perspectives, accommodating the perspectives of others, coconstructing shared perspectives and meanings, building shared goals and purposes, and producing shared artifacts (Patterson et al., 2012). Often, COIL course icebreakers will include faculty and students sharing personal cultural artifacts with the other classroom (Tuke, 2019).

Zha's (2003) conceptual framework for internationalization of higher education supports the COIL course design. Zha's framework (2003) delineates four distinct approaches to internationalization in higher education, which are ethos, process, activity, and competency. The ethos approach emphasizes creating a culture or a climate that values international/intercultural perspectives. The process approach focuses on Internationalization of the Curriculum, pedagogy, faculty and student research and university service. The activity approach involves utilizing technology like virtual exchange. The competency approach emphasizes the development of skills, knowledge, 
attitudes and values in students, faculty and staff. It is an area that many scholars (Green, 2012; Zha, 2003) have said needs further development: "There is an urgent need for further applied research to identify those competencies which help students to be successful national and international citizens and to contribute to the local and global work environments" (Zha, 2003, p. 250). COIL courses are designed to foster global citizenship and global workforce development as part of the undergraduate curriculum.

Therefore, the success of COIL is dependent on faculty engagement and enthusiasm for the project as a pedagogical experiment (Patterson et al., 2012). COIL projects should be designed and implemented at the faculty level with administrative support as a bottom-up effort (Patterson et al., 2012). Faculty engagement is driven by their commitment to re-envisioning education in a world connected through digital technology (Starke-Meyerring, 2010) and faculty "commitment to institutional innovation necessary to facilitate the kind of cross-boundary learning and knowledge making that globally networked learning environments are designed to enable" (StarkeMeyerring, 2010, p. 128). Studies have shown that student interaction alone is insufficient to create depth of learning and critical thinking (Garrison \& Cleveland-Innes, 2005). Faculty guidance therefore is a critical ingredient to achieving the intercultural learning in a COIL course (Lee \& Cai, 2018).

Faculty who teach COIL courses serve as models of collaboration for their students (Rubin \& Guth, 2015). Rubin and Guth (2015) observe that the modelling happens "through the process of planning and designing a COIL course together--a process that involves teachers examining each of their respective courses, teaching styles, 
and institutional cultures--thus experiencing firsthand the process of collaboration" ( $\mathrm{p}$. 28). The bilateral nature of COIL is driven by international and intercultural partnerships, including the needs and ends of the partner classroom (Doscher \& Rubin, 2019). The collaborative element of COIL has been emphasized by the SUNY COIL Center through the change of its name (SUNY COIL, 2018). Rather than referring to COIL as an acronym for collaborative online international learning, it now refers to COIL as a verb. It traces its origins to the Latin verb colligere and the medieval French verb coillir, both meaning "to gather together" (SUNY COIL, 2018). COIL is colloquially used as a verb to indicate transforming a course with virtual exchange, as in "COILing a course" or "having COILed a course" (Tuke, 2019).

Faculty benefits. Aside from innovating their pedagogy, faculty have accrued additional benefits from teaching a COIL course (Lee \& Cai, 2018; Rubin, 2017). These include authoring future joint publications in international journals, creating open source textbooks, seeding ideas for new research, and expanding professional networks (Lee \& Cai, 2018, p. 17). But the biggest benefit faculty reported was for their teaching:

For teaching, faculty most strongly endorsed the course in prompting their reflection on their own pedagogical practices and expanding their experience of international education. The Internationalization at Home [sic] (COIL) experience alerted faculty to new international and comparative topics, inspiring them to broaden the existing content in their courses to include international and comparative perspectives. Cultural differences and contexts are often taken for granted in the curriculum, and the Internationalization at Home [sic] (COIL) course provided a new appreciation of cultural differences on a given thematic topic in their teaching. (Lee \& Cai, 2018, p. 17) 
Faculty reported that developing and teaching a COIL course in a cohort helped them discover benefits to internationalization that they had not considered previously (Lee \& Cai, 2018).

That said, faculty face significant challenges in developing COIL courses (Rubin \& Guth, 2015; Starke-Meyerring, 2010). These include developing learning environments amenable to virtual exchange, having adequate administrative institutional infrastructure and technology support, and receiving compensation/recognition for time invested in teaching COIL. Other challenges were finding a faculty partner, negotiating the influence of the other faculty and class on their local course, encountering student trepidation, and addressing copyright/export control issues (Landeros, 2019). As Rubin and Guth (2015) state, "the normalization of COIL, ironically, may be a disruptive force at the university" (p. 26). Indeed, a significant potential for COIL is in how it may be extended beyond traditional degree programs at universities to include marginalized learners and those outside the academy (Starke-Meyerring, 2010).

Scholars say that COIL is a way for faculty to reimagine teaching and learning as a tool of equity and inclusion (Starke-Meyerring, 2010). As Starke-Meyerring (2010) believes:

Globally networked learning environments [COIL] are specifically envisioned as alternatives focused on collaboration and mutual learning, including collaboratively developed curricula, pedagogies and learning spaces. As such, globally networked learning environments [COIL] have as one of their priorities the facilitation of faculty and student participation in the shaping of a global social and economic order. (p. 128) 
Faculty are encouraged to use COIL as a way to challenge the neoliberal education agenda and participate in internationalization to improve higher education for all (StarkeMeyerring, 2010).

Rubin (2017) sees COIL is as faculty-engagement driven learning more than anything else. Indeed, he describes COIL as a faculty-driven curricular "intervention" (Rubin, 2017, p. 43). De Wit (2013) posits that COIL combines four essential elements of virtual mobility: It is a collaborative exercise of teachers and students, it makes use of online technology and interaction, it has potential international dimensions, and it is integrated into the learning process. COIL's value to faculty also lies in it is ability to prepare students for multicultural work settings while fulfilling academic program goals (De Castro et al., 2018; Patterson et al., 2012). A group of US-Filipino nursing faculty described COIL as a "practical way to prepare students for diverse, multicultural work settings likely in their professional futures...(and) it also helped faculty members conceptualize lessons [classes] that promote intercultural respect and appreciation" (De Castro et al., 2018, p. 4). While it is clear that faculty drive the success of learning through COIL (Rubin, 2017) they may have multiple end goals for their COIL teaching. Institutions view COIL as a pedagogical innovation by faculty that benefits their institutional missions around internationalization and student success (Rubin, 2017; Starke-Meyerring, 2010). Inter-institutional infrastructures have been created to support and promote COIL courses on a large scale (O’Dowd, 2018). Examples include the SUNY COIL Center, the Asia-Pacific Virtual Exchange Association, the Global Nomads Group, iEARN-USA, Soliya, and the Aspen Institute (O’Dowd, 2018). At a government 
level, the U.S. State Department established a virtual exchange unit in 2013, while the European Union created the Erasmus Plus program and Japan created the U.S.-Japan COIL Initiative.

In its most basic form, COIL is a partnership between two groups in two countries who agree to work together towards a shared educational goal using internet tools to facilitate the learning process (Schnickel, 2019). COIL is also an accessible, open-source virtual exchange framework that has been refined over time by faculty and practitioners worldwide (Schnickel, 2019). It is a pedagogy of intentional, inclusive internationalization led by faculty and supported by institutions that can benefit all students on the home campus. Indeed, COIL courses "provide participants the opportunity to experience some of the $21^{\text {st }}$ century skills firsthand-not as objects of study, but as necessary tools for the job, a kind of on-the job training for the global citizen" (Schnickel, 2019, p. 43). COIL supports the goals of a $21^{\text {st }}$ century education where graduates will be expected to collaboratively problem solve across cultures, geographies and time zones.

While as yet there is no research critiquing COIL, there are concerns that need to be addressed in practice and in future research. Other than a study (Schenker, 2013) that examined students motivation around cultural learning before and after taking a COIL class, where students were found to have high motivation both before and after the course, the literature is more focused on how COIL is implemented. Scholars share the same concerns around COIL that they do for study abroad and service learning for students (Gardner \& Krabill, 2016), namely that COIL in the Global North benefits from 
partnerships that exploit unequal power relationships around knowledge, resources and power in the Global South (p. 3). Scholars ask how modalities like COIL are framed in terms of acquiring new knowledge rather than deconstructing assumed knowledge (Buckner \& Stein, 2019). Scholars are also concerned about COIL reinforcing participant identities of being an English learners versus an English user (Helm, 2018), though others say COIL can provide redress for students living in countries where English language education is poor (Keyuravong, 2015).

\section{Global Virtual Teams}

Global virtual teams were created in the late 1990s as a way to manage workflow between international branch offices and their corporate headquarters (Lipnack \& Stamps, 1999; Maznevski \& Chudoba, 2000; Zakaria, Amelinckx \& Wilemon, 2004). Global virtual teams innovated the workplace by allowing managers to assign shared projects across geographical locations and conduct business on a 24/7 schedule. Global virtual teams have been defined in the literature as:

Internationally distributed groups of people with an organizational mandate to make or implement decisions with international components and implications. They are typically assigned tasks that are strategically important and highly complex. They rarely meet in person, conducting almost all of their interaction and decision-making using communications technology. (Maznevski \& Chudoba, 2000, p. 473)

While initially embraced to maximize productivity, global virtual teams soon became valued by corporations for assembling small groups of specialized talent for a specific purpose; this shifted the emphasis of global teamwork from task sharing to knowledge sharing (Zakaria et al., 2004). An example of this shift is the practice of multinational 
corporations to reliance on global virtual teams to develop new products (Prasad, DeRosa \& Beyerlein, 2017).

Global virtual teams were adopted from private industry to higher education programs in business and engineering (Davison, Panteli, Hardin, \& Fuller, 2017). Though computer-supported cooperative work and group support systems had already been in use, global virtual teams were believed to mimic the professional environments where engineering and business students would later work (Davison et al., 2017). Initially, students were taught how to navigate differences around language, time management, work culture, and technology in working in global virtual teams (Davison et al., 2017). However, students were not taught how to negotiate power and build trust in an intercultural environment, considered critical to team success (Hud \& Tucker, 2009). Faculty had assumed that the high-stakes work environment could not be replicated in the classroom where students were considered and treated more or less as equals (Davison et al., 2017; Panteli \& Tucker, 2009).

Despite concerns on how to best teach working in a virtual global teams, the literature shows much agreement in the value of global virtual teams use in the classroom to prepare students for professional work (Brewer, 2015; Castro et al., 2018; Cogburn \& Levinson, 2008; Cronin, Cochrane, \& Gordon, 2016; Davison et al., 2107; Dorner, 2018; Magnier-Watanabe et al., 2017; Marcillo-Gomez \& Desilus, 2016; Skagen et al., 2018). The main rationale is that students' future employers have already adopted distributed global virtual teams as way to do work in the $21^{\text {st }}$ century (Magnier-Watanabe et al., 2017). The global knowledge-based economy also requires all college graduates be able 
to work in geographically distributed, cross-cultural teams (Cogburn \& Levinson, 2008).

Interest in how to apply global virtual teams and to educational settings for collaborative learning remains strong ( $\mathrm{Hu}, 2015$; Magnier-Watanabe, 2017; McCarthy, 2012; Shea, Sherer, Quilling \& Blewett, 2011; Taras et al., 2013). Scholars (Gibson, Huang, Kirkman, \& Shapiro, 2014) have called for future research that examines how information communication technology and culture intersect to structure student learning in global virtual teams. A meta-study of virtual teams (Gilson, Maynard, Jones Young, Vartiainen, \& Hakonen, 2015) proposed that future research look at the dynamics in global virtual teams formed of participants with different knowledge and skill levels. Another large study (Gibson et al., 2014) recommended researchers explore how technology and virtuality impact cultural communication, the building of global identity within the team, and the intrinsic value of assignments. Gibson et al. (2014) called for future research on global virtual student teams that was qualitative, observational and ethnographic.

While there is enthusiasm for global virtual teams' use in formal learning, research about how best to teach this form of collaboration in the classroom is limited (Magnier-Watanabe et al., 2017). Brewer (2015) has said that universities are not alone in being challenged to prepare students for this kind of collaborative knowledge work: "Providing effective training for global virtual team communication is challenging for organizations because employees do not need separate preparation in intercultural, virtual, and team communication. Rather they need preparation in how these three skill 
sets are used together" (Brewer, 2015, pp. 184-185). The classroom is an ideal setting for the development of these skills, but how to teach them through discipline-based content and in a required university course is complex (Magnier-Watanabe et al., 2017). There is insufficient context-specific research on the use of global virtual teams in teaching to be of use to faculty wanting to use them for experiential learning in their classes (Gonzalez-Perez, Velez-Calle, Cathro, Caprar, \& Taras, 2014). This is compounded by the fact that while students are "digital natives," they do not know how to employ social media and other Web 2.0 platforms for educational and professional interactions (Davison et al., 2017).

Davison et al. (2017) argue that instructors are ultimately responsible for the success of global virtual teamwork in the classroom, especially in the heavily researched areas of "swift trust" and "group efficacy." In addition, "Instructors must carefully balance tensions between realistic experience for students and the need to ensure an appropriate degree of methodological and pedagogical control over the design of the interaction and learning experience" (Davison et al., 2017, p. 327). Another significant challenge for educators is "the migration towards alternate and likely multiple simultaneous technologies in any interactive space" (Gonzalez-Perez et al., 2014, p. 8). Faculty will be asked to lead their students "with process clarity across multiple digital platforms as well as discuss how this learning space might feel" (Gonzalez-Perez et al., 2014, p. 8). This is echoed by scholars discussing successful leadership of global virtual teams in industry: "Leading a GVT requires more than working on a project's agenda. Both human and technological issues remain paramount” (Dubé \& Paré, 2001, p. 73). 
Global virtual teams are not synonymous with COIL, however. While global virtual teams rely on digital video tools and project-based work to function, COIL does not. COIL employs a variety of modalities in the online space, including asynchronous tools such as email and text messaging (Ward, 2016). That said, global virtual teams are increasingly studied by scholars as a leading modality employed in the design and implementation of COIL courses (Haug, 2017; Steiner, 2018).

Global virtual teams require strong management leadership whether in industry or higher education. Faculty will lead them in a classroom setting, both in modeling collaboration with their faculty partner and advising students in how to best participate and produce in a global virtual team. Virtual Exchange provides an opportunity and a challenge to traditional faculty role in the classroom. The use of virtual exchange for collaborative teaching and learning holds much promise to innovate faculty pedagogy and the learning outcomes of their students for the $21^{\text {st }}$ century.

\section{Summary}

Globalization is affecting higher education by asking universities to transform themselves to produce more graduates ready to work in a global knowledge economy and engage in global citizenship. Universities responded to the mandate to internationalize themselves through a redoubling of efforts in traditional areas of international activity at the university, namely international student recruitment and sending students to study abroad. The expectation that increased student mobility would create a global climate for the campus or generate incentives and pressures for faculty to internationalize the curriculum has fallen short (Knight, 2007). While supportive of student mobility, most 
scholar-practitioners recognize that it is insufficient to mandate that an institution is international or to measure success through the number of students traveling (Knight, 2007; Leask, 2015).

Internationalization at Home has emerged as a faculty-led and institutionally supported response to internationalization of higher education. This response from universities is shaped by several factors. The first is necessity. If all students are to have a global learning experience while only $10 \%$ travel abroad for study, an alternative to study abroad must be found. Secondly, universities are pressured to produce global workforce-ready graduates, which requires co-disciplinary soft skills, including intercultural communication skills. These skills require regular practice through an inbuilt curriculum that faculty want to engage with and can be sustainably supported at the institution. Lastly, universities do not want to perpetuate structural inequities through higher education, as international education is tied to social and professional mobility. If an international learning experience is a critical element to an undergraduate education, institutions must re-frame international to a local and community context seen through a global lens.

Internationalization of the Curriculum is a main thrust of the Internationalization at Home movement because it is where students can access meaningful international learning irrespective of mobility. It foregrounds international learning from disciplinary content, for example, area studies, to something closer to general education goals. Internationalization of the Curriculum intersects institutional mission around internationalization and student learning outcomes at the university (Leask, 2015). 
University faculty are the key actors in enacting institutional goals through the curriculum they create for students. Faculty are encouraged and supported by the institution to draw upon local diversity and multicultural resources to internationalize their courses.

Virtual Exchange technology is disrupting the notion of Internationalization at Home and Internationalization of the Curriculum by blurring the lines between "here and there" and "them and us." Virtual Exchange is also adding a new tool and dimension to Internationalization of the Curriculum for faculty in particular. Faculty are now able to collaborate on a syllabus and a course, with a foreign faculty member and a foreign class, to better teach their course. It invigorates their teaching and allows them to assign projects that have more real-world context for their students.

COIL has emerged as a pedagogy that can support home-grown individual faculty curricular innovation on an institutional scale. Its simple design makes it very accessible to faculty and keeps the sovereignty of their course intact. Many internationalization efforts have failed due to their lack of commonly held and consistent design and implementation, but COIL is practiced by faculty all over the world and has emerged as a common pedagogy and structure of virtual exchange. Importantly, it provides a learning space of equality for both class groups because they need each other to accomplish their learning goals. In addition, it does not reinforce the global North-South divide in university status because it is not about brand or ranking but about the faculty, students and topic being engaged with. COIL also exposes home students to countries and 
cultures that are not usually sought after as study abroad destinations, breaking the hegemony of Spain, the UK and France.

Global Virtual Teams are ubiquitous in the private sector and have been adopted by engineering and business faculty in their courses as both pedagogy and content. COIL faculty are increasingly adopting the use of Global Virtual Teams in their courses for asynchronous and synchronous teaching and learning. Virtual collaborative learning has emerged as an important preparation for $21^{\text {st }}$ century work which will also be virtual and collaborative.

Internationalization at Home provides an empowering alternative to institutions wishing to internationalize themselves, their curriculum, their faculty and their students. Internationalization at Home is more akin to "comprehensive internationalization" (Hudzik, 2011) and "pervasive internationalization" (APLU, 2017) than these terms are actually described in the literature. Internationalization at Home is a framework both necessary and sufficient, because it highlights the importance and accessibility of global learning in domestic learning environment, irrespective of mobility and/or discipline.

The faculty and the curriculum are at the core of the university's primary duty to educate students. Therefore, the faculty and the curriculum must be at the core of any internationalization efforts undertaken by the university. Institutions can implement COIL as part of a larger strategy to fully realize comprehensive internationalization of the university. Similarly, faculty can implement COIL to provide the equity and inclusion of global learning through technology, whether or not their institution is committed to comprehensive internationalization. 


\section{Chapter Three: Methodology}

The goal of this study was to understand how COIL was implemented at universities as a faculty-driven Internationalization at Home endeavor.

Internationalization at Home was used as a framework to understand better how faculty viewed the internationalization of teaching and learning and how they were enacting it in their classes. Gaining a deeper understanding of faculty experience of COIL allows practitioners and institutions to approach internationalization of their curriculum and related academic activities with a more equitable and inclusive framework.

The main question guiding this study was: What was the experience of faculty who created and taught a COIL course? The sub-questions were:

1. Why did faculty participate in a COIL course?

2. What did faculty see as significant in their experience in preparing for and teaching a COIL Course?

3. How did faculty experience COIL through the lens of Internationalization at Home?

4. What was the experience of faculty using global virtual teams in a COIL course?

The goal of this study was to better understand how faculty interpreted their experiences in teaching COIL, how they taught COIL courses using global virtual collaborative teams, and what the experience meant for their pedagogy, their curriculum and their intended student outcomes. Faculty experience was explored by investigating the meaning they made in creating and delivering an internationalized curriculum and pedagogy around virtual exchange. A general qualitative method was used because it was 
best suited to explore the phenomenon as it was experienced by the faculty, including how faculty attributed meaning to the experience (Creswell \& Creswell, 2018). The object of my data analysis was to find recurring themes and patterns (Merriam \& Tisdell, 2016) of faculty experience with COIL and interpret them through the framework of Internationalization at Home.

This chapter provides an overview of the design and approach of this study. The first section discusses the study design and its implications for choice of the study sites and participants. The second section shows how data was collected and analyzed for the study. The final section addresses researcher positionality and the validity and transferability of the analysis methods. I conclude with a discussion of study limitations and how they were addressed.

\section{Design}

This study explored individual faculty's experience in creating and teaching COIL courses. I sought to understand how faculty made meaning of their participation in this modality. Merriam and Tisdell (2016) have posited that "in applied fields of practice such as education, administration, health, social work, counseling, business, and so on, the most common 'type' of qualitative research is a basic interpretive study" (p. 23). In addition, a basic qualitative study is well suited for scholar-practitioners seeking to understand a phenomenon and the meaning it has for those experiencing it (Merriam \& Tisdell, 2016, p. 24). For these reasons, a general qualitative study was best suited to my research purpose. 
In particular, my study sought to understand the faculty experience of participating in COIL at their institution as part of the internationalization of higher education. A general qualitative study allows the researcher to understand experiences that are constructed through action, interpretation and reflection. In this qualitative study, faculty experience was understood through how they constructed and assigned meaning to their preparation and implementation of a COIL course. This is supported by the literature (Crotty, 1998) that says meaning "is not discovered but constructed. Meaning does not inhere in the object, merely waiting for someone to come upon it...Meanings are constructed by human beings as they engage with the world that they are interpreting" (pp. 42-43). Therefore understanding how faculty experienced teaching COIL within their institutional contexts was salient to purpose of the study.

\section{Site}

The sites for this study were two affiliated urban-serving universities in the Pacific Northwest that have implemented over 25 COIL courses in the past five years as an Internationalization at Home strategy. Both campuses were early adopters of COIL and had institutionalized it as a modality to internationalize their curricula. The campuses each enrolled around 5,500 students, $80 \%$ of whom had transferred from a community college. Over $90 \%$ of the students were from the state in which the campuses were located. Each campus had an average of 350 faculty. As part of their institutional missions, both campuses were committed to workforce preparedness and creating global opportunities for their students. Both campuses had significant numbers of firstgeneration and Pell-eligible students (university websites). Very few of their students 
studied abroad. One institution had more students participating in COIL than had ever studied abroad (university websites). These characteristics made these campuses appropriate to do a study about COIL, and in particular to understand how faculty experience was affecting the implementation of COIL. Two campuses were chosen in order to net enough faculty participants to conduct the study. A tertiary study site was the 2019 International Virtual Exchange Conference. Organized by worldwide coalition of virtual exchange groups, the conference brought together 350 participants from 28 countries. Because the conference was on the teaching, research and implementation of COIL, it was an opportunity to interview additional faculty participants who were not located at the primary sites of the study. The additional participants were from open access institutions and shared similar values around access, equity and internationalization, and therefore did not alter the scope or context of the study.

\section{Participants}

Sixteen faculty participated in the study. They all had taught at least one COIL course and almost all had implemented global virtual teams in their course design. Nine faculty were affiliated with the first urban campus and four were affiliated with the second. Two faculty taught in a university system on the East Coast and one was from a European institution; all were open-access institutions in their communities.

Descriptive data for the participants in the study is summarized in Table 1. All faculty were assigned gender-neutral pseudonyms and are referred to in the singular third-person as is consistent with APA 7, section 4.18. (APA, 2020) in order to further protect confidentiality of data. 
Table 1

\section{Faculty Participants}

\begin{tabular}{|c|c|c|c|}
\hline Pseudonym & Discipline(s) & $\begin{array}{c}\text { Number of COIL } \\
\text { Courses Taught }\end{array}$ & $\begin{array}{c}\text { Number of Years } \\
\text { Teaching }\end{array}$ \\
\hline Chris & $\begin{array}{c}\text { STEM/Educational } \\
\text { Technology } \\
\text { Management }\end{array}$ & 3 & 20 \\
\hline Cameron & Communication & 1 & 10 \\
\hline Reed & $\begin{array}{l}\text { Social Work/Conflict } \\
\text { Resolution }\end{array}$ & 17 & 15 \\
\hline Tracy & Economics & 1 & 30 \\
\hline Dale & $\begin{array}{c}\text { Economics/Gender } \\
\text { Studies }\end{array}$ & 2 & 30 \\
\hline Ariel & Sociology/History & 3 & 20 \\
\hline Chiaki & Fine Arts & 1 & 10 \\
\hline Kelly & Biology & 2 & 18 \\
\hline Lee & Health Professions & 3 & 14 \\
\hline Terry & $\begin{array}{c}\text { Education/Gender } \\
\text { Studies }\end{array}$ & 1 & 8 \\
\hline Kirby & Communications & 1 & 19 \\
\hline Remy & English & 1 & 15 \\
\hline Stevie & $\begin{array}{c}\text { Foreign Languages \& } \\
\text { Literatures }\end{array}$ & 6 & 15 \\
\hline Kim & Comparative Cultures & 3 & 25 \\
\hline Robin & Anthropology & 7 & 10 \\
\hline Dana & $\begin{array}{c}\text { English Language \& } \\
\text { American Studies }\end{array}$ & 14 & 30 \\
\hline
\end{tabular}


In addition, faculty are referred to as participants to underscore their willing cooperation (Merriam, 1998), as is common practice in qualitative studies (Merriam, 1998).

Sixteen faculty were fitting for this qualitative study because as Morse \& Field (1995) have expressed, appropriateness and adequacy are the most important considerations in a qualitative sampling. The sample size was both appropriate to the nature of a qualitative study and adequate to find recurring themes and patterns (Merriam $\&$ Tisdell, 2016, p. 25). The sample size was premised on the value of the information density (Guetterman, 2015), because "sampling is not a matter of representative opinions, but a matter of information richness (Guetterman, 2015, p. 5). Faculty were representative of disciplines in Arts \& Sciences, Public Health and Business.

Purposeful sampling (Patton, 1990) allowed me to identify and select individual faculty who were knowledgeable and experienced (Cresswell \& Plano Clark, 2011) in teaching a COIL course. This was suitable for my study because purposeful sampling provides “information-rich cases for study in depth" (Patton, 1990, p. 169). In addition, predetermined criterion sampling (Patton, 1990), was used to study cases meeting a predetermined criteria key in the study design. In this study, the predetermined criteria was faculty who had employed virtual global teams in their courses, one of several virtual exchange modalities available to them in COIL. Faculty experience and willingness to participate were both important to the quality of the study. Palinkas et al. (2015) affirm that this type of purposeful sampling makes it possible to identify participants who are available and willing to participate in the study as well as having "the ability to communicate experiences and opinions in an articulate, expressive, and reflective 
manner" (Palinkas et al., 2015, p. 2). The sample of sixteen came from five different institutions, four institutions in the United States and one in Europe. All institutions served non-traditional students and were self-identified as open-access.

Faculty were initially identified by and contacted through institutional gatekeepers as a best practice (Seidman, 2013, p. 49). On the urban campuses, a COIL faculty trainer introduced me to the COIL administrators to discuss the project and review their respective IRB procedures. Once the study was approved by their institutions and PSU, I followed up the introduction to each COIL administrator with a request for an introduction to their COIL faculty cohorts. Once they had emailed their faculty about the study, I emailed each of the 56 faculty individually to introduce myself, explain my dissertation proposal, and request their participation in my study. I requested a 90-minute interview in the faculty member's office or their preferred campus location during Fall Term 2019. Those interviews were then followed up by an email 14 to 21 days later to solicit additional reflection and comments on the original questions. For faculty found through the International Virtual Exchange Conference, a request for participants was posted on a discussion thread through Whova, the conference smartphone app. Of the ten faculty that initially responded, three agreed to be interviewed after the conference with the same interview and follow up protocol.

\section{Data Collection Process}

Data was collected from October through December 2019 through semistructured interviews. Nine of the interviews were conducted face-to-face in faculty offices on their campuses, and seven were conducted through Zoom. The interviews done 
through Zoom were at the request of the participants for scheduling convenience or to accommodate physical distance. All participants were offered a \$30 Starbucks gift card for participating in the study. Three declined the gift card citing their ethics around collegiality.

The qualitative interview supported the research aims of developing detailed descriptions, describing process, developing holistic description, and bridging intersubjectivities (Weiss, 1994). When the purpose of the research is to understand the experience and meaning made out of it, then interviewing is a strong avenue of inquiry (Seidman, 2013). As Seidman (2013) asserts, “...the root of in-depth interviewing is an interest in understanding the lived experience of other people and the meaning they make of that experience" (p. 9).

Therefore, individual semi-structured interviews were done with faculty as the most appropriate method of data collection. Described as conversations with a purpose (Teijlingen, 2014), semi-structured interviews were a powerful way to gain insight into educational and other important social issues through understanding the experience of the individuals whose lives reflect those issues (Rabionet, 2011). To facilitate this understanding of faculty experience, the interview protocol was designed to foster collegial rapport, allow for participant pause and reflection, and actively listen to participant responses. Creating a space for dialogue and reflection for the participants in the semi-structured interview was particularly helpful in for exploring "the views of a person towards something” (Teijlingen, 2014, p. 20), and supportive of participants' ability to make meaning through language (Seidman, 2013). Semi-structured interviews 
were also effective for data collection because they are "well suited for exploring attitudes, values, beliefs, and motives" and that this format "facilitates getting every question answered" (Teijlingen, 2014, p. 21).

\section{Interview Protocol}

At the start of each interview, I introduced myself and made pre-interview comments to establish mutual collegiality, prime the participant for dialogue and reflection, and prepare for focused attention and active listening (see interview protocol script in Appendix A). I confirmed the participant's informed consent to be interviewed, and for their permission to record the interview for later transcription and analysis. I also confirmed that their informed consent form was signed and returned to me.

Most faculty were available for 60 minutes, though a few were able to talk for the full 90 minutes I requested. I reiterated my respect for their time by setting a timer on my phone that they could also check, if we were interviewing in person, to ensure that we would conclude in time for their next class or appointment. I delivered each question directly and paused to allow them to reflect before responding. My intention was to make the interview feel very spacious to the faculty participants in spite of the time constraints we were under. I facilitated a deep engagement with them through the observation of their non-verbal behavior and my relaxed forward posture and direct eye contact. At a natural pause, I followed up to the participant's response with questions probing for clarification, purpose, relevance, extension and evaluation (Teijlingen, 2014). At the 50minute mark, I transitioned into concluding the interview and delivering post-interview comments. This included a reminder that I would be contacting them after two weeks 
requesting any additional observations and asking clarifying questions based on the interview transcript or researcher notes. I confirmed their preferred email address and thanked them again for their time.

After each interview I made researcher notes for observations and insights in a dedicated notebook. I also developed follow-up clarifying questions to be included in the follow up email. The follow up email allowed me to request further clarification on their commentary after it was initially transcribed (Seidman, 2013). Depending on the arrangement made with the faculty member at the time of the interview, I emailed them 14 to 21 days afterwards to solicit additional comments and insights. All of the faculty responded, most reporting that they had no additional comments and answering a common clarifying question about how many courses they had COILed in total at their institution as well as how many years they had been teaching.

\section{Interview Questions}

I asked nine questions in a semi-structured protocol (see Appendix A) because semi-structured interviews have the most capacity evoke the fullest of responses from the participant (Qu \& Dumay, 2011). Semi-structured interviews are also best in exploring views on a focused topic with key stakeholders to gain larger background information and institutional perspective (Hammarberg, Kirkman \& de Lacey, 2016). The nine questions were exploratory and open-ended because such questions were most appropriate to an ongoing, inductive process looking for emerging themes, patterns and questions (Cresswell \& Cresswell, 2017). They were also constructed to elicit descriptions of thoughts and experiences from an emic perspective. In this context, 
thoughts were defined as "an expression of what is in the mind; an idea, notion" (OED, 2019) while experience was defined as "the actual observation of facts or events, considered as a source of knowledge," and "an event by which one is affected" (OED, 2019).

The nine questions started out with broad themes and then narrowed to more specific topics. Each interview was prefaced with a question about the faculty's length of time and positionality at their institution, their academic discipline and training, and their previous international experience. The initial questions asked faculty about their general experience of teaching a COIL course and the attending challenges and rewards. The next questions asked how teaching COIL affected their pedagogy, including their experience of using global virtual teams as a teaching and learning tool. The final questions asked faculty about how they perceived their roles as faculty members and what motivated them to continue teaching COIL courses in the larger context of Internationalization at Home. For the full list of interview questions, please see Appendix A.

A follow-up email was sent to each participant 14-21 days after the interview. The email solicited additional reflections, observations or commentary after giving them time to reflect on and digest the interview. The email also contained $2-3$ clarifying questions developed from my post-interview researcher notes and first read through of the transcripts. This type of dialogic communication is supported by qualitative researchers who say it highly collaborative (Harvey \& Kitson, 2016). It is also a way for a researcher to attend to intentions behind the spoken word (Sennett, 2003). The 
faculty's email responses were analyzed and coded in addition to the interview transcripts (Seidman, 2013).

\section{Coding and Analysis}

I used a Sony ICD-PX312 digital flash voice recorder to record all of the interviews. These audio files were transferred and saved on the hard drive on my laptop as the primary data location. In addition, I used otter.ai, a smartphone app, to record the interviews on my iPhone. This allowed me to have the interviews initially transcribed into a text document that could be accessed from cloud storage for later cleaning and coding. I transcribed each interview by listening to the primary audio file against the transcript generated by otter.ai. I did this to ensure transcript accuracy. The transcripts were converted into Word files for coding.

Once the interview transcript was cleaned up and accurately transcribed, I downloaded both the audio file and the Word document into Dedoose for coding. Dedoose is a web-based subscription software program designed for mixed methods research (Dedoose, 2018). Dedoose was appropriate for my study because it supported both audio and text analysis. Each interview generated 50-90 minutes of audio and 3040 pages of text to code. I coded the interview text and also cross referenced the coded sections with audio in Dedoose as needed.

Merriam and Tisdell (2016) state that the rigor in qualitative research comes from the researcher being a sound instrument herself, triangulating the data and employing “thick, rich" description in writing (Merriam \& Tisdell, 2016, pp. 191-192). As Patton (1990) asserts, purposeful sampling data collection includes two kinds of data, "high- 
quality, detailed descriptions of each case, which are useful for documenting uniqueness, and...important shared patterns that cut across cases and derive their significance from having emerged out of heterogeneity" (Patton, 1990, p. 172). Therefore, I approached coding and analysis through myself as primary research instrument (Guba \& Lincoln, 1981), as seen in the choice of purposeful sampling (Patton, 1990), the reduction consolidation of the data (Wolcott, 1994), and the employment of Thematic Analysis (Braun \& Clarke, 2006). The intention of my data analysis was to find recurring themes and patterns (Merriam \& Tisdell, 2016) and interpret them through the lens of Internationalization at Home.

My first step in analyzing the data was to review the purpose of my study as a touchstone before re-reading the transcripts and applying codes (Merriam \& Tisdell, 2016). I made printed copies of the transcripts to read through, but used their electronic versions to code them in Dedoose. I complemented this digital approach with an analog research diary where I wrote my reflections as I read and coded the interview transcripts in Dedoose.

I employed Braun and Clarke's (2006) Thematic Analysis phases to analyze the interview transcripts, the post interview emails from participants, and my researcher memo notes. Thematic Analysis (TA) is a useful coding tool in a general qualitative study because a theme "captures something important about the data in relation to the research question and represents some level of patterned response or meaning within the data set" (Braun \& Clarke, 2006, p. 82). TA is an inductive approach (Patton, 1990) to identify themes in the data that are strongly tied to the data themselves. Inductive 
analysis (Patton, 1990) of data for predominant and important themes is a "particularly useful method when you are investigating an under-researched area, or you are working with participants whose views on the topic are not known" (Braun \& Clarke, 2006, p. 83). The intention of my data analysis was to find recurring themes and patterns (Merriam \& Tisdell, 2016).

In the first TA phase, I familiarized myself with the data by listening to the audio of the interviews and transcribing the initial interview transcripts. Then, once cleaned, I re-read the interview transcripts along with my contemporaneous researcher memo notes. In the second phase, I generated codes through open coding. I followed up with a priori coding from the literature, including the AAC\&U Global Learning Values (AAC\&U, 2014) rubric and the literature on Internationalization at Home (see Appendix C for a list of codes). I collated the codes into potential themes in Dedoose and then checked them against the literature. I clearly defined and named each theme by reading excerpts from all of the interviews by thematic cluster. I balanced this by re-reading the hard copies of the sixteen transcripts individually and writing marginalia to help guide my understanding of the themes as they emerged. In the final phase, I related the emergent themes that emerged back to my research questions and the literature.

As a first-time researcher, I was mindful that my data analysis required me to keep scrupulous records, to approach the work holistically and as an iterative process, and to be very conscious of myself as a research instrument. I focused on cultivating intellectual virtues (Baehr, 2013; Ritchhart, Church \& Morrison, 2011) as part of the researcher experience to improve process, especially in the areas of curiosity, humility, 
attentiveness, thoroughness, courage and tenacity. I approached the data analysis as an “intellectual craftsman” (Mills, 1959) where the researcher keeps a "personal file” (pp. 196-197) for systematic reflection. I followed Merriam \& Tisdell’s (2016) recommendation that the researcher "think about your biases... What might you be projecting onto the data based on your own beliefs and life experiences? How does your 'positionality' or 'social location' affect you see? How are you guarding against your biases?" (Merriam \& Tisdell, p. 208). This was particularly important to me because of my professional and international learning experience background.

\section{Researcher Positionality}

My lived experience of diversity and multiculturalism has always been in an international context, just as my international experience has been framed by intersecting identities of race, class, gender, religion and citizenship. In my professional life, I direct international partnerships and initiatives at an under-resourced open-access university, where the global learning needs of local students are assumed to be met through increasing the numbers of international students in the classroom or in increasing participation in Education Abroad. In my personal life, I am the wife of a naturalized citizen from Congo-Kinshasa, who works in the skilled trades, whose members tend to lean more provincial and populist. I am the mother of four bi-racial children who selfidentify as African-American in a suburban community where they represent $2 \%$ of the population. I was an international graduate student in the U.K. and I have spent the bulk of my career working with universities in East Asia. 
I have worked professionally in the field of international higher education for 28 years. The breadth and depth of my experience makes me ever mindful of how internationalization at the institutional level can and should benefit local students. I am committed to internationalization as a tool of educational equity in higher education. I want to help guide institutional implementation of internationalization so that it leads to more successful and equitable outcomes for all students. Therefore, I am invested in the success of virtual exchange, including COIL, as an Internationalization at Home strategy.

I was responsible for launching a COIL program on my campus while conducting this study, therefore I was very careful to look to theory around internationalization of higher education for grounding and orientation. The main topics in my literature review provided the "inferential glue" (Miles, Huberman \& Saldaña, 2014) needed to let exploratory patterns emerge from the faculty interviews. Therefore, the trustworthiness of my findings have been established through triangulation of methods, checking for alternative explanations to the phenomena and patterns found, and comparing findings against existing theory about internationalization of higher education and Internationalization at Home.

\section{Validity and Transferability}

In order to maintain validity and good transferability, I used a researcher checklist (Maxwell, 2013; Merriam and Tisdell, 2016) that emphasized a highly descriptive analysis. I employed reflexive listening (Maxwell, 2013) during the faculty interviews and when replaying their audio files as a tool to counteract researcher bias. I asked for clarification of points in the follow up email to participants to ensure that their words and 
thoughts were accurately represented. I employed a dialogic approach (Harvey, 2015) to clarify and to maintain the integrity of the data. The dialogue between myself and the participant as well as the active reading of the transcripts and follow up emails helped triangulate the experience of faculty within the data. I relied on the literature to demonstrate validity (Whittemore, Chase \& Mandle, 2001). Proper audit and documentation will allow others to replicate my study (Leung, 2015). These process methods will ensure validity and transferability for future research.

\section{Limitations of the Method}

Qualitative research is ideal for extending the scope of educational research, but its quality is heavily dependent on the skills of the researcher (Anderson, 2010). In addition, weaknesses in semi-structured interviews in a qualitative study may include confusion over equivalencies of meaning, preferred social response, unique characteristics of the participant, and participant perceptions of the researcher (Teijlingen, 2014). However, semi-structured interviews are very suitable for exploring attitudes, values, beliefs and motives (Teijlingen, 2014). As Weiss (1994) states, "Qualitative interview studies have provided descriptions of phenomena that could have been learned about in no other way" (p. 12). Therefore, I exploited the benefits of the qualitative approach in my study while actively counteracting any bias. The low number of study participants is another limitation, but this is countervailed by the study's focus on eliciting rich narrative and observational data. The participants fulfilled the requirement of sample appropriateness (Robson \& McCartan, 2016) by being "good informants who have experienced the phenomenon and who know the necessary information" (p. 168). 
Sixteen participants helped me reach saturation (Mason, 2010), which is a key factor in selecting a sample size. Two study locations were another limitation of the study. However, the two sites were early adopters of COIL pedagogy and had mature COIL programs. The addition of the International Virtual Exchange Conference as a supplementary site, helped address this limitation. All sites were purposely selected (Maxwell, 2013) to find participants with adequate experience of the phenomenon given the purpose of the study (Patton, 2014).

\section{Summary}

A basic qualitative study using semi-structured interviews as outlined above addressed my research questions. A qualitative analysis was best because "qualitative description is especially amenable to obtaining straight and largely unadorned...answers to questions of special relevance to practitioners and policy makers" (Sandelowski, 2000, p. 337). Semi-structured interviews are well suited to understanding faculty experience (Teijlingen, 2014) in COIL, and supported my choice of a qualitative study. The study sample were sixteen faculty: Thirteen from two urban campuses of a Pacific Northwest university and three from open-access institutions in the United States and Europe. All had taught at least one COIL course. Data was collected through semi-structured, openended questions in a 60-90 minute interview in the faculty office or their preferred campus location. The interviews were conducted over several consecutive days in October, November and December 2019. They were individually followed up 14 days later by an email. Data analysis was done through transcription and coding in Dedoose software. My positionality as administrator was counterpointed by reliance on the 
literature. The validity of the analysis was triangulated through various methods including a validity memo as part of the researcher notebook. 
Chapter Four: Presentation of the Data

This basic qualitative study was designed to better understand the faculty experience of planning and teaching a COIL course. The main research question asked about the faculty experience of COIL. The four sub-questions explore why faculty participated in COIL, what faculty saw as significant in their experience of COIL, how faculty experienced COIL through the lens of Internationalization at Home, and what was faculty experience of using global virtual teams in COIL. Four overarching themes came out of the study. First, faculty experienced professional growth by teaching COIL. They also believed that COIL provided global learning for all students. In addition, they felt that COIL provided equity of access to international learning for students in higher education. Lastly, they thought about the future impact of COIL on faculty, students and institutions. Themes that emerged from the analysis provide a direct reflection of the participant's experience as well as that participant's understanding of their experience in an institutional context and help to answer the research questions.

\section{Faculty Professional Growth}

All sixteen faculty interviewed for this study were attracted to COIL as a professional development opportunity. The cohort-based training and institutional support promised longer-term benefits to them in several areas of practice and scholarship. Participation in a faculty fellows program increased their visibility to their peers and helped them more actively support strategic university goals. They were able to create campus-based and international communities of practice around COIL. COILing 
allowed them to work with their peers to improve their teaching skills, further internationalize their curricula, create more engaging class content and design improved course outcomes. They saw the COIL fellows programs as supporting them from wherever they started in doing this work. They saw themselves as advancing in their skills and knowledge with every subsequent course they COILed. Finally, COIL gave them the opportunity to grow a larger international network in their field or discipline for publishing and research.

\section{Faculty Fellows Programs}

Fourteen of the sixteen faculty interviewed had participated in a COIL Fellows Program sponsored by their university's International Office. All reported this training as foundational to their decision to COIL and to continue COILing. Most had learned of the Fellows Program through a colleague who had previously participated, or through outreach by their university's International Office. To participate, all had to submit an application which included a proposal for an existing course that they wanted to COIL. The cohort-based programs lasted from one to three terms and consisted of workshops and hands-on practice with Web 2.0 tools. The programs usually involved ongoing pedagogical and technical support through university units coordinated by a main office, usually the Office of International Affairs. A few faculty had also participated in country-specific intensive trainings where they designed their course with their partner on retreat. Those opportunities were inter-institutional and funded by external grants like the Stevens Initiative or 100,000 Strong in the Americas. 
The outreach done by the international office along with the COIL workshop structure was what faculty reported as having greatest impact on their participation. Some faculty had simply been waiting for the opportunity to COIL. Kelly reported, I was invited to one of the COIL workshop promotions and it was just like immediately, "this makes total sense to me"...I have always been interested in international education... and I was looking for an opportunity to collaborate internationally and bring that into the classroom...having a structure at the university would make that possible.

Other faculty were excited to learn about COIL's existence. When Chris heard of the training attached to COIL, they said, “'Wow, this is a great opportunity.' I'd always wanted to study abroad when I was a student but...I didn't really have that opportunity because of my major." For still yet others, it wasn't on their radar at all. Kirby confided that they would not have even tried to COIL without leadership encouraging participation in the COIL fellows program:

Without the COIL Fellows Program here, I wouldn't have done this. I would not have thought about doing it. It would not have crossed my mind... because I already take students [abroad]...But when it became an opportunity, I was like, "Oh! That's sort of interesting."

The timing around the promotion of COIL on campus also factored into faculty participation. For example, Stevie had been trying to figure out how to provide more opportunities for peer-to-peer interaction in their online course: "And so I was thinking about how we could have some more real-life situations for students to be able to use their language, and that's when... an ad came around about joining the COIL Fellows at our university."

The cohort-model of delivering COIL training and support was another selling point for faculty. For example, Kim said that they wanted to join the fellows program 
because "it was a cohort based model, and we kind of workshop our own courses and I would get ideas of from really smart, caring colleagues. That was super attractive." Lee appreciated the thoroughness and breadth of the COIL fellows program:

[It] gave me the formal structure, and the know-how-all of the nuts and bolts with some guided mentorship; and doing it in a cohort of colleagues, where we could bounce ideas off each other...to work through some of the challenges and hoops, administratively and pedagogically...it allowed me the space and extended me the guidance to really shape my COIL class.

Therefore, faculty were initially attracted to COIL because their colleagues were doing it and the training was well organized and well executed.

Faculty were attracted to COIL because they could either launch or join an informal faculty learning community around COIL with peers across their institution. This was based on both being part of a cohort but also having shared experience with faculty that may have trained elsewhere or earlier. Stevie said that while having broad institutional support was critical to being able to COIL, it was developing a community of practice around shared challenges around COILing that was critical to them in choosing to COIL. There was so much to learn up front that they advised colleagues to "definitely seek out support from other faculty members who have done it, to not reinvent the wheel. I was amazed at how many resources there are out there." For some faculty, the attraction of the faculty learning community was creating deeper relationships with faculty in the U.S. and abroad around global reciprocity in teaching and learning. Therefore, the partnership was not about COIL pedagogy per se, but about why they were COILing in first place. Ariel described the fellowship as thus: "I would have a hard time engaging without this closer connection...this global reciprocity network is meeting 
monthly on Zoom. India, Ghana, West Coast City, Mexico City, and Tanzania. And that's fantastic, right...we're committed to each other." For other faculty it was about reconceptualizing what a learning community was or could be. As Lee shared,

The COIL experience has given me opportunities to actually interact with other kinds of learning communities, and not necessarily international, per se...the structure of the technology, the remote interactions, and how successful or productive you can be to accomplish goals by just connecting people from different parts of the state, different parts of the country and obviously different parts of the world.

Some faculty liked how they could become leaders within their learning communities around COIL. For Chris, this was important to expanding COIL on their campus. They said,

You have new people always coming in who want to COIL...the training completion doesn't mean that support should stop...we've been building mentorships on and off campus so I can mentor for those on my campus or for any campus in our region.

Faculty learning communities augmented COIL training by giving ongoing support. Faculty were cognizant that they would have ongoing need for community and support around COIL with each course iteration. In addition some faculty saw the faculty learning community as a way to promote COIL more closely around shared faculty values.

Faculty were also motivated to join COIL because their university leadership stated it as a priority. Having the opportunity to be visible to leadership was important to faculty for several reasons. First, it mattered for promotion and tenure. Kim shared, "I had an eye on eventual promotion to principal lecturer... so being able to show evidence that I'm constantly trying to improve my pedagogy... was another motivator for me [to 
COIL]." Secondly, it signaled that the time they invested in learning how to COIL would be valued and recognized by their department chairs, deans and provosts. The course release and/or research stipend attached to the fellows program was a promise that their time invested in COIL was also respected by the institution. As Kim explained, the stipend meant more to them than just money for books, materials or travel: "It's not just that I could use that [the stipend] for travel, which was a very attractive thing, but it also signaled that the whole campus valued COIL." Similarly, Kirby, who had served as associate dean, encouraged colleagues to participate as a way to get institutional recognition. Kirby advised,

It gives [them] an opportunity that I think they wouldn't maybe think about doing, but also the added incentive, being able to put it on their CV. That they're a COIL fellow. So that people aren't going, "Why are you spending all your time doing that?"...I think in that sense, it's a really good opportunity.

Thirdly, the COIL fellows program was a way for faculty to get retroactive recognition for something they'd already been doing informally. This was Kelly's experience. They said that when they got the announcement they immediately thought:

Wow, this is what I've been wanting to do... and... without any formal training or...bigger structure, I've been doing it. I should jump into this because [of] having the support — and that's what I want to emphasize greatly, having that institutional support. Because I have a lot of enthusiasm and...ideas...but having a solid institutional support to be able to do this is so key.

Lastly, for some faculty it meant that their work mattered at their institutions. This was particularly true for non-tenured faculty who were on short-term contracts. For them, being allowed to join the fellows program meant that their institution saw them as faculty worth investing in. It also meant that they were encouraged to take risks to improve student learning. As Chiaki reported, 
So when that unexpected [outcome in COIL] is partnered with [institutions saying] 'I'm going to support you financially, because you're taking a risk,' ... actually that's it. Just supporting risks, financially. Even though there are risks, they're the challenges that make faculty grow.

Faculty saw COIL has having synergy with their university's mission statements on engagement and internationalization. Therefore, faculty saw COIL as another way to do university service on their terms. Stevie found a connection between COIL and their community engagement work. They felt encouraged to continue teaching COIL, "because I'm really involved with some of the community organizations [locally] and I work with the immigrant refugee population, so I see it all tying in together." When Stevie went to a campus presentation promoting COIL to faculty, their initial thought was “Oh my goodness, there's so many great things we can do with this that would not require a lot of financial investment on the part of the university and... we would have a lot of freedom to develop things in a way that made sense." Tracy saw COIL as highlighting institutional commitment to diversity and noted, "Where there's a real connection, build [on] it and make use of it. There's a lot of exciting places where globalization [can be] a significant part of what you do." Lee also felt that the institutional support made it possible for them to COIL their health sciences course in a department that was not traditionally internationally focused in spite of training a global population of students. Institutional support was important to faculty because it sanctioned COIL and made it easier to get buy-in from other campus stakeholders. Ariel remembered that when they had COILed informally before, they'd experienced push back from campus administration. 
The idea that I would teach a class would be half U.S. students and half students from Africa was a problem because it meant we were subsidizing the education of students for Africa ...that was somehow like a deeply, deeply problematic thing that I was doing... I'm like, "Think about what your students are benefiting from this experience and you're saying that's a problem?!"

Faculty agreed that they benefited from COIL and that their students benefited from COIL because of its institutional support. The faculty fellowship program was instrumental to their participation.

\section{Pedagogy and Course Outcomes}

The majority of participants entered into COIL with the expectation that it would benefit their teaching ability and achieve better course outcomes for their students. Most faculty articulated a personal and professional commitment to continuously improving their teaching practice. In that spirit, they were intrigued by the juxtaposition of collaborative, online and international, with learning. They felt that they acquired skills that made them better overall teachers. As Reed observed, "I just became so much better at developing curriculum and being a better teacher by doing COIL courses because it forces you to be in the ideal role of a faculty member, which that you have to facilitate learning." Faculty entered into COILing with the belief that regardless of how well the course "went," they would have strengthened their praxis. As Cameron confided,

COIL fits in with that [professional growth] because it's a way to improve your pedagogy, to challenge yourself as a teacher, which I appreciate. I think that the moment my teaching has arrived, and I no longer want to learn new things like COIL, is when I should retire.

Faculty believed that the experience of COILing would help improve their teaching skills in general. For example, Reed thought COIL gave them skills they could apply to any course they taught: 
So you learn techniques and tools on how to do...practices and simulations...you become a better teacher whether you do an international collaboration or not, all of this stuff is applicable...the cross-cultural work and the team work and the group work...I've really enjoyed learning how to communicate better.

Still other faculty saw it as just generally honing their teaching skills by pushing them out of their comfort zones. Kim shared, 'I've been teaching a long time and it was an opportunity to try something new that I thought was a high engagement kind of pedagogical practice, a high-impact practice." Faculty saw COIL as benefiting their teaching while simultaneously offering challenges to improve their practice.

\section{Benefits of COIL}

Most faculty had been teaching for over a decade and saw as COIL benefiting their pedagogy and curriculum in several ways. For many, it was a way to reinvigorate their approach to a course that they taught regularly over a period of years. They also reported that COIL renewed their motivation to teach. Sometimes this was due to faculty feeling that COIL introduced an element of the unknown into a course that had become well-rehearsed. Accommodating the unexpected required them to revisit course design and pedagogy, which in turn increased student engagement in the course. Faculty felt a strong sense of satisfaction and agency after doing COIL which included having more confidence in using digital tools in class.

Many faculty had taught the same courses for many years and wanted to find a new approach to content delivery. As Chris stated, "You get to a certain point in your career when you've gone through ten years of teaching the same course...I've tweaked it enough, so now do I sit back or keep pushing myself?” For others it was not appearing to be coasting along or languishing professionally. Kim summed up this sentiment: 
I think that I have another ten years or so [before retirement] - I don't want to just keep doing the same thing for another ten years. There are no more promotions for me. So it's clear to me now that at some of the motivation [to COIL] is not wanting to be seen as resting on my laurels.

Some faculty taught courses in tightly regulated programs and were not able to deviate in course content, even content related to their research interests. Therefore, for them, the reinvigoration came from being able to connect their research interests to their assigned course load. Lee, who taught in a professional school, reported:

I would say again that it gave me another way to think about delivering education. And to be to slot my teaching responsibilities into subject matter that I could leverage COIL to do... My research interest is labor migration and health consequences, and as a case study looking at health workers, COIL allowed me to pull that interest from the research space into my teaching space.

Reinvigoration of teaching through bringing their research interests to COIL was voiced by other faculty too. It was another avenue to connect with their research. For Dana in particular, it was their only way to connect. As Dana confided,

To be honest with you, my research doing archaeology came to a standstill because I had a child, so I knew that I couldn't travel abroad. I mean that's the reality of it, I couldn't travel to do my fieldwork the way that I wanted to. So I figured, what am I going to do locally, that's going to keep me intellectually engaged, so what I did...was embrace this [COIL] as a new way to think about [doing] research.

Some faculty reported that they liked "working with the unexpected" and wanted to improve their teaching by adopting the relatively unexplored pedagogy of COIL. Reed conceptualized COIL as an inventive space:

In terms of feel, in terms of process, I feel like I become even more creative in this environment which I really like. It's a bigger, broader palette of what's possible. So that opens up new channels of creativity... and new channels of uncertainty, which I both like and find challenging. 
Chiaki also spoke to creativity and COIL. Chiaki was an artist and had many projects they wanted to bring to the classroom but hadn't found the right support. With COIL, they saw a new opportunity:

I had an image of [a project] I wanted to do. And I needed a partner to do this kind of "interdisciplinary dancing." I'm a fan of trying new things. I'm not afraid of changing patterns. I just go forward, create, or discover a new way of being. So with COIL, I thought, "This is my chance...to make my teaching a work of art and for students to see that getting an education can be a work of art."

Therefore, COIL offered faculty an avenue of pedagogical and disciplinary innovation that they felt they needed. For some it was to stay excited about teaching by seeing themselves as learners and explorers. For others it was a way to combine research and teaching interests. Still for others, it was a way to stay connected to their disciplines.

Faculty believed that COIL helped them improve their course design and implementation. All faculty shared a sense of pressure to customize course content and make their classes more relevant to their students' lives. In addition, faculty felt more accountable to working students in explaining why assignments were given and for what purpose. This dovetailed with the perception that students needed even more flexibility in course delivery. Faculty who did not teach hybrid or online yet anticipated that they would be in the near future, and those who had already started teaching online assumed that they would be doing even more. This put a kind of pressure on faculty to get up to speed on teaching in this space. COIL provided a way to gain skills they would later be able to transfer. Lee found COIL helpful for this reason:

They had a program to help faculty members learn about COIL and develop and execute COIL projects...I was looking for ways to broaden my teaching repertoire, and I thought, "This might be interesting, it's international"...also, 
there was a big movement to go to online spaces for higher ed, so I thought, "Okay, this might be a nice opportunity for me to pursue."

Other faculty liked being challenged to apply their skills in new combinations. As Chris shared,

I love challenging myself and my students. There are so many things you can learn out there... so many methodologies, so many opportunities. So how do we get that all wrapped into one?... How do I as an educator challenge myself so that I can bring all these different competencies that are not just my discipline, but the team building, the learning how to communicate, the learning how to deal with diverse students, the dealing with different time zones, the dealing with the fact that someone may not get back to you right away...?

After teaching COIL, most faculty felt that they approached designing and teaching all of their courses more mindfully. COIL forced them to be much more intentional in how they articulated course goals and how they implemented assignments. As Kelly shared,

Actually, it's been very beneficial in terms of structuring my courses. One of the things that COIL helped me with was to go through a process, step by step, of creating a syllabus... and considering a lot of factors that sometimes, when you're just focusing on one population of students, doesn't allow you to think too much about what other things you have to consider.

Lee said that they had actually become better designing courses that could meet the different type of learners within their U.S.-based courses. In particular they described how they came to more deeply understand how their students learn differently:

I do recognize that we have a different spectrum of people born in the U.S.- - but this assumption that, "Oh well, if you're educated in the U.S., y'all learn the same kind of way," so that [COIL] helped me to be mindful that students as individuals have quite different learning styles and are receptive to different learning opportunities and assignments...so it's caused me to diversify the kinds of teaching strategies I use rather than just rely on, “Oh, I'll just lecture at you."

Dale believed that doing COIL helped them personalize their course design and goals.

They felt this was particularly important for faculty who approached learning goals the same way for all of their courses. Dale observed, 
I have become much more reflective about the particular things I would like to gain from particular courses. I used to be able to write pedagogic statements that said, "my aim in the classroom is x." COIL has made me understand that I do not have an aim in the classroom. I have an aim in this classroom, with this group of students, at this level, for this purpose. And that, I think, is useful.

Ultimately, faculty saw the course design challenge in COIL as a way to deepen their overall capacity to be adaptable. Cameron believed that their teaching resiliency was actually strengthened by doing COIL. They said,

If you do this as a teacher it shows that you are creative and that you're organized. And actually that you are culturally humble as you can be... We all have challenges, but it sort of show that you're willing to learn, be vulnerable, and be open to new processes.

Faculty saw themselves as having increased capacity to engage their students with course content when COILing. This increased capacity meant that they were improving the learning outcomes for their classes. Sometimes this increased engagement meant allowing students to redirect course content. Kim confided that in a comparative U.S.Korean Popular Culture course they taught, they and their Korean COIL partner soon learned that neither group of students were interested in U.S. popular culture, which was Kim's area of expertise. Therefore, they shifted the course accordingly. Kim reported, "I was totally happy. They were talking about things that were not related to the course and they were learning — that was the biggest surprise - things that were not tied to my learning goals, because I hadn't thought of them." Other times engagement came through the repurposing of social media for class. As Remy observed,

Along the way my students could definitely connect with each other...they didn't have to be international connections. They could be connecting through social media in my own classes. So it helped me realize that we can do COIL right in my own class, between my two sections, or between the other connections that my students have...bringing their outside lives into the classroom. 
Kim spoke to repurposing social media as not just enlivening the class experience but showing students that digital tools were powerful learning tools that they weren't taking full advantage of. They observed,

Yeah, you think about the young people having all this technology at their disposal, they could talk to people anywhere in the world if they wanted to, in a way that I couldn't when I was their age...to someone in China or Japan or Africa, and these students could, but they don't.

Faculty saw COIL as helping them better engage students in their required courses. Sometimes the students were very close to graduation and saw a specific course as burdensome or superfluous to their degree. Stevie reported that using COIL in their required courses "made it more interesting, more engaging and less onerous to these students." Stevie's small follow up study on their students' satisfaction with COIL confirmed their belief that it engaged them more deeply with course material:

What they felt they got from the experience that they couldn't have gotten in a traditional class that hadn't been COILed. And generally speaking, we got overwhelmingly positive feedback, and even when we asked the question, "Should we do this again in the future?" Overwhelmingly, the answer was, "Yes."

This was echoed by Kelly who said, "At the very end, we had really great responses from the first year students who'd initially asked, 'why are we doing this?"' Kirby believed that they could help motivate their students to turn in higher quality assignments through COIL. They explained, "I think that my students took their part of the project more seriously because they didn't want to be embarrassed internationally. I believe that's true, in fact I know that's true, because a couple of them talked about it." This observation was shared by other faculty who thought that having an international audience for assignments fostered more curiosity in their students about how their classmates were 
approaching the materials and motivated their students to perform better, which resulted in stronger learning outcomes.

Increased student engagement was not the only positive outcome for faculty; many felt increased professional satisfaction and stronger self-agency through COIL. This satisfaction and confidence in their skills came from the experience of teaching COIL. Reasons could range from seeing their students engaged in active learning, exploring the applied side of their discipline, or gaining proficiency in using digital media. For many it was also self-affirming. Kelly shared,

It gave me a lot of confidence as being an educator from somewhere else [outside of U.S.]...being able to communicate with a third culture and having confidence in my ideas... by doing COIL I have benefited not only from interactions with other faculty but from the whole experience...making me feel much more confident about my skills.

Kim described experiencing a general elation when teaching COIL:

Every time we would have one of those video conferences, I felt like this was one of the best teaching days I'd ever had. Wow. I just loved watching them, watching from group to group...on their computers through Zoom. Laughing and saying, "This is my favorite anime character," and I don't know, it was just lovely and exciting, how much they were learning.

Cameron described their growing confidence in teaching across their discipline: "I'm more comfortable with making global connections and bringing them back into my classes. It's relevant for my classes because I teach ecology, inequality in pop culture, and gender...in the media." Ariel felt that despite being a media scholar, learning how to use tech tools in COIL improved their understanding of their discipline. They observed, "I feel like I've learned a lot about technology as someone who studies media technology 
and communication; putting it into action in this particular way has been really interesting."

Faculty improving pedagogy and course outcomes through COIL was seen through their growing confidence in using digital tools to teach their courses, whether COILed or not. All had worked with university learning management systems, but for many, incorporating social media apps as class tools for learning was new. Despite some faculty being early adopters of social media technology, they were unaware that COIL was something universities were doing with these tools. Once they were introduced to the concept of COIL, it was easy for them to start thinking about how to incorporate social media tools in their classes. As Dana confided, "I'm a little bit of a freak in terms of Facebook, social media stuff ... and I just like using these kinds of virtual or digital media channels. So it [COIL] was not far-fetched for me.” Similarly, Chiaki thought COIL supported their desire to incorporate more digital content into classes:

In dance and performance, many things are moving towards the digital. So I feel more capable, like there's no stopping [me]...I realize now that I use more video after COIL... as a way of communication. ...For dance, it's just a good tool for me.

For faculty who had previously been resistant to using digital tools, COIL softened their stance. As Kelly observed:

...It has a huge value and that was a very big surprise for me, because I didn't even use cell phones. I've been using a cell phone now for a year. But that opened-you know, I learned a lot of things from my students and from people over the world. What's App--that was something that we didn't know here four years ago. And it was used all of the world for free. I mean, things like thattechnology, a lot of resources and tools that we have today that are under-used, that we can incorporate in education. 
Several faculty also reported that they were more interested in teaching hybrid or fullyonline courses after doing COIL. Dana observed, 'I'm so familiar now with working online...I see that I don't have to always be present all of the time so I ...come up with alternatives to get my students to do stuff...that I may not have thought of if I hadn't done COIL." Faculty satisfaction and confidence came from a sense of "future-proofing" their teaching skills through COIL.

\section{Challenges of COIL}

Faculty also described the challenges that came with implementing COIL and that how learning how to manage these challenges added to their sense of agency and resiliency. Faculty had to learn to share course sovereignty with their faculty partner or even their students. Faculty had to learn to pitch COIL as beneficial to students who were reluctant to try it. Managing a course across time zones with uneven broadband was new territory for faculty. In addition, faculty had to manage risk around class groups and de-escalate conflict when it arose between the different classes.

COIL challenged faculty to find new ways to accommodate classroom demographic differences while supporting course learning goals. For example, Stevie and their partner had to create mixed teams from very different student populations:

A challenge that we've had is that...we have older, non-traditional students on our campus....We have... the issue of trying to match genders or ages...We ended up getting some students who were high-school age in Latin American country and I had a lot of older men in my group. ... so if it was a young woman in [Latin American country] partnered with a 35 or 50 -year old man [USA] ...we had [the family in Latin American country] chaperoning, but also participating, because they were interested in learning English. 
Faculty learned to deal with student reluctance and self-consciousness around COILing. Part of this was addressing unanticipated "stranger danger" felt by students in their own classroom or with the COIL partners abroad. Dana shared their surprise:

I did not expect...the reticence of the students to deal with people that are different or that they can't see. I thought that this generation of Facebook and Instagram, with, you know, nothing less than 500 followers, they [would be] used to communication with people that they don't see in front of them, but...they still have their issues in dealing with strangers.

Faculty would try to introduce the COIL concept to their students in different ways to make them more receptive. Remy had their students do research papers on COIL. Chris told their students that it was similar to a regular on-campus class: "The students don't really know what it means. So I break it down... 'It means you're collaborating, which you're already normally doing in class. So now you're going to have inside class partners and you're going to have outside class partners." Cameron would emcee the first few synchronous meetings and would intervene to break the ice when necessary. Cameron recalled an example of this:

We had cameras in the classes. The students were very formal at first. And finally, one of my students asked, 'What do you do in your spare time?' And the Vietnamese student said, 'Oh, we like to drink.' And I leaned in and said, 'Oh soda? Like Coca-Cola?' The Vietnamese student said, 'Beer, I like to drink beer.' My students laughed, and their students laughed, and all of a sudden, they realizing that they're similar.

Faculty were committed to encouraging their students to engage with their COIL partners and offered support to help that happen.

A particular logistical challenge and learning opportunity for faculty was learning how to implement asynchronous and synchronous meetings in COIL. Often faculty had initially assumed that synchronous was preferential for student engagement and learning, 
while asynchronous was back-up. However, after teaching COIL, many had revised their opinion. They were becoming curious about how the modalities could be employed differently in the COIL course. Reed shared that they had initially thought that synchronous meetings were critical to the COIL course success, but had revised their opinions by class end:

I started off thinking, do as much synchronous stuff as you can. And the asynchronous stuff is just back up. And now I think they're two tools for learning how to communicate, both equally powerful...S So you'll see in my courses a lot more asynchronous stuff... [as] part of the design now.

Faculty were also curious about the pedagogical implications of asynchronous and synchronous learning. Dale was particularly interested in how the breaks or interruptions between asynchronous and synchronous assignments impacted how they taught and how students learned:

What has changed is my thinking about hybrid online. I'm thinking that some of the difficulties with the way we talk about online or hybrid is that we have focused on distance. And we talk about it as distance learning. What COIL taught me to think about is time. Not just synchronous, but asynchronous learning...that rhythm, asynchronous, the fact that we are on and off at different times...that's the learning I'm trying to think through.

These different rhythms of when students engage with course content highlighted how faculty had to learn to manage risk too. Ariel recalled a time when they had to address a fallout within the group that had escalated quickly:

I checked the class at night before I went to bed, and everything was humming along nicely and woke up in the morning and there had been a huge racial blowout among all the students. And so, I woke up to, like, a hundred messages on these posts and ad hominem attacks and, you know, really nasty horrible like really bad stuff...what qualitatively was like a semester's worth of crap went down while I was asleep in my bed... and then all of a sudden I was like wow, how do I repair this...? 
Some faculty thought that successfully managing risk was dependent on having at least one live face-to-face component in COIL or at best some faculty guided synchronous meetings. Chiaki predicted that virtual exchange would not thrive as a teaching tool without being bookended by physical human presence: "Human contact cannot be replaced. So for me COIL has to have some face-to-face, at some point, to be totally optimal or beneficial. Just online? It's like we're communicating with the mind. The body is left behind." Even so, faculty were busy thinking about how to explore these dilemmas in COIL, whether it was how to run a synchronous meeting across ten time zones or how to nurture human connection through digital tools to enhance learning. Faculty were usually able to negotiate these challenges with a combination of ingenuity, grit and relationship capital. Remy recognized that COIL could be seen as burdensome to faculty who had not anticipated many challenges. They advised faculty to not see COIL as extra work but extra depth. Remy said:

Really thinking carefully... in a way so that it doesn't feel like COIL is curriculum-plus. And maybe that's another... challenge... we have all these other things to do, these other outcomes. And then the perception that it's a whole other set of outcomes for COIL.

That time investment in planning COIL, while demanding, also helped faculty forge strong collegial bonds with their partner abroad. Chris found the process one of compounded rewards. They recalled, "Going forward I partnered with wonderful, wonderful people who take this seriously, we sit down and we spend you know time online, time on the phone, time meeting through zoom meetings, really honing our course." Chris reported they had been "COILing nonstop" for the past five years due to this level of commitment by their colleagues abroad. 
Faculty saw themselves as modeling problem solving for their students when dealing with challenges in implementing COIL. As discussed, faculty faced various challenges in implementing COIL that they found powerful for their own learning and sense of agency. In essence, they presented these challenges as opportunities to show their students how to deal with them in the course. Sometimes it was about being transparent with their students about their own learning journey in leading the course. Cameron recalled, "Everything about that [COIL] was challenging. Meeting new people. Navigating uncomfortable situations. Having to organize your time. And so it fits in with this every evolving pedagogy practice of mine." For others it was showing tough love under duress. Faculty had to be comfortable with failure, their own and their students'. As Dana said,

We do not...micromanage our COIL projects. We feel it's important for the students to try and figure out problems for themselves ...it's about confronting students with a situation that's real life and encouraging them to use their creativity to work out solutions on their own.

Even with the challenges of student engagement and working with a partner, faculty saw COIL as a modality that could help them improve their course outcomes. COIL inspired them to be better teachers by pushing their boundaries. This in turn helped them model effective problem solving for their students.

\section{Building on Existing International Networks}

Faculty found the ability to build on existing international networks a compelling reason to COIL. Many faculty had existing international networks of colleagues from living and working abroad. Being able to reactivate these relationships and take them to 
the next level was important to them. Terry explained how they had been looking for an opportunity to develop their extensive network in Latin America:

I was interested in COIL because I do have contacts. My problem is not [in] finding partners [to COIL with]...I wanted to try it out with one of the professors that I knew... I saw it as a means of institution building or partnership building.

Other faculty networks were initially heritage based, but built out from there. Lee said,

I would say my family is a family of immigrants, so we have ties and connections abroad, specifically to Southeast Asia. Professionally, I have a number of research projects that involve both in-country projects in Southeast Asia, but also research projects that look at the health effects of migration from Southeast Asia to the United States.

Some faculty saw COIL as an opportunity to create international networks, or as Tracy put it, "build my repertoire of global stuff," which for Tracy had started with four-month assignment teaching in a study abroad program housed on a cruise ship. Faculty wanted to use their respective international experiences, which ranged from having worked for an international $\mathrm{NGO}$, to teaching EFL overseas, to being an entertainer on a cruise line, to start building networks around scholarship. They believed COIL allowed them to do so.

While many had joined COIL with a pre-identified partner, usually an established colleague abroad, others relied on outside networks to find one. Faculty often turned to their global affairs office to help them find a partner if they didn't have the personal academic contacts overseas. Faculty also contacted organizations like the International Virtual Exchange Coalition, the SUNY COIL Program, or UniCollaboration, a European professional group, to find international partners. For most it took lead time to find a partner, but for others it was almost instantaneous. Remy described their experience:

Through the office of global affairs, they had a partnership with a sister university...And so that made it really easy. It was just two people raising their 
hands, saying "we both want partners," and them saying, "okay, you two are partners [now]."

Faculty hoped that sharing their international contacts with the university could help further its internationalization goals while simultaneously conferring importance on the relationship with their valued colleague. This could expand beneficial opportunities for all. Terry said that they and their Latin American colleague saw a wonderful opportunity in COIL: "It allowed us to work on continued institutionalization [of our relationship]. We'd done [reciprocal] study abroads... and we'd done conferences together... and so this would add to the possibilities of what to exchange..." They elaborated, "If we want to internationalize our universities...we have to think in terms of long term relationships that are meaningful, and where we can develop relationships of trust." They commented,

I see the COIL as just a part of a long-term project I have going on with the people of Latin America. There might be other people around interested in partnering with me, but my interest is in developing these relationships. I have a memorandum of understanding...we're building these relationships. And so I see COIL as something within that.

Sometimes the institutionalization of faculty relationships was a way for faculty to bring funded research opportunities to their university. Lee shared that COIL allowed them to build on an existing professional relationship:

I had established a line of research that involved Southeast Asia... There was one particular institution that I was hoping to get involved with in a research context. And I thought that [COIL] would be a good opportunity to introduce myself and see if that could be the space to have an initial relationship before we dove right into a full-on research pursuit.

Lee knew that this would elevate their partner's expectations of the institutional relationship and was cognizant of taking the relationship from faculty-to faculty to 
institution-to-institution level. Lee anticipated them saying, "Okay, we helped with this research project. You asked us to do this COIL thing. Okay. What is this relationship now? Are we in for a longer collaboration?" This made Lee realize their duty to shepherd the institutional relationship even if that was officially held by another unit.

Sharing contacts also raised the stakes for existing relationships. Faculty, not administration, had to figure out how to handle potential fallout. For example, Kirby's university was the only U.S. university to have a joint program with a prestigious university in Eurasia. Kirby and their partner wanted to build a COIL element to that joint program. As Kirby said, "[COIL] became a way for us to take our [programmatic] investment and find different ways to expand it." However, with expansion come new difficulties to navigate. Kirby was able to closely screen students for the joint program, but the COIL course was open to all students. "With the program, a committee of us review the applicants. I take the best students with me, but I don't have that option in the classroom...some of the students aren't going to be as strong, or they're not going to be as motivated."

Faculty experienced COIL as a way to add value to existing collegial partnerships, but this also added more pressure on them to manage them. Faculty experienced more responsibility for institutional relationships when they were built on their personal networks. However, most believed there were long-term benefits for all stakeholders that came from institutionalizing their collegial relationships. 
For some faculty, institutionalizing their relationships were about forging a new professional identity. For Dana, teaching COIL created a pathway for them to become a scholar-practitioner:

So research was something that I had never really considered...I was more interested in teaching. Suddenly I started to get interested in research and publishing — publishing has also opened doors for me ....in the United States...I'm getting more and more exposure to the way things work at an American university, as my experience was limited to having been a student [in the U.S.], not a faculty member.

Chris also shared their desire to use their experience of COIL to inform teaching praxis in the natural sciences around intercultural awareness and communication:

When you look at the sciences, again, we're very prescribed in what we need to accomplish. Global awareness, intercultural competence, communication skillsthose are never something that you would necessarily assess and measure in sciences. I love that I can now contribute to that.

Faculty saw COIL in helping them build on existing international networks that could benefit the faculty member themselves, the institution, and student. Cameron tied these international networking opportunities back to students. They advised,

So if you do COIL, you don't want to jump in... and then jump back out. These are relationships that can last. These are relationships that lead to other things that lead to more inquiry...It's about developing these international relationships that will ultimately come round to benefit students.

Faculty believed that students could only benefit from these international networks if the relationship between COIL faculty partners was strong. Most attributed the level of success of their course implementation in ratio to the quality of the relationship that they had with their partner. Kirby believed that building relationship capital with the faculty partner laid the foundation for a successful COIL course. They advised, 
One of my pieces of advice to people here has been...identify whom you are going to work with as your counterpart first, and then get that relationship started before you add the pressure of needing to get this COIL project up and running. I used my COIL funding to fly my partner over here and we spent five days putting the project together.

A strong relationship could weather the challenges in rolling out the course. Cameron described importance of relationship capital in a COIL partnership: "You have to have the social capital built up. You know each other well. They're my little sibling and I'm their big sibling. And we have trust built up, we have collaboration." This goodwill between faculty colleagues allowed for easier navigation around sticky logistical issues. For example, faculty would have to align course assignments around overlapping terms and different national holidays. They would have to negotiate over assignments to be completed by both groups of students taking into account different course goals and how students would be graded. This in turn could affect students' engagement in shared projects and faculty would have to discern when to intervene and when to allow students to work out their differences on their own.

Building international networks through COIL also depended on faculty flexibility around shared teaching and course content. Most faculty were COILing a preexisting course at their respective universities, which brought up differences when they negotiated with each other about changing established content or assignments to meet different course and university requirements. Many faculty stated that this was the most challenging aspect of COILing for them. Kelly stated, "Faculty may challenge you... when you are trying to make progress the way you're used to. But once you go down that path and you reflect on it, you see the value in the times that are challenged by 
other partners." Others also commented on this growth. Cameron confided, "the collaborations I've chosen have always been uncomfortable in a good way, because there's a steep learning curve when it comes to cultural difference [and teaching]." Dana liked the improvisation that was called upon and said, "It's been enriching...

collaborating on a class where you have to...synchronize your ideas about what the assignment will be, what the expectations are...you know that you have to agree, you have to compromise, and you also have to be able to let go."

Successful networks also depended on faculty agreement over interdisciplinary content. Tracy observed that most American faculty "have a desire to make [COIL] as interdisciplinary as possible... [they see] having courses that are tangentially related to each other as a positive thing... [that] you can find spaces to make almost anything work." Not all partner faculty were familiar with cross-disciplinary teaching and were overwhelmed by the complexity of the course goals of their U.S. partners. Even foreign born U.S.-based faculty found it difficult to cross this difference. Chiaki thought they would have an "in" because they were partnered with someone from their home country where they had been an undergraduate. However, "Working with a partner gave me a new sense of perspective for sure...even though I had graduated from Latin American country, I learned by working with my partner, yet again, how 'things are done' there and it's different from here." Some faculty had gone into COIL with some trepidation over what they'd have to relinquish only to be pleasantly surprised at what they gained. As Reed recalled, "I didn't anticipate that having a faculty partner would be such a great experience. But it broke down the isolation of teaching a class alone." 
While committed to deepening the quality of the faculty partnership to sustain international networks, faculty also shared unexpected frustrations over more mundane issues. Some faculty engaged in social media differently, which could cause one faculty member to be upstaged by another in front of their own students. For Remy, their partner was frequently online and liberally "liking” Remy's students' posts. Remy found this disconcerting as they were not regularly online and not accustomed to commenting on student posts through emojis. Remy felt pressured to be online more often and use emojis in a way that felt inauthentic. Another frustration was COIL faculty communication defaulting to course "housekeeping" matters. Faculty reported that much of the time they would have liked getting to know their partner better or building solidarity between students, was usually spent on solving logistical problems or addressing technical hiccups. Stevie remarked, "We've agreed upon our objectives, and the way that we hope to arrive at those objectives...I tend to my students and they tend to their students ...I feel like there's room to grow in terms of how much we are engaging with one another."

That said, COIL partnerships allowed faculty to experience heartfelt collegial collaboration which could only nurture international faculty networks. Remy described it as helping them transcend the daily burdens of teaching at their institution:

I did enjoy having a colleague across the word to try and work things out with... I feel like it is a model that addresses some of the issues that we have at our [home] institutions... [where] it's always a question of how often we have to show up, teach and who does what...so I feel like COIL erased all of those questions and just made us focus on "Okay, what are we going to do together? How is this going to be?"

Cameron also spoke to the rewards of having a COIL partner. They saw the partnerships as less transactional and more transformational. They explained, 
When COIL experiences are positive and meaningful, beyond 'just get the project done,' they can lead to fruitful and meaningful international collaborations. Friendships too: I count these two professors among my friends as well as my research/academic partners...And there's always that sense of, I can only describe it as solidarity between teachers, and relief because you're able to address these issues together.

So while building up solid COIL partnerships was labor intensive, faculty experienced significant professional growth by doing so.

\section{Theme Summary}

In summary, fourteen of the sixteen faculty interviewed had robust pre-existing international networks. These networks were an asset that they could share with the university and with their students in building a COIL course. It provided them challenges and opportunities to improve their teaching pedagogy and improve students' learning outcomes. COIL training embedded at the university and supported by leadership was important to faculty participation. Faculty developed communities of practice around COIL at their institutions and abroad. These international networks were nurtured through faculty relationships and beneficial to faculty who wanted to grow in their careers. In the end, faculty believed that students would benefit from strong international networks of faculty engaged in COIL.

\section{Global Learning for All Students}

All faculty interviewed experienced COIL as providing robust global learning for their students. For them, global learning involved deeper engagement with course content and with classmates overseas. It also increased student access to primary resources and ability to do virtual fieldwork. Finally, faculty saw student participation in global virtual teams in COIL an important global learning experience. 


\section{Global Identity in Teaching}

Faculty perceived COIL as exponentially increasing their students' global learning and engagement. COIL reinforced the belief that all students should have access to international learning. Faculty connected their own personal global experiences to their teaching. They saw it as something that could inform course materials as well as deepen student engagement. This was very true for faculty who identified as international students or immigrants to the United States. Faculty saw COIL as helping them further develop and deepen their international identities through working with their students.

Faculty believed that they had become more aware of the value of global engagement for their students through COIL. Cameron stated, "It's true that since I've started doing COIL a couple of years ago...I'm a little bit more cognizant of wanting to always bring the global into the classroom." COIL brought global learning from the background to the foreground for faculty in their classes.

Most of the faculty had studied, worked or lived abroad. COIL provided an opportunity for them to apply their personal lived experience to the classroom in order to benefit student learning. Faculty had had a wide variety of previous international experience. One faculty member had lived and worked in six different countries prior to teaching in the United States. Another faculty member had a formative study abroad experience in the Global South in the 1980s. One had worked in the MENA region for both Mercy Corps and Bridges to Understanding. Another faculty member had received three degrees from three institutions on three different continents. A number had been 
inbound international graduate students or outbound Fulbright Scholars. Several regularly led study abroad programs.

Faculty believed that their previous international experience was an asset to them when teaching a COIL course. For example, if they had been an incoming international student, they understood the challenges of adjusting to a new academic culture. Kelly often drew upon their experience as an inbound international student with their students. What changed after COIL was that they felt even more empathetic and attuned to the learning needs of both their international and local students. Kelly described it as thus: "Even though I myself was an international student...COIL has made me way more sensitive and much more careful about learning more about the different backgrounds of my local students." For those that had studied abroad as undergraduates, they felt that they possessed an openness and humility around learning from others that could be shared with their students. Cameron had never forgotten an experience in Southeast Asia when they had left a tip as a compliment only for it to be taken as an insult.

Some faculty identified strongly with their immigrant backgrounds. They wanted to use this positionality to help their local students learn more about people who choose to emigrate to the United States. They also wanted to support their communities in the diaspora. Lee designed their COIL course with these two goals in mind:

Nursing is a main avenue for people in Southeast Asia to earn a decent income abroad...the students there... always had so many questions about, "What's it like to be a nurse in the United States? And how do we get there? And who are good employers to work for?" And that's - when I stumbled upon COIL — the two things just kind of clicked, and I said, "Wouldn't it be helpful if nursing students in Southeast Asia got to be in a COIL experience with nursing students in the United States, and have an exchange about what it's like to be a nurse in the US?" 
Other faculty wanted to look at issues of refugees and political asylees with their U.S. students because the faculty identified themselves as global social justice activists. For Ariel, it was an extension of their positionality:

I was sort of radicalized, I mean politically, fairly early on. I was involved in antiapartheid work in college, and after college...we brought ANC youth folks to Portland, to raise funds for the upcoming elections, to talk about...the violence that was taking place at the time, and also just to educate folks on apartheid.

They took this consciousness raising to their COIL courses through teaching about media portrayal of human rights issues as seen between the Global North and Global South.

In summary, then, the faculty in this study possessed a strong sense of international identity based on their life experiences. They wanted to use their global experience to inform their curriculum and well as guide their students in COIL. They also wanted to share how their global views were formed with their students through COIL.

\section{Student Global Self Awareness and Perspective Taking}

Faculty believed they were helping increase the global awareness of their students through COIL. Many of their students had not been outside of their local municipality or state. Faculty believed that COIL could help their students start to place themselves in a larger world. This widening of identity was linked to concepts of global citizenship and learning to deal with difference in both the U.S. as well as abroad. Faculty felt that many of their students were a little intimidated by the term global or saw it as something unrelated to their life experience. For Lee it was a way to start the conversation with their students:

[COIL] was an opportunity that I was able to offer them to think about themselves as global citizens, right? And to think about..."At some point in my life I'm going to have to, or I may very well encounter [someone different]"...and maybe even 
this encouraged and inspired them to want to seek out people unlike themselves... and this [COIL] kind of broke the ice for them... if they'd never interacted with somebody from a different country.

For some faculty, COIL offered them an opportunity to guide their students into applying the principles of empathy and responsibility in global citizenship. Stevie experienced this in their COIL course. Stevie's class was COILing with an institution in Latin America when the El Paso, Texas shooting occurred. Stevie's student wanted guidance in how to talk to her COIL partner about the shooting:

The student wanted to make sure that she wasn't giving the sense that this antiLatin American sentiment was representative of everybody. She was trying to figure out how she could position herself as an ambassador for the U.S. and for the university. She felt horrified by what had happened... she was having now these weekly conversations with someone, and all of a sudden it made her more aware of how important it was for her to have a better understanding about things, and to deal with the raw emotion from her conversation partner who just kept saying things like, "I just can't understand how somebody can do something so terrible against my people. And have so much hate."

Stevie and the student both practiced new skills as Stevie helped the student navigate difficult but meaningful conversations with her COIL classmate in Latin American country.

Some faculty saw global citizenship through a more critical lens and used COIL to bring that perspective to their students. These faculty wanted to challenge students' sense of complacency about already being broadminded and knowledgeable about the world. Cameron decided to employ COIL as a way to get their students to be more critically self-reflective by examining how bias can take many forms. They explained, The students like to think of themselves as being post-racial, maybe not having stereotypes. So [COIL] gave me something new to work with, because I was able to understand that they want to feel that way, but that they're probably not...we 
all want to think of ourselves as being enlightened...you are only enlightened when you realize that you're not enlightened.

Dale made similar observations about addressing unconscious bias in their students:

Each time [I COIL] I get a little better at identifying...the work I need to do to address [student assumptions]. The assumptions are not about "bad foreigners," but more about what I call sentimental charity — "Oh, the sweet foreigners"which is problematic because it sends the message that we're all alike, and if we're all alike there are no problems, which means there's nothing to negotiate.

So, faculty experienced COIL as both introducing a sense of global self to students while simultaneously challenging students to be more self-reflective about themselves in the world.

COIL was seen by faculty as most beneficial for students who had not selfselected into a COIL course. Cameron believed that the students who most benefited COIL were those who were less globally aware to begin with:

You see the most explicit impact in the required classes. Because so often the students who are already seeking out ...international experiences....are already thinking that they will benefit from COIL. But I think for students for whom [COIL] never crossed their minds, this is a pretty low stakes, low stress way to broaden horizons.

COIL as broadening student horizons was echoed by Kim:

It's a global world and students need to appreciate and learn from the whole globe. Not just their own little world. When I think about the purpose of higher education, especially for undergraduates...it makes your world bigger. You start to see things that you didn't even know existed, and COIL is... a great way for that to happen.

Faculty believed that cultural stereotypes could be more quickly revealed in a COIL class, allowing faculty and students to have real-life opportunities to examine and challenge them. Chris described a time when their faculty partner and Chris's students 
were operating on incorrect assumptions on who could speak Spanish. Chris was

particularly pleased at the double take their students gave them:

It's our first meeting and we're on Zoom...my students are sitting there, very quiet, just kind of watching them. My partner turns around to their class and says "You can't speak Spanish because the students don't know Spanish," and I'm thinking, "My students are from Long Island, half of my classes are Hispanic"... So I started joking with the Latin American students in Spanish and I turn around to see my students and they're like, "Whoa, you speak Spanish?"

Faculty believed that students doing COIL, especially those who would not intentionally seek it out, was an important global learning intervention. Faculty believed they were helping increase the global awareness of their students through COIL because many of their students had not been outside of their local municipality or state.

Addressing Xenophobia. Some faculty used COIL as a way to talk with their students about issues related to provincialism and populism. Their students came from both more insular rural communities and immigrant urban enclaves. Faculty were concerned for both groups of students in the current political climate. For Lee, the concern was about challenging the narrative in the classroom before it spilled into the workplace:

I'll be quite frank, when I was starting [COIL] there was this kind of build-up of anti-immigrant sentiment in many parts of the United States. This was my attempt to kind of counter that, ...to... use education as a way to break down cultural barriers, such that when the students get out into their professional lives they will have been prepared in some small way.

Remy shared similar concerns about anti-immigrant sentiments being both experienced and generated by their different students. They were having their class read a book called Enrique's Journey, about a boy from Honduras trying to find his mother in the United States. Remy said, 
I saw [COIL] as something that would go really well with the theme of reading about immigration... and to complicate the idea of why people are immigrating illegally...getting students to think about the danger of that single story.

Other faculty saw COIL as a way to get their local students to engage with each other around cultural difference. Because of the student populations they served, they could have students wearing MAGA hats in the same course as students wearing the hijab. For Chris, they were frustrated that their students were indifferent to the multiculturalism around them. Chris observed, "Even though our students are predominantly multicultural or live in proximity to the city, many have no idea about other cultures. They'll sit next to a student and have no idea what's going on with them." Chris used COIL as a foil for fostering engagement between their local students. Lee, other the other hand, employed COIL as a way to create rules of engagement between students and observed,

We're being more mindful of...respecting different identities, be it along racialethnic lines, gender identity, ability... and that experience with COIL...has applied to how I inform and expect students in non-COIL courses of how to treat each other. How to interact with each other.

Faculty expressed a desire to help their students see the cultural diversity within their own communities as a way to address xenophobia and anti-immigrant sentiment. COIL was a way to discuss these issues from a kind of third space.

Teaching Cultural Humility. Faculty saw COIL as a powerful tool to help increase their students' global awareness and global perspective. For faculty, having a global perspective meant also cultivating personal cultural humility. The concept of cultural humility was brought up by the majority of participants as something that they 
tried to address in their teaching generally. However, COIL was something that they could intentionally employ to explore the concept of cultural humility with their students.

All faculty explored cultural humility with their students around language difference. Faculty saw global self-awareness and cultural humility important in working reciprocally and respectfully with non-native speakers of English. Since most COIL courses are conducted in English with non-native speaking partners, faculty wanted to their students to start seeing English as a world language, spoken most widely by nonnative speakers. Dana, who taught at a European institution, described how they often reinforced this concept with their students:

I try to open up their minds to that that that English is a tool. It's a communication tool. But that they need also to understand that there's a certain complexity to it, due to the fact that other people are also using it as a tool, and it's not their native tongue. So, that's something that I've been able to do also with the virtual aspect and it's also something I try to communicate to American students as wellbecause of our global economy, they are going to be dealing with people in the English language, who are not fluent as natives, and therefore they need to consider that when they are communicating.

Faculty also wanted to challenge students' assumptions about English learners in the Global South. Remy wanted to challenge a stereotype that people learned English in Latin America because they planned to emigrate to United States:

I was assuming that my students would have a kind of single story of Latin America - of people wanting to emigrate north. We started have this COIL interaction and that helped them realize that this was not the case. Many people are studying English because it's a global language...there were students there that were [becoming] engineers and most of them were going to work for some petrochemical company off the Gulf of Mexico.

Faculty were aware that students could have stereotypes about non-native speakers living in the United States. Faculty wanted to challenge their students' belief that native 
speakers spoke a superior type of English to non-native speakers. They wanted to use COIL to help their students explore language bias in not only the classroom but the workplace. Lee, in particular, hoped that COILing could prepare their students to be better colleagues and co-workers. They explained,

Here in the US...in some healthcare institutions, you'll have foreign-trained nurses experiencing discrimination, for example, being disciplined for using their native language speaking to each other. And so I thought, well, given that nursing students in the United States are going to be encountering more and more a multicultural work place, having a COIL experience would allow them to have... interactions with somebody that in theory could potentially be their colleague.

For many faculty addressing cultural humility through language difference in COIL came down to seeing others as equals no matter their level of English fluency or their accents. Remy wanted their students to see working with English learners as necessary to engage in the wider world. Remy stated,

My students here, reflecting on the language practices of students who are learning English in Latin America, and realizing that they are not going to be perfect English speakers, raises the idea that there are many world Englishes. And while their [classmates'] English might be imperfect and full of grammatical errors...it's used that way every day in international trade. What becomes more important is that the content of the language is understood and that the person is not seen as less of a person if their grammar is not perfect or if they have an accent.

Other faculty used COIL to explore cultural humility in the context of Global North and Global South power dynamics. This was particularly important to faculty who were COILing with a class in the Global South. Cameron wanted their students to explore their Global North-Global South stereotypes in preparation to COILing with a Southeast Asian class. Cameron said,

I had to prep my students, and I knew that I had to prep myself to talk about cultural humility... What are our preconceived notions? And so we had to have 
lectures on cultural humility, how to approach these projects and the people in them, and how to think of our role in this [COIL], which is not the leader.

Faculty were concerned that COIL courses conducted in English gave an undue advantage to students in the Global North and could unintentionally reinforce stereotypes. For Remy, this meant being very strict about what roles their students could take on in their COIL course. They stated,

We have to be careful about how we colonize the other courses, or that they colonize us, even if it's unintentional colonization. The idea that my students are more powerful in English and therefore, the experts. Telling them [COIL classmates] what to do with their papers, or being used as labor to do things that they should be working on there.

Several faculty wanted to explore cultural humility and cultural identity with their students through COIL. They thought that this was important for their students' global learning because it increased their global self-awareness and perspective taking. For Dale, it meant having their students link culture to social structures:

You need to provincialize your own culture so that it becomes one culture among many... and not just provincialize it, like "you have this culture and I have that,"...but that you can locate it in a history, in a context, in a structure...for me, that's what COIL provides.

Ariel expressed similar views about COIL challenging students to think about culture and privilege:

I just feel like it's such an amazing experience for students to connect with folks from a significantly different location to where they live their lives. ... I think that idea of like meeting people in a way that allows them to see shared humanity, as well as appreciate difference at the same time, is an incredibly valuable life experience ....

Terry also spoke to COIL helping faculty foster a sense of shared humanity overcoming universal stereotyping: 
I find it interesting that even international students have stereotypes about other students from abroad, so it's not just a U.S. thing. I think that it [COIL] helps them see more of the humanity of the other person living in another culture.

Remy thought that students could best understand cultural humility and culture by simply

building relationships through COIL around collaborative problem solving:

I think that having a relationship with another person in another country is part of the whole point of COIL. To have a way to practice cultural humility through relationship. And how else to do that, other than being placed or given a task to work on something together with another person? ...that's the way that they are going to build that relationship, by solving a problem.

While most faculty agreed that COIL projects were helpful in students practicing cultural humility, Dale was concerned about not confusing the means with the ends in COIL.

Faculty needed to make sure that students were not just studying difference but thinking how to negotiate it. They explained,

I've had to renegotiate what COIL is and does for my classes in order to ensure that it retains what I think that the spirit of COIL should be, which is not learning about foreigners, but which is about promoting a capacity in our students to more self-reflexive about their interactions with the rest of the world.

Remy did something similar in their COIL class by asking both groups of students to define racism in their national setting. Students ended up not focusing on race but rather place. Remy recalled,

The students there said, "racism isn't represented here like in the U.S. Here we have the same look, but we're different because of where we're from." I don't think that many of us had thought before about "race" being based on place... it just changes ways of thinking. It's exciting.

Faculty experienced COIL as a way to help structure their students' engagement with cultural humility and how to approach difference between students in the classroom. In addition, faculty used COIL to deepen their students' global self-awareness and perspective-taking, especially in the area of migration, multi-culturalism and language. 


\section{Global Perspective in the Curriculum}

Faculty believed COIL helped them infuse a global perspective into their course content for their students. They saw this global perspective as helpful to students to engage more deeply with the curriculum. This was reflected across all of the disciplines and included concepts of gender and race, environment and society, policing and free speech.

Faculty members found COIL a way to make content more relevant to their students. For Terry, COILing with a class in Latin America was useful in teaching about concepts of gender and race:

[COIL is]an opportunity for students to have that experience of dialogue with someone from another country, to see how, for example, race and ideas of gender can be the same, and also different in other contexts. ... it is interesting for them to have that experience, where they're talking about gender, gender norms, and ...to see the similarities but then also to understand that there are... differences as well.

Similarly, Kelly and their partner developed a COIL course that examined environmental and social issues between North American and Latin America. Kelly was particularly pleased how COILing could connect the past to the present for their students: "Gold mining for example. It was something that happened here in the 1800 s to the 1920 s. And right now, as we speak, there is active mining in the rainforests of Latin America. So just to bring these stories together for students...is fantastic." Ariel COILed with a class in Sub-Saharan Africa. They had their class look at police brutality in both their countries. Students then discussed what the appropriate cultural interventions could be for local citizens. Ariel found it important that students examined activism in a global context: 
They're learning that police brutality isn't one that is unique to place but that there are broader issues to it... and then thinking about what it would be like to build solidarity across these circumstances...for example, what would it look like when Palestinians and Black Lives Matter connect over issues that they're facing?

Some faculty wanted to use COIL to transcend the U.S. centrism inherent in some of their disciplines. For Kirby, who studied American civil society, COIL gave their courses more breadth:

I study the First Amendment, but I would very much argue that we need to place our speech laws in the context of global community as well. We can't separate ourselves. So even though...my courses are still predominantly U.S. based. ...I encourage students to still think about the global piece.

For Kim, COIL gave them an opportunity to see their discipline in a context that they had previously overlooked:

My background is in American studies, so there isn't a natural global component to it, at least not one that was obvious to me, but...now [after doing COIL] I'm thinking, ...the people who live in ...America came from all over the world, and understanding what has happened in the rest of the world matters. It makes a difference. And so it makes a difference in my own scholarly work and teaching.

Therefore, COIL could bring more global and comparative content to courses that had previously not had this dimension.

Faculty also concurred that COIL was a helpful tool in teaching about culture and intercultural communications to their students. They wondered how it could complement other in-depth area studies or intercultural competency courses on their campuses. In Robin's case they also worried how COIL could inadvertently supplant these courses, for example,

... there's this push towards internationalization of the curriculum. So there's this belief that well, if we do a COIL component, and we put it in the engineering department, then our engineering students will be prepared to be experts in culture. 
While some faculty wanted to think through how they could integrate cross-cultural learning more explicitly through COIL, others thought it was already "baked in" to the structure of COIL. Cameron saw COIL as a less contrived or self-conscious approach to learning about culture and intercultural communication and observed,

The fact is that they learned so much...just in chatting with people from other cultures. Just telling them to break down some cultural stereotypes with each other doesn't work. But when they are focusing on a shared problem, like plastic pollution, as part of a COIL project, they are still learning and interacting, but they don't know they are because they're focused on ... getting the project done.

Still other faculty saw the point of authentic intercultural communication learning through COIL as something that could be highjacked by course content if faculty weren't vigilant about global power imbalances. In particular, some wrestled with COIL as a curricular modality in fields of international business, economics and science where its application was seen as most powerful for student learning. For Dale, using COIL for reciprocal content learning rather than mastering the content per se, was a way to reconcile this. They wanted their students to negotiate difference, not transcend it. Dale found that for them, "Being able to place this interaction [COIL] in a social justice interpersonal interaction to learning about ourselves and we navigate social justice, to me ...is what made the difference [for my COIL course].

For all faculty, using COIL allowed their curriculum to address global citizenship and global stewardship. For some faculty, it meant giving their students a sense interconnectedness to the world. Kelly commented, "When you meet people from somewhere else, it's just that the world increases...that gives an incredible opportunity to be a better global citizen." Other faculty saw global citizenship as a mindset that they 
wanted to cultivate in their courses. For Lee in particular, "COIL was an opportunity that I was able to offer [to my students] to think about themselves as global citizens... and maybe this even encouraged and inspired them to want to seek out people unlike themselves." Robin was excited about the intersectionality of global citizenship and stewardship in their COIL course:

I thought it would be a really interesting [to have a] COIL experience between an archeologist... and an architect. We had them look at historical buildings in their city in Latin America... and my students were involved in with trying to assess what would be good preservation ethics. So for example, what would UNESCO want to see preserved... what are the cultural resource impacts for changing buildings...from my perspective, this was the most successful [COIL project] I'd done.

Remy developed the idea of global stewardship and sharing resources with their students through COIL. He wanted students to look at leisure travel in the Global South differently. Remy explained,

Our students started to see tourism...as an extension of our colonizing...By understanding the history of a place, they can now realize that you [don't] go there to vacate your mind, you go there to pay attention. To think about how the United States has impacted our neighbors and what's around us...connects to my COIL.

Chris had also had their students study leisure travel and sustainability in their COIL course. This COIL took place in classrooms across three continents. They wanted their students to see that all "travel destinations" were also someone's home. Chris said, "I had the students create a video explaining a day in the life of their neighborhood. Then they had to respond to classmates in Latin America and Europe who did the same." Cameron implemented COIL similarly in a course on water pollution. They believed that 
creating a sense of global citizenship was easy in COIL courses that involved service projects:

They did beach cleanups, so one group went down to a beach here, and the other went to their beach [in Southeast Asia]. But the fascinating thing was, they both found Starbucks cups. And so there was a bonding experience, where they both thought, "Oh, this is horrible! Look at our plastic. Look what we share."

COIL provided faculty ways to teach to global solidarity in unexpected ways.

After the 2017 Puebla Earthquake, Chris's faculty partner informed them that their students couldn't COIL anymore. The earthquake had made some of the them jobless and homeless. When Chris explained it to their class, Chris compared it to their community's experience of Hurricane Sandy when students had also lost their homes, couldn't get gas, and school was closed. Chris recalled, "Immediately my students jumped on Facebook and started sending them well wishes and telling them that they would be able to get through it... I didn't have to say a thing. I'm getting chills just thinking about it."

Faculty also connected global stewardship and global citizenship to student success. For Kirby, preparing their students to take on global issues was central to the university mission:

and for us, "being successful" means that we give them... an old school liberal arts education. We want our students to be critical thinkers. That's something we talk about all the time. We want them to have-one of our main missions here has to do with social justice, and that social justice connection, I think, is partly what keeps us connected to global issues, because you can't really separate those out.

Faculty saw COIL as a way teach their students about global citizenship and stewardship.

It was important to faculty that their students develop a sense of responsibility and 
agency in solving problems for the future, or as Kelly said, "to give them opportunities to interact among the solutions."

For faculty, giving their students a global perspective through the curriculum also meant using COIL to access new primary sources of information. Often this started with classmates interviewing each other or holding group discussions on a specific topic, although some faculty wanted their students to talk to community activists or stakeholders, usually accessed through their COIL partner class. Faculty were motivated in part because they felt their students were relying too much on curated media to be informed. This translated to the sources they relied on for research papers and other assignments. Faculty saw COIL as an opportunity to address this.

Kirby's approach through COIL was to have their students act like cross-border journalists in doing assignments. Kirby explained:

in some other parts of the world, cross-border journalism is a big deal, because we can take teams of journalists from different countries and bring them together and they can share information in a way that allows for stories that have a much broader scope and can give insight, sometimes into our own problems...A lot of our big stories really do need to be thought about in this broader framework. And so in that sense the teamwork that we do in this [COIL] classroom is mimicking what can happen.

For Reed, both groups of students having reciprocal access to local activists and decision makers could break information silos:

Couldn't a Rwandan student interview a U.S. community member who's working on a similar issue and get primary source information for that interview?...why not start with that kind of direct collaboration across countries?

Reed described this access to leaders as creating a "global brain trust" for students to use for lifelong learning: 
Students are going to learn more if they understand the international context in any issue I can imagine across any discipline. And that is what they're going to be relying on when they get out in the world is their personal international global brain trust. They're going to need that kind of network so why not have them start developing it while they're at university?

Terry built on the concept of building an international corpus of information. For Terry, it was also about building an international corpus of global citizen power. This could be accomplished by students through COIL by seeing themselves as citizen diplomats. Terry said,

So I think that was one of the main goals, to be able to spark that interest in international relations. I call it international relations--I tell them, "This is international relations, you know. It's not just the State Department talking to it someone else's State Department. It's people talking with one another about issues."

Terry felt that dialogue with community partners abroad could help students understand larger global issues:

I see COIL as another way to present subject material to students and for them to have this experience of learning about the social construction of categories throughout the world. You can read an article and learn about it, but being able to discuss that with people in other countries adds another layer... and for them to ask these questions directly, not mediated through me, but directly to that person in that other country...adds to the possibilities in the classroom.

Faculty experience of COIL was that it gave their students the skills to access original sources of information, seek a wider variety of sources internationally, become more discerning consumers of media and create "global trusts" of information and self-agency.

Faculty also saw COIL as a way to introduce research to students to gain a global perspective on the curriculum. For many, this meant using COIL to conduct student field research virtually. Sometimes this meant interviewing their classmates. Other times it meant having their classmates interview people in their community and sharing it back 
with the class. Cameron's COIL class did "person-on-the-street interviews" in both the U.S. and Southeast Asia about pollution in the Pacific. For Cameron, it helped students understand public awareness of global problems too. Cameron shared,

The Southeast Asian interviews were so thoughtful. The people my students interviewed here were like, "Yeah, I don't know anything about the Great Pacific Garbage Patch," and over there they're like, "Well, let me tell you all about this problem."

Stevie used COIL to connect their students to indigenous activists in Latin America:

Through my COIL partners' help, we were able to invite a very well-known music group that's been making traditional music in that region for 30 years. And they offered to have a mini concert, just for my small class, and to be interviewed by my class. They had recently released a song acknowledging the 43 disappeared students in Mexico. And so we were talking within the context of disappearances, and the importance of voice and breaking the silence, and fighting against impunity and injustice. ..And the students were able to ask them questions that they ordinarily wouldn't have had an opportunity to do.

Some faculty had extensive experience as field researchers and wanted to bring that kind of learning to their students in the classroom. Kelly used COIL to connect their students with professional researchers in the field:

I work in the Amazon, and I've taken study abroad students to Latin America every year for the past 12 years... [therefore] I'm always looking for ways to bring tropical ecosystems into the classroom. So one way I did that early on was to connect my students with researchers... who are colleagues of mine living in different parts of the world.

Faculty also encouraged their students see their COIL classmates as experts too. Kim liked having their students learn from their international peers to inform their research projects:

So if I had a student who wanted to do research on the history of Godzilla movies, they would ask their partners in Indo-Asia. You know what, "Have you seen any of these movies that's part of the popular culture lore?" 
It was important to faculty that their students saw their COIL classmates themselves as a global learning resource, so that students were not confusing learning with each other with learning about each other. Dale found this distinction particularly important in delivering global learning content. They said:

We're doing COIL to learn from our peers in another country... This is not a class about Indo-Asia. This is not an Indo-Asian Studies class. This is why I said I won't do it [COIL] in an international class. If I do it in an international class, that whole question about learning about Indo-Asia overlays everything and they cannot distinguish between learning about Indo-Asia and learning from IndoAsians.

In summary, all faculty used COIL to infuse a global perspective into their curriculum. They saw this global perspective as helpful to students to engage more deeply with the curriculum and with each other as co-creators of knowledge. COIL helped them teach about intercultural communication, global citizenship and global stewardship. Faculty also implemented projects in COIL that required students to seek direct sources and conduct virtual field research. This desired for students to learn with and from their classmates in COIL was also reflected in faculty use of global virtual teams.

\section{Global Virtual Teams}

Almost all faculty used global virtual teams in their COIL courses. The reasons varied. For some, it was about preparing their students for $21^{\text {st }}$ century work. For others it was learning how create solutions collaboratively to shared problems. Still for others it was learning how to more skillfully learn in a team.

Faculty believed that student success was at the core of their work. They saw global virtual teamwork as part of a larger education that would be essential to their 
students' lives. This was particularly important for underrepresented and first-generation

students seeking social mobility through higher education. Kirby observed,

The students are here for the most part because they do see this degree as a way to have a career as opposed to a job... That's their hope, right? When we think about our students here, we're not thinking about training them for a job... we are thinking though about what we can give them to enable them to be successful in a career...so, yes, we do talk a lot about wanting our students to be successful. We're not preparing them for a specific career, but we are trying to prepare them to enter into a workforce in a way that will give them the tools they need to be successful across a multitude of areas. Because we can't...predict what the jobs are going be.

In this context, therefore, Dana felt that it was their duty to prepare their students

for careers involving virtual work. They thought COIL helped them give their students skills that they would need all their working lives:

Over $50 \%$ of employees are working virtually at this point in time; oftentimes they will never, ever meet their project team members. So having that kind of skill to work on a project virtually is an invaluable skill for their employability later ... it's not even cutting edge anymore, it's standard, to be expected that when students graduate ...they need to have that kind of experience of working together, project management skills, virtual digital communication skills, and communicating through virtual means with people from different cultures.

Stevie hoped that students would realize the benefits of global virtual teamwork too.

This was especially true for graduating seniors looking for a job:

For those who are doing this at the very tail end of their university experience, to have that last-minute, eye-opening experience of why a university might require them to do this and how it might be relevant in their personal and professional life... and being able to say that they have at least some sort of experience with international communication and interacting with international colleagues is beneficial....

Faculty saw global virtual teamwork in COIL a preparation for the real-life challenges working in a team later in their professional lives. Kirby observed, 
I think it was good for them to learn a little bit about the frustrations of that come from working a in a team [in COIL]...you add in a level of cultural differences, time zone differences. Even the fact that there's an imbalance in the penalties will be. Welcome to the real world!

Chris saw COIL as a way for students to develop professional teamwork skills in a supported environment. They would advise their students: "It doesn't matter what your discipline is...you will have to work in a situation with colleagues, as a team, and you can either learn it on the job or you can learn it for credit here. It's a safer environment here to learn to work a team."

Part of this preparation involved teaching students how to anticipate and manage team dynamics. The challenges of COILing could surprise students. As Reed shared,

At the very beginning the excitement overwhelms the uncertainty....but then they run into challenges like "this isn't just about talking with each other, this is about producing quality work... and I'm dependent on these other people to produce." This is when students want to throw in the towel. You have to give them a lot of support to get through this crisis period as well as have them pull on the resources of their global team, and if they do that, they have a big breakthrough...then they feel like this was a great way to learn even though that was really tough.

In addition, U.S. students often go into COILing with expectations of harmonious cultural interaction only to be challenged by their COIL classmates abroad. Dale observed,

...They come in bright-eyed [to the course], wanting to learn about Indo-Asia, [but] they all feel utterly miserable by week four because they are not getting what they wanted of that inner-insight to the other culture... [also]they feel that they were anti-racist before and suddenly they are being called out by their COIL partners abroad. I do tons of emotional labor to make them happy again and by the end they all are.

The point of doing this work was to learn but also to produce. Faculty often asked their global virtual teams to address a problem and then produce a solution-based project that 
could be used by community leaders and other stakeholders. Reed described what he asked the deliverables to be:

Products would be a report that's given to an NGO with a list of recommendations on how they can improve. It could be in the form of a live video conference presentation, in which a business person is in the room in one of the two cities and hearing the five to seven minute presentation by the global team. A third is where the global team produces a five to seven-minute mini documentary defining the problem and then offering a solution.

Global virtual teamwork in COIL as preparing students for real-world challenges went beyond professional skill building for some faculty. A few hoped that students would build a solidarity with their classmates in looking at global problems to not just find solutions but to stop them to begin with. Kelly saw global virtual teamwork as empowering students to join forces and act on global issues and observed, "Global teams, I think for me is... a kind of [collaborative] power. We get much more powerful when we get much more diversity." Faculty hoped that this would create student activism around climate change, gender equality and pollution.

\section{Theme Summary}

In conclusion, faculty all agreed that COIL provided global learning for all students. They believed that this learning involved increased self-awareness the student's global self as an actor in the world. They saw students gaining awareness of potential stereotypes that they had about others in their classes locally and internationally. This self-reflection in a global context engendered cultural humility for the students and the faculty. Faculty found that students could learn this especially by working with nonnative speakers who were their class collaborators and problem solvers in COIL. Faculty liked how COIL enabled them to infuse a more global perspective into their course 
curriculum in a relevant way. They believed that student engagement with the global curriculum helped foster a sense of global citizenship. That citizenship could be supported by students doing virtual fieldwork and interviews with policy makers and community leaders abroad. That citizenship was also fostered by student experience in global virtual teams, which was also seen as an important $21^{\text {st }}$ century skill by faculty. As Kim observed, "It's a fun challenge. I think students genuinely learn things that they could not learn in other ways. That's pretty much it. Students like it, I like it. And we all learn from it. And that's enough to do the work."

\section{Equity of Access to International Learning}

Faculty came to see COIL as a way to offer all students greater access to international learning. This was particularly true for students who had never traveled or would not be able to travel for educational purposes. Fifteen of sixteen faculty interviewed saw COIL as benefiting students who could not or would not be able to have an education abroad experience. This was a theme that came up consistently in the faculty interviews in response to questions about faculty motivation and experience of teaching COIL at their institutions. Faculty saw themselves as activists around the importance of international learning on their campuses and that COIL was a way that they could enact and support the mission of their open access institutions.

\section{Faculty Equity Work}

All faculty interviewed taught at open access institutions. Many had intentionally chosen the institution because they saw higher education as empowering the historically disadvantaged and overlooked. They wanted to be part of a larger societal movement 
around educating for equity and self-agency. They believed that global learning helped address the structural inequalities in education. As Reed shared,

I was working in $\mathrm{K}-12$ poverty schools, and I felt like those students had very little contact outside of their local community, let alone a global community, even though highly racially and economically diverse... at that point I had had enough of my own international experiences, I realized this was an important part of understanding yourself, and understanding the way of the world, and how do we do that in low-income schools? Higher income places the students get oftentimes will travel abroad but not here. So, that was probably my initial motivation [to COIL], was seeing how I could connect [them] globally.

COIL was also a way for faculty to help their students see global learning as something they could have or were entitled to. Kirby talked to their experience as a working-class student and how international learning through study abroad or other means was not something they would have ever remotely considered. They shared,

I think about this, having grown up in the middle of nowhere in Eastern State; very working class; went to a school like this. I would not have felt that I had the agency to travel abroad, to interact that way. And so sometimes it's a little frightening for the students, but if we can put them in those situations in the classroom, where there's a bit of a safety net, we can help them move past their fear. We can help them feel entitled to those experiences.

Furthermore, COIL could help students be open to possibilities that they'd never considered before about their futures. This resonated for Stevie in particular as they saw themselves as having a career that they would have never considered but for international learning experiences. Stevie explained,

I'm trying to ensure that as many students as possible have access to these international experiences...it's born out of my experience. I do language studies and I am a non-native speaker and so I never would have expected that I would ultimately be a Spanish professor. That was not ever a part of the plan.

Faculty spoke to COIL as a movement in higher education, a force for equality in global learning. They saw themselves as activists through COILing. 
I feel like there's momentum building. So on this grander stage, you know, I always saw myself as being part of larger movements that are creating progressive social change and in education to me this is one of those leading edges that's doing that.

Seeing themselves as activists for international learning for all, faculty implemented COIL as a tool to redress the lack of study travel mobility for the vast majority of their students. It was a way to feel that they had the power to bring the world to their students irrespective of their students' life circumstances. Chris commented,

My students are not your typical learners... a lot of them are underrepresented students. They have family dynamics that pull them away, they have jobs that pull them away, they have financial stress. How can we give them the most enriched learning opportunity? I can't bring them everywhere, but I can bring a lot of the world to them [through COIL].

For other faculty it was about bringing the world to their students and then giving them students the skills to navigate that world. Those skills included cross-cultural awareness and working in teams. Kirby used COIL to assign project work to accomplish this. They explained,

And so we have a lot of students who can't travel for lots of reasons, right? Family obligations. Financial reasons. Jobs. And so I like the idea of them having-not the same experience - nothing is going to replace actually being in another country - but I like the idea of giving them some ability to work on a project with people from another culture. And so that's how I got involved in COIL.

Faculty embraced COIL as an educational intervention to give their students more social and professional mobility. Chris explained it this way:

With COIL you get the skills that you need to go out in the workforce, anywhere in the world, with any population of people... if I dropped you into a setting in a foreign country now and you didn't have those skill sets, you'd be at a disadvantage...The world's getting smaller. I mean it's really getting smaller...either our students have to get out there, or we have to bring the world to them. And we know how it's going to work; we have to bring the world to them. 
Faculty saw COIL as a way to have agency in bringing international learning into the classroom for their students.

While faculty were concerned that their students would not travel abroad, they also worried that their students weren't experiencing or learning from the existing diversity in their local area. Faculty repeatedly brought up that students were often living in or near culturally rich and diverse communities, but had not cultivated the awareness, skills or opportunities to engage with it. They thought that learning to engage with difference was a hallmark of higher education, and they saw COIL as a tool to engage students around multiculturalism and diversity at home. For Kirby, it was about getting their students to step out of their habituation:

I've found that $85 \%$ of my students have never been out of the country before... and a lot students have never been out of the state. I want [COIL] to give them an opportunity to stretch past their normal experiences, their everyday experiences...

Stevie, by contrast, was rather flummoxed by their students' lack of background engagement with other cultures and people. Especially since their students lived in a large metropolitan area. Stevie admitted,

It just sort of boggles my mind, because... I've always been surrounded by people from other countries. And so to be able to introduce students to this kind of experience, and hopefully get them to shed some of the fear or misgivings they might have had about it initially, has been something that encourages me to keep this [COIL] up.

Faculty discerned that students didn't engage with others in their community often because it simply didn't occur to them to do so. Part of COILing involved promoting the idea that engaging with difference was an interesting and worthwhile endeavor. The other part of COILing was convincing students that they could do it. Terry observed, 
I thought it was interesting that a lot of students remarked that they never thought they could have an experience like this in a class in the United States. When I announced the first day of class that we would have... an activity with Latin American students, they confessed that they were kind of wary about that. Like, how is that going to really work out? And so they were surprised that it actually worked, and that they were able to communicate with people from a different country in a class...

Terry said that their reluctant students went on to take more courses with a multicultural or global content after their COIL. Terry hoped that it would build a curiosity in the students to engage with more international and multicultural students on campus.

Creating opportunities for global engagement for local students was important to faculty. Faculty spoke to the mission of their institutions to serve place-bound students in their region as part of the region's development. In fact Kirby stated that their institution was focused on globalization because of the demographic they served. They said,

It's not possible [to study abroad]. You can't leave your job. You can't leave your children. You can't leave your life. Our students have a lot of responsibilities. We've always been aware of that here... [therefore] we're focused on globalization... because we worry that our students don't travel much. This whole campus was started because we were trying to reach the community in this city, the place-bound students in this region.

Faculty saw themselves as advocates for their students' global learning through COIL.

For them there was equity work embedded in teaching COIL. They wanted to communicate that all students were entitled to a globally relevant education irrespective of travel.

\section{COIL and Education Abroad}

Faculty grappled with how to define the value of COIL alongside Education Abroad in terms of accessibility and inclusion. Over half of them had led study abroad programs previously and felt strongly that all students should have an educational travel 
experience. That said, they believed that very few of their students would actually

participate in an Education Abroad program. Therefore they worried whether the success

of COIL could inadvertently reduce the institutional financial support for study abroad.

While the numbers of students studying abroad were quite low on their campuses, they

didn't want participation to decline further. Similarly if they promoted study abroad as

the gold standard of global learning and engagement, would their students who COILed

feel marginalized? Faculty grappled with how to present the pedagogical value of COIL

as different but equal to Education Abroad.

Some faculty were straightforward in presenting COIL as a substitute for study

abroad. They did not see their students able to participate in education abroad

programming or travel. Lee summed it up thus:

My students can't really avail themselves of travel abroad, like study-abroad experiences... One of the benefits of COIL is that students would cannot travel or spend extended time away...can have some sort of learning experience in an international context. Because of our student body, I wanted to give an opportunity to them, through COIL, to have an international learning experience.

Faculty often focused on the experience of COILing as being beneficial for place-bound students. Cameron was attracted to COIL for this very reason:

Our students might really like the chance to 'travel' - that's in air quotes, right? But to travel and to get to know other cultures without having the expense, the time of having to leave your family or your work. So, from the moment I read about it [COIL], the allure of it was the experience for students.

Some faculty presented COIL as a low-threshold and low-cost opportunity to their students. As Terry recalled,

Another motivator for this, too, is that with the large portion of students coming from underrepresented backgrounds, that they may not have a lot of money or opportunities to study away. And so, bringing the courses together through the 
practically-free resources that they already owned anyway - the big piece of it was the idea that it wouldn't cost much at all, other than time, to COIL, and to start to get students open to that idea of possibly studying abroad someday, if that was possible.

Like Terry, other faculty hoped that COIL would get their students to seriously consider studying abroad in the future. They saw study abroad as a high impact practice that could be supported through and with COIL. Stevie said,

I'm sure you're well aware, there are issues of equity and access at our population with the particular profile of students we have. It's not too surprising but there aren't as many people participating in study abroad programs as we'd like; and we really think that-I mean it's such an important high-impact practice, we would love for everybody to get to participate in one.

Some faculty had created year-long support programs at their university for underrepresented minority students and first-generation students who studied abroad. These programs offered pre-trip and reentry support and created a community of nontraditional study abroad students. Faculty hoped that COIL could support their advocacy and outreach to those students.

Several faculty looked at how COIL could deliver some similar types of learning to their students as a study abroad experience might. They explored themes such as students being forced out of the familiar and seeing with a new perspective. In this context, Remy compared COIL to travel:

While one can't afford to always travel, so maybe it's that idea of [COIL] helping students see what they might see as other, in a different way. One of the things that I like about traveling is getting more comfortable being out of my comfort zone. I think I can definitely see my students being out of their comfort zone when I'm asking them to talk to somebody in another country.

Other faculty thought that COIL could bring some of the immersive elements of study abroad to students by engaging with others beyond the classroom in their partner class' 
country. Reed described how he felt COIL combined with service learning could have similar impact on students' perspectives:

I did this [COIL] in partially classroom settings, meaning classrooms connecting with community centers or within NGOs. I said, this is incredibly valuable. Yes, you can replicate most of what it's like to have an experience like you have in study abroad, that changes your point of view of yourself and others, and we need to scale it at a university level.

Other faculty were intrigued by how they might draw upon the intercultural empathy developed in study abroad by creating opportunities for their students to engage empathetically with partners in COIL. They thought COIL would help their students develop a curiosity about those they were partnering with abroad. Remy envisaged it this way:

Even though COIL is not a study-abroad program, it's trying to be. So how do we take the best of what it is to go to someplace and meet new people, have conversations about things you didn't even plan on having a conversation about? Maybe the ... work or issues that students are facing in other countries become interesting for my students here, and so then they start writing research papers about what they didn't even realize was something that they also find an interest in.

Faculty were curious to explore what high impact practices around global learning in education abroad might be replicable in COIL. They clearly recognized that on one hand, they were two very different experiences. As Terry explained,

A study abroad experience is just much more holistic. The person is eating the food. They're trying to find their way around. They're encountering people. They're seeing what it's like in that particular city. And so it's a much more intensive experience that I don't think COIL can substitute...

On the other hand, COIL could be more strategically implemented for learning outcomes tied to a course or curriculum. COIL made it possible to design assignments to build empathy or cross-cultural skills along with content. COIL could be seen as more 
efficient in delivering intercultural learning to students. One faculty member even championed COIL as more authentic to fostering intercultural engagement and learning. Dale reported,

For me, COIL is preferable to study abroad because study abroad is such a curated experience. And you engage students more and the students engage the foreign [students]more than simply as an object of study. With COIL they are forced to actually engage as co-equals [because] the students on the other side are actual students.

In the faculty discussion over equity of access to international learning, many had initially seen COIL in situ with Education Abroad programming. A larger question emerged from faculty about how to position COIL as different from but equal to study abroad in some situations and for some students. Some faculty thought deeply about how COIL and study abroad might be presented in comparison to each other. Some faculty saw the potential dangers, however, of comparing COIL to Education Abroad. Ariel observed,

COIL is qualitatively different than study abroad. I think it's time we start describing COIL in its own terms rather than in comparison to study abroad. Understanding it merely as a less-desirable but cheaper version fails to account for its substantive strengths, and continues to romanticize study abroad.

They went on to list COIL's unique strengths as being able to create closer academic collaborations in specific program subjects; to build faculty relationships through longerterm collaborations; to facilitate collaborations at multiple sites simultaneously; and to free students and faculty from roles of "host" and "guest" so as to collaborate on more equal terms than is usual in study abroad. Ariel observed how COIL had started individuating itself from study abroad in the past few years and how that was helpful in developing it as a modality of global learning. 
That said, faculty observed that there no support frameworks to help students digest their experiences in COIL. Faculty were facilitators of the whole experience. Some faculty had concern that this made COIL more demanding to teach than regular courses and that the university would need to provide intercultural support to faculty if COIL were scaled up. Ariel remarked,

When you study abroad, you have the mind space to be really thoughtful, for better or worse about everything you're encountering. When you do COIL, it's just one of your regular daily activities. And so you can actually be... reinforcing stereotypes and unethical ideas without even realizing you're doing it because ... it's not being marked out ....as something that needs to be paid attention to.

Faculty connected university support for COIL to building increased capacity at the institution. This made some concerned that it might be scaled up too quickly. Ariel observed,

The biggest risks are ... that the ethical considerations of how to do it well aren't paid enough attention to. And so, the excitement over being able to claim you've done this... sort of the idea of like how many courses do we have, how many students have done it... that those metrics drive a push towards doing COIL in a way that loses sight of the ethics of preparation, ethical engagement, and you know re-entry or reconsideration after the fact.

There were some faculty who countered that those concerns were no different than those in education abroad while education abroad had more supports in place. Their larger concern was a lack of faculty area studies knowledge or expertise. Faculty needed to have deep knowledge of the place they were COILing with or leading a study abroad program. Terry spoke to this:

I think it is quite possible, for example, for a student to do a study abroad and come back and not have learned a whole lot, or maintain stereotypes that they had, or even reinforce stereotypes that they already had. So, I think that with any discussion about other cultures or social categories of race, gender and class, it 
has to be mediated through a more substantial understanding of that region, or those categories.

Ariel was concerned that students could not only have reinforced stereotypes but that the tools of engagement were so easy to access that students could become numb to the experience. They compared it to using drones:

I don't think we have [support] like that for COIL folks. And I think there's an assumption that oh it's not as intense. And it's like that... you're not sort of displaced from the rest of your life. But it's sort of like virtual warfare in that actually makes it harder in some ways, right?

Robin echoed concerns that COIL could undermine international engagement if not done properly and ethically. They observed,

In cases where you have COIL experiences where it really isn't as successful or deeper... it really does the whole process of internationalization disservice. Because, it becomes voyeurism, it becomes online pen pals or, you know, the equivalent of Instagram in classrooms. So, unfortunately, there's that potential.

Though faculty could see where COIL, like study abroad, could be better supported for student learning, they remained optimistic about it as a tool of equitable global learning and engagement. All had received positive student feedback which motivated them to do it again. Stevie said this about the feedback:

And it sort of validates why we're doing this, and that, "Yes we're accomplishing what we set out to do." We're getting students excited about interacting with one another. They're using the skills that we're trying to develop... Students are reporting back to me, not just at the end of the quarter, but sometimes years later, how much of an impact the experience has had on them.

Faculty also felt that the feedback guided them in improving COIL on their campuses and thinking more deeply about its optimal implementation. Faculty wanted to use COIL to support overall student success. Ariel stated,

My argument was always that what COIL did was it met a very specific need and met a very specific learning goal, and that the technology was a tool to meet that 
learning goal, which was connecting students who wouldn't otherwise be able to connect. Right? And I think if you keep your eye on why you're doing it, then it really helps you keep from doing it just to do it, right, just because it's cool or it's flashy.

Other faculty remained laser focused on the benefits COIL to prepare their students for $21^{\text {st }}$ century work. They saw their students success through the lens increased employability after graduation. They wanted their students to feel that they had been given every opportunity possible. Dana said,

I was convinced that this was good for the students. That it was enriching for them, that it would give them opportunities that they would not normally have. And since we do have a lot of part-time students, older students, ones with families who are unable to go abroad, I was convinced that this was an alternative that would give them insight into working with people different from themselves and... that it would increase their employability because they would experience, you know, virtual teamwork and intercultural competencies and all of those skills and knowledge... so my focus was on students, what's good for them.

Faculty grappled with how to compare and contrast COIL with Education Abroad.

Some saw it as a reasonable substitute for studying abroad, especially in making global learning accessible and inclusive. Others saw COIL as a different but equal modality for students to learn and engage in an international context. In either case, faculty believed that students needed more curricular support to process their experience of COIL not unlike how study abroad students got pre-departure and re-entry programming. Finally, faculty speculated about how COIL could be used to either cheapen or deepen global engagement depending on how thoughtfully it was implemented by faculty.

\section{Theme Summary}

In conclusion, faculty believed COIL gave their students equity of access to international learning. This was particularly important because they saw their students as 
having significant obstacles to participation in study abroad. The focus on access was aligned with their values to serve students at open access institutions. Part of this service was developing new and innovative models of global learning and engagement. Some hoped that COIL would encourage students to study abroad, while other saw it as separate but equal modality. Faculty felt it was important to approach COILing with foresight and ongoing support for students.

\section{COIL Forecasting}

Faculty described COIL as a future-facing pedagogy. They believed that it would shape future teaching and curriculum development at universities. While they couldn't anticipate all of the potential impacts, they did predict some. They saw a new type of faculty community of practice emerging around COIL, where faculty would be the leaders in best practice around COIL rather than specialists in online learning. They also saw COIL being integrated with Education Abroad in the university curriculum, where COIL might bookend or be an optional add on to a study abroad program. They believed COIL would be utilized to build for explicitly focused curriculum around global sustainable development. They also saw COIL as a disruptor to higher education delivery, and were cognizant of both the risks and opportunities in scaling up COIL.

\section{Communities of Practice}

Faculty believed that COIL would impact the approach and shape of faculty communities of practice at the university. Many of these faculty learning communities were designed to help faculty teach better for student retention and success. Though many faculty were already part of such communities, they felt that teaching COIL added 
value to them. For some faculty, it was about taking skills they already had and more widely developing them through COIL. For others it was about applying these skills to other teaching contexts. For example, at Chris' institution, faculty who were in a program supporting first year students were recruited to also participate in COIL. Chris shared,

I chair our First Year Experience Committee, and we run faculty communities of practice where ... you have two [first year] courses, different disciplines, joint students, and a project... on campus. So that's exactly how we bill [promote] COIL to faculty [to increase faculty participation] on campus: If you've done a first year community of practice, you can do COIL and if you've done COIL, I'm putting you in a first year community of practice.

Connecting existing communities of practice around COIL to address other issues was also something that faculty discussed. Several were interested in co-teaching courses on campus but said that it was structurally impossible at the university because course could not be cross listed. Therefore, some hoped that COIL could encourage more interdisciplinary collaboration. Others thought it could help faculty reconceptualize how to better cooperate on campus. Remy noted,

I feel like the COIL model addresses some of the issues that we have, trying to link courses within our universities... it creates that sense of, all over the world we're in this together, trying to educate our students... whatever it is, whatever the topic is.

Faculty also imagined these communities of practice would lead to further scholarship around teaching and learning through COIL. They were excited about being thought leaders around COIL praxis. This brought them into conversation with other scholars around the world. As Stevie shared,

I was really inspired to find new and exciting ways to tweak some of what we had done... and then I presented at one of our national conferences... and I had some 
really rich conversations with people who were not just in distance learning groups, but educators in higher education, to talk about how exciting this is as a possibility for students in linguistic and cultural studies.

Faculty research was increasingly focused on the impact of COIL on students. Though they were early days, faculty wanted to champion this work. Stevie recalled,

I was just at International Virtual Exchange Conference and somebody was talking about the impact of COIL, and there was sort of stickler like, "Well, is the idea really meaningful, isn't this kind of subjective when it's qualitative analysis?" And I thought, "Well we've got to work with something and start from somewhere."

Faculty could therefore lead the exploration of teaching and learning in COIL through action research in their own courses. This in turn could give it more credibility within the academy.

\section{Integration with Education Abroad}

Faculty predicted that COIL would be further integrated into Education Abroad at the university. They believed that COIL might come up with a way to address the low participation for students at their institutions. At some institutions, this was already happening. One faculty member described a COIL course on environmental sustainability with a university in Latin America where the U.S. students had the option of traveling there for ten days. Students would self-select to join and would have to pay for this option, usually held during winter or spring break. While this option still had the same financial obstacles to study abroad, some faculty were able to obtain grants to take their COIL students abroad as part of the course. COIL could be used as an avenue to subsidize study abroad for students. Robin explained,

I'm teaching a special topics and anthropology course, which is specifically a COIL course with a bilateral travel component. And that's being funded through 
the 100,000 Strong in the Americas grant. So basically I'm able to give community college students a free study abroad program to Mexico.

At the very least, faculty believed that COIL could help their students find their own path to study abroad, perhaps even years after the class had ended. They felt that COIL planted a seed of interest and possibility that would incubate through ongoing communication between students. Stevie shared,

Students talked about how excited they were to have developed friendships and that they are now planning to study abroad. And I've heard from students years later who are still in touch with their conversation partners and people from our COIL Facebook group.

Some faculty looked at COIL as potentially more effective way to deliver pre-departure information for students studying abroad. This was especially important for short-term faculty-led programs or programs that went to multiple sites organized by a third party. Not only could it prepare students for cross cultural learning but it could build a solid foundation for content learning. Tracy in particular liked the idea of COILing with students beforehand to lay the groundwork for their time on ship:

We were in the Mediterranean and so we went...to four ports in the space of eight [days]. Every other day we're landing at a new port... and so it was hard to lay down the foundations for the class. That's not a problem in COIL. In COIL you can control your environment. You're much more in control.

Faculty were also interested in using COIL to develop more study away opportunities for students. They thought that study away programs could include the immersive travel element while not involving the burdens of added expense or legal status documentation. Remy shared, "I did a study away program with my students here this spring, where we went to Hawaii, which is about as far away from the United States can get and be in the United States. We intentionally made it study away so that students that don't have the 
documentation can go on a study abroad like program." Remy imagined building on a future offering of this trip by COILing first with a class or community in Hawaii to learn more about the impact of sugar cane plantations on their indigenous culture. Remy then hoped that the classes could later meet in person as part of the study away program.

\section{Integration into the Curriculum}

In addition to being integrated into Education Abroad, faculty believed that COIL would be further integrated into the general university curriculum. Faculty envisioned COIL as anchoring and promoting the curriculum in various ways. Some wanted to implement COIL to create more consistency across course sections. Others hoped that COIL would make required courses more relevant and engaging to students. Stevie and their department were considering this:

We've been thinking about scaling this up and requiring a COIL component across all of our sections of $102 \ldots$ for purposes of standardization to make sure that students are having similar comparable experiences, since it is a graduation requirement, but also in hopes of encouraging further language study.

Faculty also envisioned COIL as a way to integrate undergraduate and graduate students to enrich the curriculum. Some faculty already COILed with a graduate classes abroad because graduate students' English language proficiency was usually stronger. However, U.S. based faculty liked how their undergraduate students got more deeply engaged in the curriculum through discourse with graduate students abroad, many of whom had broader content knowledge. Dale had been struck at how their partner's master's and doctoral students were engaging in issues around social justice and how this helped with their students learning. Dale said, 
I've been working on this course and was struck by how much my students were quite unaware of the very large volume of experiments in alternative efforts to make a difference, and social movements in other parts of the world. And I couldn't assume that they were getting enough from my class...they knew local stuff and they knew what was happening in the U.S. but they did not really have a global sense of social movements and social politics.

Still other faculty imagined curricular integration possibly happening across institutions by COILing with classes studying the same topic. Stevie taught about Latin American culture and literature in the United States. They imagined being able to COIL about Latinx identities with multiple partners across the United States. Stevie envisioned it thus:

So, really, for every course that I'm teaching, even if it's U.S.-based...I have been thinking more about how I could infuse COIL into these classes... and one idea ...is do what University of Chicago is [doing]; they have their students do projects with a Latino Studies class in Southern California, and also in New York, and in Florida... to be able to understand that Latino or Latina in many cases depends on our specific regional influences.

Though COIL courses were not cross listed between institutions in the U.S. and abroad, or even listed within the same discipline, some faculty imagined this as a future possibility. Terry spoke to this by describing how their COIL class had been able to satisfy requirements at both institutions. They said,

My partner was teaching a class — it's required in Brazil that students have some type of education in diversity and on race- - So he was teaching educators about race relations in Brazil. And I was teaching an introduction to race and gender studies. So we took a couple of articles on intersectionality and [the students] read those same articles and commented on them through Facebook. It was an interesting experience for us both. We thought it would only last for a few weeks but the students ended up working together for a month.

While most faculty easily saw COIL being integrated into the curriculum, others took it a step further and saw it being incorporated into degree programs. They believed that 
COIL would need to be implemented at this level to "mainstream" global learning for all students. As part of that, it could be implemented in cooperation with institutions abroad who were interested in co-creating new curriculum. Lee imagined it this way:

I think that would be really exciting is if there were a whole suite of courses that complimented each other and utilized COIL; and it was all structured around COIL or using COIL with a specific institution abroad or two. Not like a single class with institution A in country A, but ... something like having 36 credits of a degree program with institution $\mathrm{A}$ in country $\mathrm{A}$, and building a whole learning experience using COIL in that other setting... helping the students meet the academic program goals and learning objectives of the degree.

This was not actually a big conceptual leap because many faculty already designed their COIL classes around issues of global sustainable development.

Faculty expected that COIL would inform university curriculum that addressed global challenges around people, the planet, prosperity, peace, and partnerships. While no faculty had specifically designed courses around the UN 2030 Sustainable Development Goals, most of their COIL assignments implicitly addressed them. Faculty anticipated that their future COIL courses would be shaped and driven in response to global challenges around sustainability.

For example, Kelly described a successful river systems COIL course that they were going to develop further and offer again on their campus:

I'm into nature, science, natural history and how you use the environment as a main inspiration to teach...so we looked at issues associated with the Nile, the Columbia River and the Amazon. The students looked at the environmental issues associated with these rivers. How they impact the economy and the society.

Lee, as a scholar of labor migration, foresaw increased movements of people around the globe due to environmental and economic disruption. Lee thought that COILing would be a useful way to keep their curriculum topical and current. Lee wanted to always be able 
to COIL with parts of the world experiencing high levels of outbound migration. As a start, Lee designed a course around the growth of cities in relation to labor migration with a partner in Southeast Asia:

Since I was teaching a global labor course and he was teaching an urban studies class, we thought we could...do something on urban economics [and] labor economics...We were focusing on our two respective cities...in terms of how much labor migration affects [them].

This course would be a basis for future courses or even programs that addressed how human migration, the growth of cities and environmental problems were all connected.

Faculty did not just want to teach to issues of global sustainability, but have their students address problems for the future around these topics. For example, Reed had already designed a COIL course which required students to generate solutions to endemic problems around sustainability and human rights. Reed described the course model thus:

The students have a central question that they need to solve...like... [how] to clean up a particular river system in a community, for example, the Columbia River or the Nile...or how to reduce female harassment in a large city in the MENA region or the United States... or how community participation can protect fragile agricultural ecosystems in Sub-Saharan Africa or North America.

Other faculty envisioned that COIL classes would require students to take climate action as part of the course. Cameron was already doing this with their classes in various ways:

I'm always asking them to do something, to connect abstract theoretical concepts with real world environmental issues. And so, you know, my students have given up plastic for a couple of weeks. They've tried to reduce their carbon footprint. They've tried to buy nothing new for a month.

Integration of COIL into the curriculum would necessitate more intentional and robust intercultural learning content. Faculty anticipated that COIL courses would require more explicit incorporation of intercultural communication and cross-cultural skill 
building. This was in part due to faculty seeing COIL team projects fell apart when the U.S. students lacked cultural humility and cross-cultural understanding. Cameron gave an example:

This is a combination of perhaps the hubris of my students, mixed with the fact that they were driving the project, mixed with the problem of translation... [but] my group decided that they wanted to make the beeswax fabric that everyone's using these days...s you don't have to use saran wrap. When they came to me with the idea, I said, "huh, and where would you be getting this beeswax?", the students said, "Amazon." I said, "Okay, where would the students in Southeast Asian country get it?" and they said, "Don't worry, we messaged them and asked if they had beeswax in their country." ... So in a few weeks, my students came to me and said, "Well we made our beeswax fabric but the other group did not. In fact, they said that they were just busy studying for their exams. How could they do this to us?"

Cameron's students later learned that Google Translate had confused beeswax with bees and that beeswax was not an easily obtained commodity in that Southeast Asian country. Their Southeast Asian classmates had been confused initially about the project requirements and then were embarrassed to disclose that they couldn't get beeswax. Cameron's students ended up making a presentation at professional conference about the rupture and subsequent repair with their COIL classmates about this misunderstanding. Cameron was extremely proud of how the COIL course resulted in this added learning around cultural humility for their students.

\section{Disruption to Higher Education}

Faculty believed that as COIL was scaled up it would cause disruption to higher education. The disruption would come from advances in internet communication technology but more so from how social media would be repurposed for teaching and learning in ways yet unknown. Faculty would be called upon to prepare their students for 
a more intense and higher stakes learning environment. In turn, faculty would rely more on university staff to help them do so. For example, faculty reported that their institutions were exploring how to award digital badges or micro-credentials through COIL and this would require further investment in full-time staff to manage. Kim said, "The investment in full-time staff to support all kinds of global learning... is what enabled us to institutionalize COIL at our university."

Disruption was built into COIL as classes regularly adopted new and emergent digital technology. Faculty frequently experimented with new digital communication platforms for their classes. This sometimes was based on student preference or broadband capacity, but it was also driven by faculty desire to better coordinate synchronous and asynchronous communication in their classes. Because of this, faculty often used digital platforms that were not usually supported by their offices of information technology. This could be challenging when trying to prepare for unanticipated technical glitches during class. Dana devised a work-around by bartering with the student workers in their technology support office. Dana recalled,

I asked if I could borrow them basically for a Saturday, just to set that up for me in a room and they just did it and I bought him a case of beer and I gave it to him as a thank you and ... they were jumping in to do it again the next time.

Sometimes faculty worried about being able to keep up with COIL as virtual exchange and communication evolved. Reed spoke to this:

Certainly technology is a big driver of this, but...the information we have and then what people are doing with it is spiraling so quickly that you know, even something like COIL that is really on the forefront how courses ought to be taught... it's just going to, in an instant, go clear over there; it'll be [qualitatively] different. 
Faculty predicted that COIL would also build new international networks of institutions who would partner with each other around virtual exchange. The plethora of digital platforms coming to market already offered ways to communicate with more than one partner simultaneously. Some faculty had even tried COILing their course with more than one classroom overseas. These faculty were often early adopters of new technology and they liked to experiment with it in their classes. This is how Dana ended up simultaneously COILing with four classes around the world:

As we went along, we became aware, more and more, of other collaborative platforms...so we experimented with different possibilities.... And the project went from one-on-one to expand to four different cultures in three different time zones and in the end took on another complexity.

Some faculty saw the international networks growing outside of the United States as excitement and momentum built up around COIL worldwide. As more universities adopted COIL, the opportunities to COIL grew in proportion, giving faculty more options for partnering. Stevie, who particularly liked working with Latin American institutions, was pleased that more institutions there were starting to adopt it. Some were even establishing COIL networks specific to Spanish and Portuguese speakers. Stevie said,

So I think that now we've got the momentum, and having my colleague in Latin America who was just really kind of a cheerleader for the cause, and now they've gotten all of their colleagues excited about it. And they actually just organized a conference in April, at their campus, that was all about innovation and pedagogy. And so they invited us to be the keynote speakers to talk about the evolution- the development of COIL and how it's changed. And they're really excited about doing more COIL as well.

Faculty also predicted that COIL technology would disrupt foreign language teaching and learning. As more non-native speakers of English participated in COIL, there would be greater pressure to negotiate and accommodate language differences. 
Some faculty hoped COIL would encourage more foreign language learning in the United States, but others believed it would make students think that foreign language learning was unnecessary. Faculty and students were increasingly relying on digital translation tools to communicate between classes and within virtual teams. Dana spoke to their concerns around their students using Google Translate:

Yeah, some may try to use it when it comes to writing the report...I discourage them. But to be honest with you, it's reality. People at companies are doing this all the time... so it would be kind of ridiculous to expect my students not to use it, but I discourage it because most of the time the translation is awful.

Some other faculty looked at it from a different perspective. In this case, it was about the partner institutions' non-native English speakers having more equal power within the group. Remy saw Google Translate as a potential tool of equity:

I've seen COILs where neither group has mastery of the English language... and I feel, even if they have to use a terrible Google translate, that this somehow levels the field...we have to be careful of situations where English is the language of power. Maybe having my students use some of the translation tools, and not have English be the default language [as potential solution]...COIL has to be thoughtful about [not] perpetuating the idea that English is the only world language.

COIL faculty were also beginning to play a role in development of future COIL digital platforms. They were in direct contact with software designers who were building learning management platforms or smartphone apps to specifically support COIL. Faculty saw themselves as practitioner-innovators in this sense as they knew that their COILing would be affected by future upgrades and innovations in digital tools. Reed spoke to how COIL practitioners were going to part of shaping the future of these digital tools. He said, 
We're in the advance beginner stage of doing this kind of stuff. And this is how artificial intelligence learns, you know, you start accumulating knowledge and pretty soon it begins to bend and go like this. We're going to get so much better in the next few years because more people are coming online and sharing information on how to do this well. So I think we're going to get some really interesting breakthroughs and improvements...I think that's what's on the forefront and it's exciting.

Though pleased to be innovators of COIL, faculty acknowledged that there was still much unknown on how to best prepare students for the learning experience of COIL. While it did not involve travel, it involved an intense level of engagement. Students were not always prepared for the differences between a COIL course and others at their university. For example, Reed said their students came into their classes thinking, "Okay, this is just like any other class and we just happen to be having some people internationally we're working with. I'm just going to treat it just like I do another class." But then Reed went on:

They find out that some of the things that they are asked to do are very different...[for example] they're asked to be on social media when they're in class instead of turning it off. They're expected and required to interact with their international partners and do it in deep and meaningful ways. It can really throw students off because it's not what they normally do, or are expected to do [in their other classes].

Similarly, COIL could disorient students in other ways. In Stevie's class, it was not always clear who was speaking in their native language and therefore which class group the students belonged to. Stevie explained,

Students are required to post in their target language, and then I require my students to comment on at least two posts in Spanish that are posted in Spanish... and then my students have to respond to at least two posts in English that are posted in English. It's been tricky in trying to navigate the altering languages at times, because this is a $100 \%$ online class... so some students have no idea which students come from our university and which students are from Latin American university. 
While acknowledging that COILing required students to adapt quickly to difference, some faculty conversely imagined it would highlight what was shared. Remy hoped students could build a shared kinship over universal struggles around learning difficult subjects:

I have a Math colleague that's going through the COIL program. And he asked, "What do you think about doing this in another country for math?" And I thought, there are definitely some benefits to realizing that people on the other side of the world - a different culture, a different country - are struggling with the same things. That there might actually be some relief in that [for students].

COIL disruption extended to new issues of privacy and social media as learning tools in class. Faculty acknowledged that they required students in their COIL classes to use digital tools tied to individual or private accounts. They believed that this would not be sustainable in future as students were already reluctant to use social media tools that identified them individually. Other students objected to having social media accounts on platforms they didn't trust or that didn't reflect their values. Some faculty employed work-arounds, some unsanctioned, such as asking students to create alias Facebook or Twitter accounts just for the duration of the course. Terry spoke to this:

I thought that some students might be against Facebook. There were a couple that didn't have Facebook accounts. I told them that I had never had a Facebook account and I set one up just for this class... and that they could ... set up an account just for this class and they could put in a different name if they wanted. I think that's against Facebook policy, but...some of them already had Facebook accounts that were under different names than what they use.

There was also concern about conflicting national data and privacy laws for the respective COIL partners. Faculty already found it difficult to navigate the various privacy laws imposed at their home institution, and to ask their partners to do so was perceived as a burden. Often faculty voiced frustration with university administrators 
who were unfamiliar with privacy laws outside of the United States or European Union. Therefore, the burden of compliance usually fell to the Global South partner, who would have to devise ways to interface with the U.S. learning management system. Dale noted that this put strain on their partner: "Due to FERPA and other reasons they ask us to use Canvas...but the reality is that it's a kind of work to learn these systems and...that just we assume that people on the other side are going to learn our systems."

Faculty also anticipated future challenges to the U.S. academic calendar with COIL. Faculty observed that synchronizing academic calendars would continue to challenge U.S. centrism on course timing and goals. Dale described a conversation with their faculty partner:

My colleague said, look my university is excited about this. They like the idea of the students having these connections. But they do not pedagogically plan to change everything in order to fix some American ten-week term...our projects are not going to be speeded up to meet the American speedup.

Faculty spent a significant amount of course planning time to synchronize the course assignments around respective countries' holidays and breaks. This was viewed as unsustainable in the future. Dale described what was involved:

They have a semester system, we have a quarter system. They start in August and we don't start until late September. There is a twelve to thirteen hour time difference. They don't do daylight savings time. Apparently in the middle of all our interactions they are supposed to change the time. The rhythms that we have are not their rhythms. Holidays don't align. It's not a Christian country. They are not organized around Christmas. Thanksgiving is only in the New World. Their holidays are different, their breaks are different. When they do exams are different.

While faculty described how U.S. institutions currently expected the COIL partner to conform to the U.S. academic calendar, they foresaw several possible alternatives. They 
imagined that COIL courses might eventually have their own international timetables on top of existing national academic calendars. They also foresaw institutions adapting national academic calendars to make synchronization of COIL courses easier.

Finally, faculty described COIL causing disruption in higher education through its use of global virtual teams. Faculty were assigning higher stakes assignments and paraprofessional work routinely as part of a COIL team project. This could change the role of the faculty member in class. Faculty saw their facilitation roles spanning from being a coach to a manager. For example, Kirby wanted COIL to make their students "feel like I was more their editor than their professor" in executing a global virtual team project. Reed was enthusiastic about their students having to give a formal presentation to local leaders on solutions to global urban problems. Dana was proud of their students competing with international teams to design a real-life marketing campaign for a local company. Other faculty felt that the new kinds of learning delivered through COIL could take away from the engaged learning that comes from in person human contact. Chiaki explained,

I have mixed feelings about COIL because the more I do things online, the more I value the human connection. So now that I know both, and I know how virtual exchange...is comfortable for people, and it opens more windows for them. But it closes many others. Because human contact cannot be replaced.

Faculty overwhelmingly saw student participation in COIL, especially in working in global virtual teams, as good preparation for professional life. However, they also wondered about its future impact on the teacher-student relationship. 


\section{Theme Summary}

Faculty viewed COIL as a future-orientated teaching modality. They anticipated it impacting their communities of practice by expanding their current networks. They expected COIL to be explicitly combined with study abroad and internships programs to strengthen pre-departure and re-entry programming. They hoped it would increase participation in education abroad on their campuses. They saw COIL as driving the integration sustainable development into the curriculum. Lastly, they expected COIL to disrupt higher education by its use of exponential growth of digital tools and global virtual teams in classroom learning.

\section{Chapter Summary}

This basic qualitative study examined faculty experience of teaching COIL. Four main themes emerged. First, faculty found that teaching COIL courses helped them grow in professional practice and disciplinary knowledge. Through the COIL fellows programs at their respective institutions, faculty gained skills and grew communities of practice that they found valuable to teaching all of their courses, whether they COILed them or not. Faculty felt that COIL helped them reinvigorate their teaching through its combination of online, collaborative and international elements. COIL also increased their motivation to re-engage more deeply with courses that they had become accustomed to teaching as well as gave them confidence designing courses that implemented social media and digital tools. For some faculty, COIL was an opportunity to take their research interests to their teaching or their teaching to explore new lines of research. Faculty experienced more agency in engaging their students in a COIL course by modeling active problem solving 
around logistical and technical challenges. Faculty valued how COIL helped them establish and build on international networks that would nourish them professionally as well as help them build social capital at their home institutions. They believed that robust and active international networks would ultimately benefit student learning and success at their institutions.

The second theme that came out of the study was that faculty saw COIL as a way to deliver global learning to all students. By its nature in partnering with another class abroad, COIL brought an international perspective to the curriculum. In addition, faculty believed that COIL gave them a pedagogical platform to share their own personal international experiences. They saw that in sharing their lived experiences of navigating cultural difference and learning cultural humility, they could add value to their COIL courses. The value would be in helping students engage more deeply with the materials and illuminating course objectives for student learning. It was important to faculty that students developed cultural humility in the COIL course. This was in part due to improving collaborative learning but also to address populism and provincialism at home. Faculty thought that COIL could be another context to for students to gain awareness of the multiculturalism and diversity on campus and learn how to navigate that difference. COIL also allowed faculty to study concepts such as gender, race, and free speech in a global context across all of the disciplines. Faculty used COIL to experiment with applied global learning by having their students do assignments in global virtual mixed teams. It was not only a way to deepen student engagement with the course, but it would provide them with skills for careers in the $21^{\text {st }}$ century. 
The third theme that emerged from the study was that faculty saw COIL as a way to give access to international learning to students unable to study abroad. All of the faculty taught at open access institutions where participation in education abroad programs was far below the national average. Faculty didn't want their place-bound students to be disadvantaged in accessing the benefits of global learning and engagement. Faculty described teaching in COIL as a kind of equity work that they could do at the institution that would address inequalities around student learning. They were mindful that their students were entering higher education for social and economic mobility and while faculty could not train students for specific jobs for the future, they could equip them with skills that would make them employable. Faculty saw use of global virtual teams in COIL as a way to give their students such skills. Faculty believed that they could bring the world to their students through COIL and simultaneously prepare them for global work and citizenship.

The fourth theme that emanated from the study was faculty speculation and foresight about where COIL was going next. Faculty saw several trends that they believed would drive the future of COIL and teaching. One was that faculty would become the experts in digital tools and course design for COIL as its iteration would outpace the ability of the university IT specialists and course designers to keep up with it. They expected that COIL courses would start offering optional short-term travel components as part of the course design or be incorporated themselves into traditional study abroad programming. Faculty also viewed COIL as driving increased integration of global sustainable development issues into the general university curriculum. Faculty 
anticipated that COIL would advocate for the incorporation of intercultural communication skills in all course design. This would engender increased faculty awareness about cross cultural guidance and support to students in all courses taught at the university. Faculty also predicted that COIL would foster student demand for microcredentials and digital badges and that universities would need an infrastructure to support this. For faculty who were attentive to signals of change in higher education, COIL was a bellwether for forces that would drive such changes. 
Chapter Five: Discussion and Implications for Practice

This study explored faculty experience of teaching COIL to better understand how faculty viewed COIL as a modality within the larger movement of Internationalization at Home. Sixteen faculty were interviewed to get a more in-depth understanding of faculty motivations around international engagement in a domestic setting. Four key findings emerged from the data. First, faculty experienced COIL as an intervention for Internationalization at Home. This observation speaks to why faculty participated in COIL, what they found significant into their experience of teaching COIL, and how they saw COIL related to Internationalization at Home. Second, faculty saw COIL as a way to prepare their students for $21^{\text {st }}$ century life. This understanding speaks to faculty experience of using global virtual teams in COIL. Third, faculty found that teaching COIL benefited them. This finding helps us understand why faculty were motivated to teach COIL and what they saw as significant for their participation. The complexity and intentionality in implementing COIL heightened their curiosity and motivation around teaching, and inspired them to innovate. Fourth, faculty integrated the 2030 Sustainable Development Goals, or SDGs, into the curriculum through COIL. These key findings help answer the four sub-questions of the study, namely, why faculty participated in COIL, what they saw as significant in the experience, how COIL was related to Internationalization at Home, and faculty use of global virtual student teams. The chapter concludes with recommendations for practitioners who are charged with internationalization at their institutions as well as recommendations for future research, 
especially research that will counter the narrative that the student mobility and top-down curriculum internationalization are the cornerstones for global learning at the university.

\section{COIL is a Faculty Intervention for Internationalization at Home}

Faculty experienced COIL as a strategic, targeted way to bring global learning to the classroom for all students, irrespective of student mobility or institutional directives around internationalization. This is consistent with the core definition of Internationalization at Home, where faculty purposefully integrate a global dimension into the teaching and content of the curriculum for all students in a domestic setting (Beelen \& Jones, 2015). While faculty did not explicitly connect teaching COIL to Internationalization at Home, their descriptions of their experiences aligned with its definition and associated activities (Robson et al., 2018; Lee \& Cai, 2018; DeWit \& Leask, 2017; Baldassar \& McKenzie, 2016; Soria \& Troisi, 2014). The alignment was demonstrated through their desire to COIL because it offered place-bound students access to global learning that they would have not otherwise received at the university (Custer \& Tuominen, 2017; Baldassar \& McKenzie, 2016; Agnew \& Kahn, 2014; Soria \& Troisi, 2014). Faculty also viewed COIL as an important equity work and practice in their pedagogy since they all taught at open access institutions that served non-traditional, first generation, and underrepresented students. This alignment is also affirmed in the literature that has described Internationalization at Home as empowering to faculty who saw global learning as a pedagogical imperative (Leask, Beelen \& Kaunda, 2013; Landorf et al., 2018). 
Faculty saw COIL as a way to address inequity of access and inclusion in global learning in higher education (Landorf et al., 2018; De Castro et al., 2018). They were aware of how universities conventionally delivered global learning around student mobility, area studies or foreign language study, and they were concerned that this excluded the majority of students on their campuses. Faculty saw COIL as a way to bring all students to global learning, which to them was an essential component of higher education and should be built in to all degree programs. For faculty, COIL was able to bypass inherent structural obstacles for student participation in study abroad, including cost, time away from work and legal documentation. COIL could advance the conversation around global learning from student access to faculty implementation in the curriculum. Faculty perceived COIL as a game changer at their institutions. COIL allowed them to start delivering global content and skill building through courses they were already teaching. It allowed them to collaborate with classes abroad for reciprocal global learning and engagement, which was not usually evident in other forms of internationalization at the university. Faculty also came to see the desirability of acquiring cross-cultural communication skills because COIL made best practices around intercultural communication a necessity in course design.

Faculty saw themselves as agents of internationalization on their campuses through their teaching of COIL. This shift to faculty as the key agents of internationalization was predicted in the literature, specifically by Beelen and Jones (2015) who said that academics would have to take center stage in the process of global learning was to become mainstream. Similarly, and Niehaus and Williams (2016) 
asserted that faculty would ultimately internationalize the university curriculum because top-down policies would fail to have a broad impact. Faculty were able to achieve through COIL what the literature described as the ultimate goals of Internationalization at Home. For example, most faculty designed their courses around global issues that had relatable local contexts. This aligns with Internationalization at Home delivering a university curriculum globally focused but not reliant on student mobility (Beelen \& Jones, 2015). Several faculty used COIL in general education required courses at their universities around migration, language, and identity, as does Internationalization at Home (Beelen \& Jones, 2015; Leask, 2015). Other faculty designed their COIL courses around the multiculturalism of their students which is a cornerstone of Internationalization at Home (Mak \& Barker, 2013; Wächter, 2003; Nilsson, 2003). Still others taught COIL courses connected to their research interests as is necessary to drive the design and content of the internationalized curriculum (Leask, 2015; Niehaus \& Williams, 2016). All faculty utilized digital media tools like Facebook or WhatsApp to have their students do coursework. This aligns with the literature that says faculty must adopt virtual exchange tools in the classroom in order to provide rich international learning for their students (O’Dowd, 2018; Rubin, 2017).

Faculty described COIL as a high impact practice within Internationalization at Home that could deliver global learning outcomes on its own merits and of its own accord. Faculty did not see COIL as replacing the benefits of a traditional immersive study abroad experience. However, they questioned whether study abroad was the only gold-standard for intercultural and international learning, recognizing that COIL, when 
done intentionally and well, possessed strengths that study abroad did not. They saw COIL's strengths coming out of strategic and thoughtful course planning geared to specific global learning goals for students, a high-impact practice (Rubin, 2017; Whitehead, 2015). COIL met the threshold of engagement for high impact practices (AAC\&U, 2013) in several ways. COIL faculty taught about critical environmental issues such as the Pacific trash vortex and mining in the Amazon, promoting class interaction over relevant and substantive matters (AAC\&U, 2013). Faculty designed COIL courses that had students study race and gender with peers in the Sub-Sahara and Latin America, which align with high impact practices asking students to negotiate diversity and the unfamiliar as part of the course design (AAC\&U, 2013). Faculty who COILed had students collaborate on solutions addressing police brutality or river pollution, which required a real-world application of knowledge (AAC\&U, 2013). Faculty also used COIL to have students disseminate knowledge, such as woman-on-thestreet interviews or presentations to local stakeholders, which fulfills required public demonstrations of competency in its class projects (AAC\&U, 2013). Overall, Faculty employed COIL to increase opportunities for students to access high impact practices at the university.

Faculty saw COIL as a prescriptive learning intervention for students who had never considered that global learning was relevant to their education or simply felt reluctant to internationally engage. Faculty believed that COIL introduced the concept that global learning was for everyone, not just the privileged or internationally oriented, and that all learners would benefit from it no matter their preconceptions. This finding 
challenges Harrison's (2015) assertion that Internationalization at Home programming ignores or bypasses students who resist intercultural group work and who avoid contact with international peers. While COIL courses were built around faculty and student international engagement, most students did not self-select into them because they were often offered in the general studies curriculum. Faculty learned to cultivate student buy-in as part of the rationale of the course itself and faculty discovered that the students who benefited most from COIL were often the ones most initially resistant to participating. This then gave faculty a sense of agency in be able to ensure that all of their students were receiving an education required for $21^{\text {st }}$ century work and citizenship.

\section{Faculty Use COIL to Prepare Students for $21^{\text {st }}$ Century Life}

Faculty saw COIL as a way to prepare their students for future careers through the use of problem-based learning, collaborative projects and global virtual teams. This had been anticipated by scholars (Beelen \& Jones, 2015) who saw that an important but unrealized contribution of COIL and Internationalization at Home was its framework for teaching skills for $21^{\text {st }}$ century work and engagement. While faculty did not see their teaching COIL as vocationally oriented, they believed that students got practice and support in building skills around teamwork and collaboration in a multicultural and crosscultural setting which would be necessary for professional life. Faculty were keenly aware of their students entering higher education to create a better life for themselves and for their families. Faculty believed it was the mission of the university to improve the life of citizens in their communities and for some faculty, this was the reason that they chose to teach at an open-access institution. Therefore, faculty felt obligated to ensure 
that their students were receiving an education that provided a solid foundation for lifelong learning and professional adaptation. In addition, Faculty used global virtual teams in their courses as an innovative and creative way to teach students how to work and produce in a team while giving them practice and in problem solving and crosscultural collaboration. This approach is supported in the literature which describes employers looking for graduates with transversal skills developed through virtual mobility (Standley, 2015) and faculty looking for a way to create better classroom environments to teach them (Schnickel, 2019; Davison et al., 2017; Panteli \& Tucker, 2009).

COIL was discovered inadvertently by faculty to be a tool to address multiculturalism and difference at home. While they had come to COIL to deliver global learning to their local students, many faculty unexpectedly found that COIL helped them think about how to address issues of populism and provincialism within their classrooms and community. On the surface, it appears paradoxical that it took looking outward for faculty and students to appreciate and learn from diversity at home. Longtime campus advocates of diversity and inclusion may rue that the glamour of cosmopolitanism upstaged campus awareness-raising efforts on the value of local multiculturalism. However, faculty recognized that COIL was able to reframe or mirror "other" in a way that enabled students to see and appreciate the diversity in their classrooms. For them, this is what mattered most because then they could connect students to the work of the multicultural centers on campus and reinforce the critical work of offices of diversity and inclusion. Interestingly, this finding supports how faculty and scholar-practitioners first 
conceived the purpose of Internationalization at Home (Wächter, 2003; Nilsson, 2003).

It was not initially designed as a substitute for study abroad or intended to deliver global learning content per se, but it was meant to prepare students to live and work together in growing cities fed by migration from the Global South. Educators then, like today, were trying to respond to populism backlash against migration and immigrants. They saw Internationalization at Home as way to prepare students to work and live together and to "to vaccinate all our students against the dark forces of nationalism and racism." (Nilsson, 2003, p. 39).

Faculty saw cultural humility, not international or intercultural expertise, as the most important tool for faculty when teaching COIL. It was not possible for faculty and students to possess the area studies and language skills for every COIL course they participated in, nor did all faculty have a COIL partner that shared their disciplinary orientation. Faculty described COIL as something that helped them explore cultural humility with their students in a higher education context. Cultural humility was not discussed in the literature around Internationalization at Home, except as one of several desired outcomes for global learning (De la Garza, 2019; Deardorff, 2011). Therefore this was not expected prior to the study. The literature also describes cultural humility as an asset to deeper learning and engagement (De Castro et al., 2018). Faculty saw cultural humility as a co-requisite for COIL and as a value that faculty wanted to instill in themselves and in their students through their teaching of COIL. Faculty saw cultural humility benefiting students in the $21^{\text {st }}$ century because students would be needing to adapt to new situations and work with diverse teams of people throughout their careers 
(Foronda et al, 2016). While it was not possible for all students to become intercultural communication experts, they could develop cultural humility as a skill that allowed them to negotiate, learn from and adapt to difference in their careers (Murray-Garcia \& Tervalon, 2017). Cultural humility was a value that helped faculty recognize the learning differences among students in their local classes as they strategized to bridge differences with the partner class. The literature (De Castro et al., 2018) speaks to this by saying that COIL helps faculty develop respect for multicultural perspectives and increases their interest in collaborative problem solving in the curriculum. This is borne out in other studies that described how relationships between immigrant and local students flourished in COIL projects (Rubin, 2017) and that COIL could provide "multiculturalism at home" (Bruhn, 2017).

\section{Faculty Experienced Benefits to Teaching COIL}

Faculty believed that their teaching had improved through their experience with COIL. The complexity and intentionality around implementing COIL heightened their self-awareness of how they taught in general and encouraged them to continue to innovate their approach to teaching. This experience of improved pedagogy was further enhanced through participation in communities of practice and international networks built up around COIL. This finding is affirmed in the literature which describes faculty benefiting from COIL most in their teaching and research (Lee \& Cai, 2018; Rubin, 2017; Edwards \& Teekens, 2012). It also responds to earlier criticisms (Stohl, 2007) that universities have failed to engage faculty in internationalization because they overlook the risk and focus on the rewards. In this study, faculty saw their institutions rewarding 
them for risk-taking around COIL, especially through the COIL fellows programs and grants.

After teaching COIL, faculty became more amenable to hybrid and online teaching as well as using social media for teaching. Most had felt pressure at their universities to offer more of their courses in online and hybrid formats. They had been reluctant to do so due to a perceived lack of knowledge of digital technology. Since they created assignments in COIL which involved virtual synchronous or asynchronous formats, faculty found that teaching COIL gave them skills that they could also apply to distance and online learning. The literature addresses this idea slightly through the concept of virtual internationalization (Bruhn, 2017), which conceptualized how faculty could combine digitalization with internationalization in their courses. Faculty liked how they were able to teach their students how to use social media for learning. This is considered an emergent practice in the literature (Jarrett, 2013; Wojcicki, Izumi \& Chang, 2015) where faculty are strongly encouraged to engage with students through their smartphones as part of teaching and learning. Faculty experience also affirmed that while students were perceived to be digital natives, they needed to be taught how to employ Web 2.0 platforms for educational and professional purposes (Davison et al., 2017). Therefore, through COIL, faculty not only learned skills that they could apply to online and hybrid courses, but they could also teach their students how to use social media for learning in those settings.

COIL created faculty community around innovation in teaching, course design and curriculum through the campus COIL faculty fellows programs. Faculty viewed the 
fellows programs as an explicit and visible institutional investment in their professional growth, in teaching and scholarship, and in their existing international collegial networks. These networks, in turn, helped faculty create wider communities of practice that coalesced around COIL but also supported other research and disciplinary interests. The literature speaks to this in several ways. First, faculty created networks around COIL through necessity because their institutions did not have the infrastructure yet to find partners or deal with emergent digital technology (Rubin, 2017). Secondly, COIL fostered a "co-laboring and co-construction" of faculty knowledge through international activities (Barkley, Cross \& Major, 2014). Third, faculty networks were what sustained class to class partnerships around COIL and its continuity from term to term. Therefore, faculty were not only COILing to deliver a specific course but also to create and sustain community around teaching innovation through delivery of globalized learning (Sutton, 2018).

This study provides additional discourse on faculty engagement around internationalization of the curriculum. Whereas some studies (Niehaus \& Williams, 2016) posited that institutions would have to mandate an internationalized curriculum in order for faculty to gain a global perspective on teaching, this study shows that faculty's global experiences, as distilled through teaching COIL, is what helped internationalize the curriculum on their campuses. In addition, the faculty fellows programs, conceived initially to deliver training on COIL, ended up embodying the Five I's of successful faculty engagement with internationalization (Childress, 2010). Intentional space for faculty learning and experimentation was created through the cohort training model. 
Investment was made by leadership through the funding of the fellows programs. Infrastructure for the programs was provided by the offices of global studies, sometimes in partnership with the teaching and learning center. Institutional networks for faculty were fostered both locally and internationally. Incentives were offered to faculty for improving their COIL practice through the funding of travel, research and attending virtual exchange conferences, resulting in the necessary conditions for faculty buy-in (Jones \& Killick, 2013) around internationalization of the curriculum.

This study also responds to Beelen's (2018) assertion that there was a disconnect between faculty and course design in the internationalization of the curriculum. Faculty in this study took a stronger interest in course design after doing a COIL course. They reported that they had heightened awareness over how courses could be tailored to meet the needs a particular class for a particular purpose from term to term. They approached their non-COIL courses more mindfully and strategically by applying skills from COIL to improve group work or design project-based assignments. COIL's scheduling challenges also made them more intentional in creating assignments that made the best use of students' limited study time outside of class. COIL also inspired faculty to incorporate more global or cross-cultural content in courses that were not designed around global learning. While the literature describes the challenges of getting faculty buy-in to adapt pedagogy and curriculum for global learning (Dewey \& Duff, 2009, Childress, 2009, Neihaus \& Williams, 2016, Landorf et al., 2018), faculty in this study internationalized their teaching and curriculum of their own volition after doing COIL. 
FACULTY USE OF COIL FOR INTERNATIONALIZATION AT HOME

\section{COIL Integrates UN Sustainable Development Goals into the Curriculum}

Faculty taught COIL courses that addressed issues of global sustainability as described in the seventeen UN Sustainable Development Goals (SDGs), though they did not realize they were doing so. For example, their course content clustered around climate action (SDG 13), gender equality (SDG 5), responsible consumption and production (SDG 12), life below water (SDG 14), strong institutions for peace and justice (SDG 16), and life on land (SDG 15). In one COIL course, faculty had student teams compare the social and economic effects of current mining in the Amazon to that of the Pacific Northwest a hundred years earlier. In another COIL course, faculty had students in three separate countries learn more about the river deltas where they lived to better understand shared global pressures on their respective ecosystems. In still yet another course, faculty had students in North America and Sub-Saharan Africa collaborate on designing citizens' campaigns to address policy brutality in their cities. Faculty also employed COIL to teach about gender and race, social justice and the economy, refugees and human migration; they assigned projects in global mixed teams to have students become better at conceptualizing and solving problems. In this way, faculty were advancing what the literature advocated for building global citizenship, namely aligning taught university curriculum more closely with the UN Sustainable Development Goals (Egron-Polak \& Marmolejo, 2017; Harrison, 2015). Interestingly, faculty experience in this study counters the literature which asserts that faculty are resistant to the interdisciplinary nature of virtual exchange (O’Dowd, 2018; Starke-Meyerring \& Wilson, 2008). This study found that faculty teaching to topics embedded in the Sustainable 
Development Goals in COIL were more open to interdisciplinarity and some were attracted to interdisciplinary teaching in this context. This was due to the interdisciplinarity of the SDGs themselves (UN, 2015) which were around large themes such as no poverty (SDG 1), reducing inequality (SDG 10) or responsible consumption and production (SDG 12). Curriculum built around the SDGs also encouraged faculty and students to collaborate across disciplines because of the problem-solving and solutionoriented nature of the projects and problem-based assignments (Egbelakin \& Jiang, 2020; Sachs, 2015).

\section{Implications for Practice}

COIL is a faculty-driven inclusive global learning intervention for students in a domestic setting. The results of this study lead to six recommendations for the benefit students, faculty, and institutions.

First, the university should shift the bulk of their internationalization efforts from Education Abroad to Internationalization at Home. Faculty in this study reported a sense of leadership and innovation in teaching COIL on their campuses because it could benefit all of their students, irrespective of self-selection or mobility. Therefore, international education practitioners should shift the bulk of their current internationalization efforts to institutionalizing COIL on their campuses as part of providing global learning "at home." COIL provides the most accessible and inclusive way to deliver global learning for all students as part of their formal education. All of the faculty in this study reported that very few of their students could or would be able to study or travel abroad and that this was a disenfranchisement in their learning. As Beelen and Jones (2015) argue, "while 
mobility can bring additional benefits to the global few, this should not be at the expense of internationalization for all" (p.68). With 90\% of students in the United States and 99\% of students worldwide not studying abroad (De Wit \& Jones, 2018), higher education must deliver global learning through modalities like COIL. Faculty believe that their international experiences and networks could have a profound impact on students global learning and intercultural skill development whether or not those students studied abroad. This is supported by studies (Kinzie et al., 2017; Kinzie \& Helms, 2019) in which students reported that faculty international experience had the most impact on their global learning and skills in the curriculum. It is important to remember that education abroad was designed to deliver global learning, not to simply enable international travel. If open access institutions are serious about preparing all of their students for competitive global work and international engagement, practitioners must promote COIL as separate but equal international learning modality to study abroad.

Second, institutions need to create sustainable infrastructure and dedicated support for faculty-led communities of practice around virtual exchange which also could help drive and inform the internationalization goals of the university. This shift would involve creating a collaborative support structure at the university for faculty at all stages of engagement with COIL. It is critical that all faculty, whether reluctant, uncertain or curious, be encouraged to participate, and be reassured that COILing is an evolving practice. It is important to reiterate to faculty that technical savvy and pre-existing international networks are not pre-requisites to COIL well. There are no COIL experts, but simply faculty who are committed to an evolving practice around COIL as part of 
their larger commitment to the improvement of teaching and learning. The office of teaching and learning, the information technology team, and the international office would cooperate to offer wrap-around services. Faculty could be supported to contribute at virtual exchange conferences and build globally engaged networks. COIL could be used as part of or in addition to a traditional study abroad program, and several COIL/study abroad hybrids could be piloted to see if this model increases participation in study abroad. As predicted by some scholars (Rubin \& Guth, 2015), mainstreaming COIL means disruption of how global learning is conceived of and delivered at the university. COIL is a way to empower faculty engagement and leadership of internationalization, which is necessary for it gain a foothold in the academy, which has outsourced global learning since the late 1950s. This recommendation is supported in the data from this study that shows that students who did not choose COIL benefited from it. This is further echoed by scholars (Starke-Meyerring, 2010; Lee \& Cai, 2018) who have pointed out that groups most disadvantaged by globalization benefit most from COIL. This is because it is a pedagogical innovation where faculty and students collaborate to make new knowledge that can be of benefit to all.

Third, faculty should receive dedicated special training to be facilitators of global virtual teams in order for students to not only learn more effectively in teams, but to give students practice in skills they will need for $21^{\text {st }}$ century work. Faculty used COIL to prepare their students for $21^{\text {st }}$ century life. In this study, faculty described this preparation in terms of students learning how to work collaboratively and virtually in teams. While faculty implemented global and virtual teams in COIL, they felt that higher education 
was falling behind in preparing students for the iterative demands of professional life. A recommendation for practice is to ensure that COIL training workshops for faculty include best practices on how to help students work effectively in global virtual teams. Faculty would then be equipped to better teach students how to be most effective in their respective team roles. But faculty could also embed content on how to manage the life cycle of a team (Davison et al., 2017), build swift trust (Crisp \& Jarvenpaa, 2013) and improve group efficacy for problem solving (Hardin, Fuller, \& Davison, 2007). This kind of training is usually housed in extended studies programs for people who are already employed, but supporting faculty in this way benefits students.

Students will need to show evidence of greater mastery of these $21^{\text {st }}$ century skills, so a fourth recommendation is to create digital badging or micro-credentials that could be attached to a COIL course. Faculty agree that in $21^{\text {st }}$ century life, students needed to have evidence of acquired knowledge, skills and attitudes to advance to the next stage of their learning or career. Therefore, practitioners should work with departments and schools to create a digital badging or micro-credential for students who take a COIL course. This would allow them to build their resumes through one COIL course or a series of COIL courses. These badges could identify development of soft skills such intercultural communication acquisition through working in a global virtual team. They could also identify durable skills such as proficiency in digital social media platforms to complete a virtual international service learning project. Furthermore, the badges could communicate more formal content knowledge acquisition such as COIL courses connected to the UN 2030 Sustainable Development Goals. This would help 
students curate the knowledge, skills and attitudes they've learned through COIL. The micro-credentialing or badging would also support university efforts to better prepare students for professional mobility. It would make showing evidence of intercultural competence and global learning accessible to all students.

A fifth recommendation is that universities encourage and support faculty to build their COIL courses around the UN 2030 Sustainable Development Goals. Faculty were unintentionally using COIL to integrate the 2030 Sustainable Development Goals into their courses. The implication for practice is that practitioners should help faculty build a university curriculum around the SDGs through COIL. The SDGs are the most widely recognized and inclusive framework for internationalization of the curriculum in higher education worldwide. There are a number of universities around the world already tying their curriculum and their engagement to the framework (Egbelakin \& Jiang, 2020). Supporting the SDGs also addresses concerns in the literature that there are great contradictions in higher education trying to create both global citizens and global workers (Killick, 2012, 2017; Pashby \& Andreotti, 2016; Harrison, 2015). The SDGs are able to reconcile the global worker-global citizen duality because faculty will be able to teach SDG content using collaborative problem solving within global virtual teams. It also speaks to concerns that Internationalization at Home is not addressing inequality in higher education (Harrison, 2015; Krabill, 2019). Other recommendations for practitioners would be conducting an inventory of the undergraduate curriculum to see how specific courses align with the SDGs and explore how these courses could be COILed in the future. 
This could be accomplished in part through the sixth recommendation, that universities inventory their undergraduate curriculum against the SDGs to encourage faculty to implement COIL at the university. This inventory would supplement existing course clusters in the general studies or major curriculum. It would expand the framing of sustainability curriculum around majors such as environmental sciences and urban planning to the fine arts and other underrepresented disciplines in sustainability curricula.

These six implications for practice highlight the importance of practitioners to support faculty agency in making global learning accessible and demonstrable for all students at the university. Providing infrastructure for COIL and providing knowledge and skills around internationalization for faculty are the best way for practitioners to support student access and inclusion in global learning and engagement.

\section{Limitations and Future Research}

My next steps for future research are based on new questions I now have as a result of doing this study, as well as questions that the study could not answer. Of the latter, I include ideas for other researchers to take up to build up our knowledge of COIL.

A new question emerging from this study is how COIL delivers global learning vis-a-vis traditional study abroad programs. Disruptions like global pandemics and environmental disasters challenge practitioners to think about delivering new forms of global learning. Virtual exchange will be at the forefront of this exploration and I would like to study how faculty use virtual exchange as a separate but equal modality for global learning in the curriculum. Studying faculty fellows programs could shed light on how 
this discourse is evolving and what impact, if any, is being seen in departments and in curriculum committees.

I would also like to explore how COIL fellows programs may help prepare faculty to work better with international students in their local classrooms. Though this is not the intention of these programs, faculty in this study reported that they were more sensitive to the needs of their local students, including international students. Some faculty, especially in the professional schools, can see international students as difficult to teach and evaluate due to language and academic culture differences. In response, many international offices run regular workshops to help faculty better serve international students on their campuses. Unfortunately, they are usually not well attended or have the same faculty returning every time. It would be helpful to practitioners to explore whether faculty fellows programs improved faculty's orientation towards international students in the classroom as another way to approach this challenge.

Questions that this study could not answer were students' experience of COIL on their learning. Therefore, I also want to investigate COIL's impact on overall student success. A longitudinal study comparing students who took COIL courses with students who did not could inform practitioners on how COIL might affect overall academic performance and retention. It could also explore how COIL could be a student success intervention in addition to being a global learning intervention. Looking further, I would want to conduct a study exploring further how COIL most benefits students who do not self- select into a COIL course. Faculty reported this as an outcome, but we need to 
corroborate with student experience. This would be particularly salient at institutions with low study abroad participation or offering fewer high impact practices to their students.

The population of this study was limited to 16 faculty at five urban open-access institutions in the United States and Europe. The results therefore may not be representative of experiences of faculty at other types of institutions. My recommendation for other researchers would be to see how COIL as an international learning intervention is implemented at institutions with more traditional students and where study abroad participation is higher. This study was focused on open access institutions that were early adopters of COIL, so it would be important to consider that other institutions may not have the same faculty support for COIL. A recommendation for other researchers would be to look for other types of institutional support for virtual exchange at universities to see how they undergird faculty activity in this modality and pedagogy.

All of the faculty in this study had self-selected in to teaching a COIL course and were highly motivated teachers. This study does not address faculty experience of teaching COIL who did not volunteer to do so. A recommendation for other researchers would be to look at faculty communities of practice with participants who had been recruited through other avenues, such as distance learning or first year experience teaching. It would be useful also to see if reluctant faculty experienced an improvement in their teaching skills after COILing the same course over a period of time.

Further research could examine the impact of COIL on international higher education. There are a number of scholars interested in COIL's adoption and 
implementation at open access institutions in relation to study abroad participation. For universities who have already built a curriculum to the SDGs, it would be interesting to research on how COIL impacted student learning with this content. Another study could explore how COIL might interface with service learning at the university. COIL is often promoted as a way to give students global skills. Further research on students is merited to see if COIL actually helped them land a job or participate in socially engaged learning.

Such investigations would not only benefit pedagogy and curriculum but guide institutions in how to best and most equitably approach internationalization. In particular, it would deepen our understanding how faculty are leading and shaping the implementation of Internationalization at Home in higher education.

\section{Conclusion}

This study looked at faculty use of COIL for Internationalization at Home. Faculty considered COIL as mutually beneficial and reciprocal capacity building around learning and engagement for their students, themselves and their institutions. Faculty liked that COIL could offer a specific internationalization intervention for their student populations, which were mostly first-generation, underrepresented, and non-traditional. Faculty shared a concern that while most of their students would be required to work with people of other backgrounds in various settings, most would not receive preparation to do so as part of their undergraduate study experience. Therefore, providing global learning for all students, regardless of mobility, was what faculty valued most about COIL.

Faculty have been overlooked in the literature as front-line actors of internationalization of the curriculum and in employing internationalization of higher 
education as a tool of equity for underrepresented students. This study shows that faculty were mindful of the contradictions of comprehensive internationalization at their institutions, but nevertheless chose to use COIL to help prepare their students, coming from groups appearing to be most disadvantaged by the forces of globalization, to acquire knowledge, attitudes and skills that would prepare them for $21^{\text {st }}$ century life. This study highlights how institutions may decide to invest in internationalization as a pedagogy rather than a policy to be more successful in distributing its benefits more widely. This counters the narrative in the literature that initiatives around mobility are the cornerstone of such efforts. It also poses questions of how to replicate the learning of content and skills from one type of study experience and transfer them to another through virtual technology. In the age of personalized, targeted education, COIL is a vehicle for global learning that will make the academy seem relevant and responsive to the needs of employers and to the community.

Another contribution of this study to the literature is that experience of COIL supports faculty professional identity and confidence. COILing drew on faculty intellectual and intercultural attitudes of curiosity as teachers and scholars. Faculty felt that their institutions supported their interest in and desire for pedagogical innovation and experimentation through the offering of COIL fellows programs. That the COIL fellows programs were not simply about improving teaching but to build institutional international engagement, made faculty feel that their work was of added value to their institutions. This challenges the literature that describes faculty as reluctant to engage in comprehensive internationalization and internationalization of the curriculum. It also 
addresses the literature that concludes that institutions have failed to engage faculty in internationalization efforts. This study posits that institutional investment in internationalization through traditional faculty roles in the classroom, with targeted and visible support of innovation, can be successful where administrative policy has failed to gain traction in the academy. Lastly, this study invites further discussion of how faculty are taking what was often seen in the world of service learning back to the traditional classroom by COILing around the SDGs.

Faculty were committed to higher education as a tool of equity and they saw COIL as a way to advance further inclusion in global learning for their students. As faculty at open access institutions, they believed that they were duty bound to equip their students for social and professional mobility in a more complex world. For them student success included solid preparation in the knowledge, attitudes and skills for global work and citizenship. They experienced COIL as a way to exercise personal agency as well enact the missions of their institutions around global learning and equity of outcomes in higher education.

The increased need to engage in online learning due to world events has highlighted the importance of COIL. Faculty and scholar-practitioners activate their regional and international networks to offer support and share ideas of how to stay connected and to collaboratively problem solve around issues that affect the entire globe simultaneously. They support colleagues who may be new to the virtual space around teaching, creating a new forum for collaboration and sharing best practices. Faculty demonstrate how COIL can be implemented to strengthen the global human connection 
around teaching and learning. This will only add to global learning as a way to build resiliency for higher education institutions and the students they serve. 


\section{References}

Ackers, L. (2008). Internationalisation, mobility and metrics: A new form of indirect discrimination? Minerva, 4, 411-435. Retrieved from https://link.springer.com/content/pdf/10.1007\%2Fs11024-008-9110-2.pdf

Acquaye, L. A., \& Edmonds Crewe, S. (2012). International programs: Advancing human rights and social justice for African American students. Journal of Social Work Education, 48(4), 763-784. https://doi.org/10.5175/JSWE.2012.201100130

Aerden, A. (2014). A guide to assessing the quality of internationalization. The Hague, the Netherlands: European Consortium for Accreditation.

Agnew, M., \& Kahn, H. E. (2014). Internationalization-at-home: Grounded practices to promote intercultural, international, and global learning. Metropolitan Universities, 25(3), 31-46.

Agnew, M., \& Kahn, H. E. (2017). Global learning through difference: Considerations for teaching, learning, and the internationalization of higher education. Journal of Studies in International Education, 21(1), 52-64.

Allport, G. W. (1954). The nature of prejudice. Cambridge, MA: Perseus Books. Almeida, J., Robson, S., Morosini, M., \& Baranzeli, C. (2019). Understanding Internationalization at Home: Perspectives from the global north and south. European Educational Research Journal, 18(2), 200-217. https://doi.org/10.1177/1474904118807537

Altbach, P. (2013). The international imperative in higher education. Boston, MA: Sense Publishers. 
Altbach, P. G., \& De Wit, H. (2015). Internationalization and global tension. Journal of Studies in International Education, 19(1), 4-10. https://doi.org/10.1177/1028315314564734

Altbach, P. G., \& Knight, J. (2007). The Internationalization of higher education: Motivations and realities. Journal of Studies in International Education, 11(3-4), 290-305. https://doi.org/10.1177/1028315307303542

Altbach, P. G., Reisberg, L., \& Rumbley, L. E. (2010). Trends in global higher education: Tracking an academic revolution. Global perspectives on higher education: Vol. 22. Boston, MA: Sense Publishers.

American Council on Education. (2015). CIGE model for comprehensive internationalization. Retrieved from https://www.acenet.edu/newsroom/Pages/CIGE-Model-for-Comprehensive-Internationalization.aspx American Psychological Association. (2020). Publication manual of the American Psychological Association, (7 $7^{\text {th }}$ ed.). Washington, D.C.: American Psychological Association.

Anderson, L., \& Krathwohl, D. (Eds.). (2001). A taxonomy for learning, teaching and assessing: A revision of Bloom's taxonomy of educational objectives. New York, NY: Longman.

Anderson, P. (2007). 'All that glitters is not gold' — Web 2.0 and the librarian. Journal of Librarianship and Information Science, 39(4), 195-198. https://doi.org/10.1177/0961000607083210 
Andreotti, V. (2006). Soft versus critical global citizenship education. Policy and Practice: A Development Education Review, 3, 40-51.

Applegate, J. (2018, November 13). Winning the global war for talent, and beyond [blog entry]. Retrieved from https:/www.insidehighered.com/views/2018/11/13/whyinternationalization-colleges-imperative-opinion

Aspen Institute. (2019). Learn together today. Retrieved from https://www.stevensinitiative.org/

Association of American Colleges \& Universities. (2013). Ensuring quality and taking high-impact practices to scale.[updated January 2018]. Retrieved from: https://www.aacu.org/sites/default/files/files/LEAP/HIP_tables.pdf

Association of American Colleges \& Universities. (2014). Global learning VALUE rubric. Retrieved from: https://aacu.org/value/rubrics/global.

Association of American Colleges \& Universities. (2017). Intercultural knowledge and competence VALUE rubric. Retrieved from: https://aacu.org/value/rubrics/intercultural-knowledge. Association of Public and Land-Grant Universities (APLU). (2017). Pervasive internationalization: A call for renewed leadership (A report from the Association of Public \& Land-grant Universities Commission on International Initiatives). Retrieved from http://www.aplu.org/library/pervasive-internationalization-a-callfor-renewed-leadership/file 
FACULTY USE OF COIL FOR INTERNATIONALIZATION AT HOME

Association of Universities and Colleges of Canada (AUCC). (2008). Internationalizing Canadian campuses: Main themes emerging from the 2007 Scotiabank-AUCC workshop on excellence in internationalization at Canadian universities. Retrieved from http://www.aucc.ca/_pdf/english/publications/irc_e.pdf

Astin, A.W. (2016). Are you smart enough? How colleges' obsession with smartness shortchanges students. Sterling, VA: Stylus Publishing

Austin, A. (2003). Creating a bridge to the future: Preparing new faculty to face changing expectations in a shifting context. The Review of Higher Education, 26(2), 119144. Baltimore, MD: Johns Hopkins University Press.

Austin, A., \& Sorcinelli, M. (2013). The future of faculty development: Where are we going? New Directions for teaching and learning, 2013(133), 85-97.

Baehr, J. (2013). Educating for intellectual virtues. From theory to practice. Journal of Philosophy of Education, 47(2), 248-262.

Baldassar, L., \& McKenzie, L. (2016). Beyond "just being there”: Teaching Internationalization at Home in two qualitative methods units. Teaching Sociology, 44(2), 84-95. https://doi.org/10.1177/0092055X16631126

Banks, J. A. (2008). Diversity, group identity, and citizenship education in a global age. Educational Researcher, 37(3), 129-139. https://doi.org/10.3102/0013189X08317501

Barkley, E.F., Cross, K.P, \& Major, C.H. (2014). Collaborative learning techniques: A handbook for college faculty. San Francisco, CA: John Wiley \& Sons. 
Bartell, M. (2003). Internationalization of universities: A university culture-based framework. Higher Education, 45(1), 43-70. https://doi.org/10.1023/A:1021225514599

Bedenlier, S., \& Zawacki-Richter, O. (2015). Internationalization of higher education and the impacts on academic faculty members. Research in Comparative and International Education, 10(2), 185-201. https://doi.org/10.1177/1745499915571707

Beelen, J. (2011). Internationalisation at home in a global perspective: A critical survey of the 3rd Global Survey Report of IAU. Universities and Knowledge Society Journal, 8(2), 85. https://doi.org/10.7238/rusc.v8i2.1094

Beelen, J. (2013). Internationalisation at home: History and conceptual notions. Guide of Good Practices. Tempus Corinthiam Project No. 159186-2009-1-BE-SMGR. Brussels, Belgium: European Commission.

Beelen, J. (2014). The other side of mobility: The impact of incoming students on home students. In B. Streitwieser (Ed.), Internationalization of higher education and global mobility (pp. 287-299). Oxford, England: Symposium Books Ltd.

Beelen, J. (2018). Watering a hundred flowers: Institutional leadership for internationalisation at home. In J. Beelen \& J. Walenkamp (Eds.), Leading internationalization in higher education: People and policies. The Hague, the Netherlands: The Hague University of Applied Sciences. 
Beelen, J., \& Jones, E. (2015). Redefining internationalization at home. In A. Curaj, L. Matei, R. Pricopie, J. Salmi, \& P. Scott (Eds.), The European higher education area (Vol. 81, pp. 59-72). Cham, Germany: Springer International Publishing. https://doi.org/10.1007/978-3-319-20877-0_5

Belz, J. A. (2002). Social dimensions of telecollaborative foreign language study. Language Learning \& Technology, 6(1), 60-81.

Blackmore, P., \& Kandiko, C.B. (2011). Motivation in academic life: A prestige economy. Research in Post-Compulsory Education, 16(4), 399-411.

Bloom, B. S., Engelhart, M. D., Furst, E. J., Hill, W. H., \& Krathwohl, D. R. (1956). Taxonomy of educational objectives: The classification of educational goals. Handbook I: Cognitive domain. New York, NY: David McKay Company.

Bondi, L., \& Matthews, M. H. (2017). Education and society: Studies in the politics, sociology and geography of education. London, UK: Routledge.

Brandenburg, U., \& De Wit, H. (2015). The end of internationalization. International Higher Education. Advance online publication. https://doi.org/10.6017/ihe.2011.62.8533

Braun, V., \& Clarke, V. (2006). Using thematic analysis in psychology. Qualitative Research in Psychology, 3(2), 77-101.

Brewer, P. E. (2015). International virtual teams: Engineering global success. IEEE PCS Professional Engineering Communication Series. Hoboken, NJ: IEEE Press; Wiley. 
Bruhn, E. (2017). Towards a framework for virtual internationalization. International Journal of E-Learning \& Distance Education, 32(1), 1-9.

Buckner, E., \& Stein, S. (2019). What counts as internationalization? Deconstructing the Internationalization Imperative. Journal of Studies in International Education, 1(1), 1-16. https://doi.org/10.1177/1028315319829878

Camblin, L.D., \& Steger, J.A. (2000). Rethinking faculty development. Higher Education, 39(1), 1-18.

Cantwell, B. (2015). Are international students cash cows? Examining the relationship between new international undergraduate enrollments and institutional revenue at public colleges and universities in the US. Journal of International Students, 5(4), $512-525$.

Childress, L. K. (2010). The twenty-first century university: Developing faculty engagement in internationalization (Vol. 32). Bern, Switzerland: Peter Lang.

Childress, Lisa K. (2009). Planning for internationalization by investing in faculty (Report). Journal of International and Global Studies, 1(1), 30-49.

Churches, A. (2008). Bloom's digital taxonomy. Retrieved from http://www.ccconline.org/wpcontent/uploads/2013/11/Churches_2008_DigitalBloomsTaxonomyGuide.pdf

Cogburn, D. L., \& Levinson, N. S. (2008). Teaching globalization, globally: A 7-year case study of South Africa-U.S. virtual teams. Information Technologies and International Development, 4(3), 75-88. https://doi.org/10.1162/itid.2008.00018 
Cole, J.B. (1991). Black students and overseas programs: Broadening the base of participation. Introduction to the papers and speeches presented at the CIEE. Retrieved from ERIC database. (ED340323).

Creswell, J. W., \& Creswell, J. D. (2018). Research design: Qualitative, quantitative, and mixed methods approaches (5th ed.). Thousand Oaks, CA: SAGE.

Crisp, C. B., \& Jarvenpaa, S. L. (2013). Swift trust in global virtual teams: Trusting beliefs and normative actions. Journal of Personnel Psychology, 12(1), 45.

Cronin, C., Cochrane, T., \& Gordon, A. (2016). Nurturing global collaboration and networked learning in higher education. Research in Learning Technology, 24(1), 26497. https://doi.org/10.3402/rlt.v24.26497

Crotty, M. (1998). The foundations of social research. London, England: SAGE.

Crowther, P., Joris, M., Otten, M. Nilsson, B., Teekens, H., \& Wächter, B. (2001). Internationalisation at home: A position paper. Amsterdam, the Netherlands: EAIE.

Custer, L., \& Tuominen, A. (2017). Bringing 'internationalization at home' opportunities to community colleges: Design and assessment of an online exchange activity between US and Japanese students. Teaching Sociology, 45(4), 347-357.

Davison, R. M., Panteli, N., Hardin, A. M., \& Fuller, M. A. (2017). Establishing effective global virtual student teams. IEEE Transactions on Professional Communication, 60(3), 317-329. https://doi.org/10.1109/TPC.2017.2702038 
De Castro, A. B., Dyba, N., Cortez, E. D., \& Pe Benito, G. G. (2018). Collaborative online international learning to prepare students for multicultural work environments. Nurse Educator. Advance online publication. https://doi.org/10.1097/NNE.0000000000000609

De la Garza, A. (2019). Internationalizing the curriculum for STEAM (STEM + Arts and Humanities): From intercultural competence to cultural humility. Journal of Studies in International Education, 1-13. Retrieved from: https://doi.org/10.1177/1028315319888468

De Vita, C. (2007) Taking stock: An appraisal of the literature on internationalising HE learning. In E. Jones \& S. Brown (Eds.), Internationalising higher education (pp. 154-167). London, England: Routledge.

De Wit, H. (1999). Changing rationales for the internationalization of higher education. International Higher Education 15. Retrieved from https://www.researchgate.net/profile/Hans_De_Wit/publication/313407781_Chan ging_Rationales_for_the_Internationalization_of_Higher_Education/links/58b6d4 2245851591c5d52baa/Changing-Rationales-for-the-Internationalization-ofHigher-Education.pdf

De Wit, H. (2011). Globalisation and internationalisation of higher education. Internationalisation of universities in the network society, 8(2), 241247. Retrieved from http://rusc.uoc.edu/rusc/ca/index.php/rusc/article/download/v8n2-globalizacion-einternacionalizacion-de-la-educacion-superior/1247-2214-2-PB.pdf 
De Wit, H. (2013). An introduction to higher education internationalisation. Milan, Italy: Vita e Pensiero.

De Wit, H., \& Jones, E. (2018). Inclusive internationalization: Improving access and equity. International Higher Education, 94, 16-18. Retrieved from https://doi.org/10.6017/ihe.2018.0.10561

Deardorff, D. (2009). The SAGE handbook of intercultural competence. Thousand Oaks, CA: SAGE.

Deardorff, D. (2011). Assessing intercultural competence. New directions for institutional research, 2011(149), 65.

Deardorff, D. K., \& Jones, E. (2012). Intercultural competence: An emerging focus in international higher education. In The SAGE handbook of international higher education (pp. 283-304). Thousand Oaks, CA: SAGE. https://doi.org/10.4135/9781452218397.n16

Dedoose. (2019). What is Dedoose? Retrieved from https://www.dedoose.com/

Department of Education. (2012). Succeeding globally through international education and engagement, U.S. Department of Education international strategy 20122016. Retrieved from https://www2.ed.gov/about/inits/ed/internationaled/international-strategy-201216.pdf

Dewey, P., \& Duff, S. (2009). Reason before passion: Faculty views on internationalization in higher education. Higher education, 58(4), 491-504. 
Dorner, H. (2018). Exploring students' conceptions of internationalised learning: Experiences from international online collaborative seminars. Innovations in Education and Teaching International, 55(3), 304-313. https://doi.org/10.1080/14703297.2016.1210530

Doscher, S. \& Rubin, J. (2019, March). What do we mean by impact? Presentation at the COIL Leadership Institute, Florida International University, Miami, Florida.

Dubé, L., \& Paré, G. (2001). Global virtual teams. Communications of the ACM, 44(12), $71-73$.

EAIE. (2015). Internationalisation at home. Retrieved from https://www.eaie.org/ourresources/library/publication/Forum-Magazine/2015-winter-forum.html

Edwards, J., \& Teekens, H. (2012). Leveraging technology and the international classroom for cross-cultural learning. In The SAGE handbook of international higher education (pp. 267-282). Thousand Oaks, CA: SAGE. https://doi.org/10.4135/9781452218397.n15

Egron-Polak, E., \& Hudson, R. (2014). Internationalization of higher education: Growing expectations, essential values. IAU 4rd Global Survey Report. Paris, France: International Association of Universities.

Egron-Polak, E., \& Marmolejo, F. (2017). School internationalization and its implications for higher education. In H. De Wit, J. Gacel-Avila, E. Jones, \& N. Jooste (Eds.), The globalization of internationalization: Emerging voices and perspectives. New York, NY: Routledge Taylor \& Francis Group. 
Egbelakin, T., \& Jiang, B. (2020, February). How to implement the U.N.'s sustainable development goals (SDGs) in higher education—examples and recommendations. Workshop presented at the Association of International Education Administrators (AIEA), Washington, D.C.

European Commission. (2013, 11 July). European higher education in the world. Brussels, Belgium: European Commission.

European Union. (2014). The Erasmus impact study. Effects of mobility on the skills and employability of students and the internationalization of higher education institutions. Brussels, Belgium: European Union.

European Union. (2019). Erasmus and virtual exchange: 2018 impact report. Luxembourg: Publication Office of the European Union. Retrieved from: https://op.europa.eu/en/publication-detail/-/publication/a6996e63-a9d2-11e99d01-01aa75ed71a1

Gardner, B., \& Krabill, R. (2017, July 5). Against the romance of study abroad. Africa is a Country. Retrieved from https://africasacountry.com/2017/07/against-theromance-of-study-abroad.

Farrugia, C., \& Sanger, J. (2017) Gaining an employment edge: The impact of study abroad on $21^{\text {st }}$ century skills and career prospects in the United States. Retrieved from https://educationabroad.wvu.edu/files/d/fbd30891-5f37-4309-a9b99bde74bd52bf/gaining-an-employment-edge-the-impact-of-study-abroad.pdf

Feldman, K.A., \& Paulsen, M.B. (1999). Faculty motivation: The role of a supportive teaching culture. New Directions for Teaching and Learning, 1999(78), 69-78. 
Ferrazzi, K. (2014, December). Managing yourself: Getting virtual teams right. Harvard Business Review, 92(12), 120-123.

Fischer, K. (2019, March 28). How international education's golden age lost its sheen. The Chronicle of Higher Education. Retrieved from https://www.chronicle.com/interactives/2019-03-28-golden-age

Foronda, C., Baptiste, D.L., Reinholdt, M.M., \& Ousman, K. (2016). Cultural humility: A concept analysis. Journal of Transcultural Nursing, 27(3), 210-217.

Frehywot, S., Vovides, Y., Talib, Z., Mikhail, N., Ross, H., Wohltjen, H., Scott, J. (2013). E-learning in medical education in resource constrained low- and middleincome countries. Human Resources for Health, 11, 4. https://doi.org/10.1186/1478-4491-11-4

Friesen, R. (2013). Faculty member engagement in Canadian university internationalization. Journal of Studies in International Education, 17(3), 209227. https://doi.org/10.1177/1028315312451132

Garrison, D. R. (2011). E-learning in the 21st century: A framework for research and practice (2nd ed.). London: Routledge.

Garrison, D. R., \& Cleveland-Innes, M. (2005). Facilitating cognitive presence in online learning: Interaction is not enough. The American Journal of Distance Education, 19(3), 133-148. 
Gibson, C. B., Huang, L., Kirkman, B. L., \& Shapiro, D. L. (2014). Where global and virtual meet: The value of examining the intersection of these elements in twentyfirst-century teams. Annual Review of Organizational Psychology and Organizational Behavior, 1(1), 217-244. https://doi.org/10.1146/annurevorgpsych-031413-091240

Gillespie, S. H. (2002). The practice of international education in the context of globalization: A critique. Journal of Studies in International Education, 6(3), 262-267. Retrieved from https://doi.org/10.1177/102831530263006

Gilson, L. L., Maynard, M. T., Jones Young, N. C., Vartiainen, M., \& Hakonen, M. (2015). Virtual teams research. Journal of Management, 41(5), 1313-1337. https://doi.org/10.1177/0149206314559946

Gonzalez-Perez, M. A., Velez-Calle, A., Cathro, V., Caprar, D. V., \& Taras, V. (2014). Virtual teams and international business teaching and learning: The case of the Global Enterprise Experience (GEE). Journal of Teaching in International Business, 25(3), 200-213.

Gopal, A. (2011). Internationalization of higher education: Preparing faculty to teach cross-culturally. International Journal of Teaching and Learning in Higher Education, 23(3), 373-381.

Green, M. F. (2012). Measuring and assessing internationalization. NAFSA: Association of International Educators, 1, 1-26. 
Green, M. F., Marmolejo, F., \& Egron-Polak, E. (2012). The internationalization of higher education: Future prospects. In D. Deardorff \& H. De Wit (Eds.), The SAGE handbook of international higher education (pp. 439-456). Thousand Oaks, CA: SAGE. https://doi.org/10.4135/9781452218397.n24

Guetterman, T. C. (2015). Forum qualitative sozialforschung/forum: Qualitative social research. Retrieved from http://www.qualitativeresearch.net/index.php/fqs/article/view/2290/3826

Guth, S., \& Helm, F. (Eds.). (2010). Telecollaboration 2.0: Language, literacies and intercultural learning in the 21st century (Vol. 1). Bern, Switzerland: Peter Lang.

Hamir, H. B., \& Gozik, N. (2018). Promoting inclusion in education abroad: A handbook of research and practice. Sterling, VA: Stylus.

Hammarberg, K., Kirkman, M., \& De Lacey, S. (2016). Qualitative research methods: When to use them and how to judge them. Human Reproduction, 31(3), 498-501.

Hardin, A. M., Fuller, M. A., \& Davison, R. M. (2007). I know I can, but can we? Cultural and efficacy beliefs in global virtual teams. Small Group Research, 38(1), 130-155. https://doi.org/10.1177/1046496406297041

Harrison, N. (2015). Practice, problems and power in 'internationalisation at home': Critical reflections on recent research evidence. Teaching in Higher Education, 20(4), 412-430. https://doi.org/10.1080/13562517.2015.1022147 
Harvey, G. \& Kitson, A. (2016). PARIHS revisited: From heuristic to integrated framework for the successful implementation of knowledge into practice. Implementation Science (11)33, p. 1-13. Retrieved from https://implementationscience.biomedcentral.com/articles/10.1186/s13012-0160398-2

Harvey, L. (2015). Beyond member-checking: A dialogic approach to the research interview. International Journal of Research \& Method in Education, 38(1), 23 38.

Haug, E., \& UAS, A. (2017). Examples and outcomes for embedding Collaborative Online International Learning (COIL) in the curriculum. In Conference Proceedings. The Future of Education (p. 253). Libreriauniversitaria. It. Edizioni.

Helm, F. (2015). The practices and challenges of telecollaboration in higher education in Europe. Language Learning \& Technology, 19(2), 197-217.

Helm, F., \& Guth, S. (2010). The multifarious goals of telecollaboration 2.0: Theoretical and practical implications. Telecollaboration, 2, 69-106.

Herschbein, B. (2016, February 19). A college degree is worth less is you are raised poor. Brookings Institution. Retrieved from: https://www.brookings.edu/blog/socialmobility-memos/2016/02/19/a-college-degree-is-worth-less-if-you-are-raisedpoor/

Hook, J.N., Davis, D.E., Owen, J., Worthington Jr., E.L., \& Utsey, S.O. (2013). Cultural humility: Measuring openness to culturally diverse clients. Journal of Counseling Psychology, 60(3), 353-366. 
Hu, H. (2015). Building virtual teams: Experiential learning using emerging technologies. E-Learning and Digital Media, 12(1), 17-33. https://doi.org/10.1177/2042753014558373

Hudzik, J. K. (2011). Comprehensive internationalization: From concept to action. NAFSA. Retrieved from http://www.nafsa.org/_/File/_/downloads/cizn_concept_action.pdf

Hudzik, J. K. (2014). Comprehensive internationalization: Institutional pathways to success. London, England: Routledge.

Institute of International Education. (2018). Open doors report on international educational exchange. Retrieved from http://www.iie.org/opendoors Ippolito, K. (2007). Promoting intercultural learning in a multicultural university: Ideals and realities. Teaching in Higher Education, 12(5-6), 749-763.

Jarrett, J. (2013). Bigfoot, goldilocks, and moonshots: A report from the frontiers of personalized learning. Educause Review, 48(2), 31-40.

Jarvenpaa, S. L., \& Leidner, D. E. (1999). Communication and trust in global virtual teams. Organization Science, 10(6), 791-815.

Jon, J. E. (2013). Realizing internationalization at home in Korean higher education: Promoting domestic students' interaction with international students and intercultural competence. Journal of Studies in International Education, 17(4), $455-470$. 
Jones, E. (2013). Internationalization and employability: The role of intercultural experiences in the development of transferable skills. Public Money \& Management, 33(2), 95-104. https://doi.org/10.1080/09540962.2013.763416

Jones, E., \& De Wit, H. (2012). Globalization of internationalization: Thematic and regional reflections on a traditional concept. AUDEM: The International Journal of Higher Education and Democracy, 3(1), 35-54.

Jones, E., \& Killick, D. (2013). Graduate attributes and the internationalized curriculum. Journal of Studies in International Education, 17(2), 165-182. https://doi.org/10.1177/1028315312473655

Jones, E., \& Reiffenrath, T. (2018, August 21). Internationalisation at home in practice [Blog entry]. Curriculum \& Teaching. Retrieved from https://www.eaie.org/blog/internationalisation-at-home-practice.html.

Keyuravong, S. (2015). The implementation of an online collaborative project: Lessons learned from failure. In P. Darasawang, \& H. Reinders (Eds.), Innovation in Language Learning and Teaching (pp.63-75). London, UK: Palgrave Macmillan.

Killick, D. (2012). Seeing-ourselves-in-the-world: Developing global citizenship through international mobility and campus community. Journal of Studies in International Education, 16(4), 372-389.

Killick, D. (2017). Internationalization and diversity in higher education: Implications for teaching, learning and assessment (Palgrave teaching and learning). London, England: Palgrave. 
Killick, D. (2018). Developing intercultural practice: Academic development in a multicultural and globalizing world. London, England: Routledge.

Kinzie, J. \& Helms, R. (2019, January). Mapping and NSSE: Relating institutional internationalization efforts and student global learning. Presentation at the Association of International Education Administrators, San Francisco, CA.

Kinzie, J., Helms, R. M., \& Cole, J. (2017). A glimpse of global learning: Assessing student experiences and institutional commitments. Liberal Education, 103(2), $30-37$.

Knight, J. (1994). Internationalization: Elements and checkpoints. CBIE Research No. 7. Canadian Bureau for International Education (CBIE)/Bureau canadien de l'éducation internationale (BCEI). Ottawa, ON: CBIE.

Knight, J. (1997). A shared vision? Stakeholders' perspectives on the internationalization of higher education in Canada. Journal of Studies in International Education, 1(1), 27-44. https://doi.org/10.1177/102831539700100105

Knight, J. (2003). Updated definition of internationalization. International Higher Education, 33, 2-3.

Knight, J. (2004). Internationalization remodeled: Definition, approaches, and rationales. Journal of Studies in International Education, 8(1), 5-31. https://doi.org/10.1177/1028315303260832 
Knight, J. (2007). Internationalization: Concepts, complexities and challenges. In J. J. F. Forest \& P. G. Altbach (Eds.), International handbook of higher education: Vol.18, (pp. 207-227). Dordrecht, the Netherlands: Springer. Retrieved from https://doi.org/10.1007/978-1-4020-4012-2_11

Knight, J. (2008). Higher education in turmoil: The changing world of internationalization. Global perspectives on higher education: Vol. 13. Rotterdam, the Netherlands: Sense Publishers.

Knight, J. (2011). Five myths about internationalization. International higher education, (62), 14-15.

Knight, J. (2012). Concepts, rationales, and interpretive frameworks in the internationalization of higher education. In The SAGE handbook of international higher education (pp. 27-42). Thousand Oaks, CA: SAGE. https://doi.org/10.4135/9781452218397.n2

Krabill, R. (2019, October). Flipping the script: A critique of discourses surrounding COIL vis a vis study abroad. Presentation at the International Virtual Exchange Conference, University of Washington, Bothell, WA.

Kowalska, A. (2016, November 9). Internationalisation at home: A sustainable alternative [Blog entry]. Curriculum \& Teaching. Retrieved from https://www.eaie.org/blog/internationalisation-home-a-sustainablealternative.html. 
Kuh, G., Schneider, C., \& Association of American Colleges \& Universities. (2008). High-impact educational practices: What they are, who has access to them, and why they matter. Washington, DC: Association of American Colleges and Universities.

Labi, A. (2011, April 26). Faculty-inspired team-teaching makes internationalization affordable. The Chronicle of Higher Education. Retrieved from https://www.chronicle.com/article/Faculty-Inspired-Team-Teaching/127266

Landorf, H., Doscher, S., Hardrick, J., \& Musil, C. M. (2018). Making global learning universal: Promoting inclusion and success for all students (1st ed.). Sterling, VA: Stylus Publishing.

Leask, B. (2015). Internationalizing the curriculum. London, England: Routledge Taylor \& Francis Group.

Leask, B., Beelen, J. Kaunda, L. (2013). Internationalisation of the curriculum: International approaches and perspectives. In H. De Wit, F. Hunter, L. Johnson, \& H. VanLiempd (Eds.), Possible futures (pp.187-205). Amsterdam, the Netherlands: European Association for International Education.

Lee, B. K., \& Cai, H. (2018). Evaluation of an online "Internationalization at Home" course on the social contexts of addiction. Journal of Studies in International Education, 21(2), 365-388. https://doi.org/10.1177/1028315318797155

Lemke-Westcott, T., \& Johnson, B. (2013). When culture and learning styles matter: A Canadian university with Middle-Eastern students. Journal of Research in International Education, 12(1), 66-84. 
Leung, L. (2015). Validity, reliability, and generalizability in qualitative research. Journal of Family Medicine and Primary Care, 4(3), 324-327. https://doi.org/10.4103/2249-4863.161306

Lipnack, J., \& Stamps, J. (1999). Virtual teams: The new way to work. Strategy \& Leadership, 27(1), 14-19. https://doi.org/10.1108/eb054625

Magnier-Watanabe, R., Watanabe, Y., Aba, O., \& Herrig, H. (2017). Global virtual teams' education: Experiential learning in the classroom. On the Horizon, 25(4), 267-285. https://doi.org/10.1108/OTH-02-2017-0007

Mak, A. S., \& Barker, M. C. (2013). Internationalisation at home: Enhancing the intercultural capabilities of business and health teachers, students and curricula. Sydney, Australia: Australian Government Office for Learning and Teaching. Retrieved from https://www.researchgate.net/profile/Anita_Mak/publication/265729570_Internati onalisation_at_home_Enhancing_the_intercultural_capabilities_of_business_and_ health_teachers_students_and_curricula/links/541a71fb0cf2218008bfb6d7.pdf

Mak, A. S., \& Kennedy, M. (2012). Internationalising the student experience: Preparing instructors to embed intercultural skills in the curriculum. Innovative Higher Education, 37(4), 323-334.

Marcillo-Gomez, M., \& Desilus, B. (2016). Collaborative online international learning experience in practice opportunities and challenges. Journal of Technology Management \& Innovation, 11(1), 30-35. https://doi.org/10.4067/S071827242016000100005 
Maringe, F. (2010). The meanings of globalization and internationalization in HE: Findings from a world survey. In F. Maringe \& N. Foskett (Eds.), Globalization and Internationalization in Higher Education: Theoretical, Strategic and Management Perspectives (pp. 17-34). New York, NY: Bloomsbury.

Marmolejo, F., \& Egron-Polak, E. (2017). Higher education internationalization: Adjusting to new landscape. In H. De Wit, J. Gocel-Avila, E. Jones \& N. Jooste (Eds.), The globalization of internationalization: Emerging voices and perspectives (pp. 7-17). London, England: Routledge. Retrieved from https://content.taylorfrancis.com/books/download?dac=C2015-0-59084$5 \&$ isbn=9781317328377\&doi $=10.4324 / 9781315657547-11 \&$ format $=$ pdf

Mason, M. (2010). Sample size and saturation in $\mathrm{PhD}$ studies using qualitative interviews [63 paragraphs]. Forum Qualitative Sozialforschung/Forum: Qualitative Social Research, 11(3), Art. 8. Retrieved from: http://dx.doi.org/10.17169/fqs-11.3.1428 Maxwell, J. A. (2013). Qualitative research design: An interactive approach (3rd ed.). Applied social research methods series: Vol. 41. Thousand Oaks, CA: SAGE.

Maznevski, M. L., \& Chudoba, K. M. (2000). Bridging space over time: Global virtual team dynamics and effectiveness. Organization Science, 11(5), 473-492. https://doi.org/10.1287/orsc.11.5.473.15200

McCarthy, G. (2012, July). Virtual teams and blended learning. Paper presented at the $4^{\text {th }}$ International Conference on Education and New Learning Technologies, Barcelona, Spain. Retrieved from https://library.iated.org/publications/EDULEARN12. 
FACULTY USE OF COIL FOR INTERNATIONALIZATION AT HOME

McMurtrie, B. (2011, November 14). International enrollments at U.S. colleges grow but still rely on China. The Chronicle of Higher Education. Retrieved from https://www.chronicle.com/article/International-Enrollments-at/129747

Merriam, S. (1998). Qualitative research and case study applications in education. San Francisco: Jossey-Bass Publishers.

Merriam, S., \& Bierema, L. (2013). Adult learning: Linking theory and practice. San Francisco, CA: John Wiley \& Sons.

Merriam, S. B., \& Tisdell, E. J. (2016). Qualitative research: A guide to design and implementation (4 ${ }^{\text {th }}$ ed.). San Francisco, CA: Jossey-Bass.

Mestenhauser, J. A. (1998). Portraits of an international curriculum: An uncommon multidimensional perspective. In J. A. Mestenhauser \& B. J. Ellingboe (Eds.). Reforming the higher education curriculum (pp. 3-39). Phoenix, AZ: Oryx Press.

Mestenhauser, J. A. (2006). Internationalization at Home: Systems challenge to a fragmented field. In H. Teekens (Ed.), Internationalization at Home: A global perspective (pp. 67-77). The Hague, the Netherlands: Netherlands Organization for International Cooperation in Higher Education.

Miles, M. B., Huberman, A. M., \& Saldaña, J. (2014). Qualitative data analysis: A methods sourcebook ( $3^{\text {rd }}$ ed.). Thousand Oaks, CA: SAGE.

Mills, C. (1959). The sociological imagination. New York, NY: Oxford University Press. Moore, A. S., \& Simon, S. (Eds.). (2015). Globally networked teaching in the humanities: Theories and practices. Routledge research in higher education: Vol. 11. New York, NY: Routledge, Taylor \& Francis Group. 
Morey, A. I. (2004). Globalization and the emergence of for-profit higher education. Higher education, 48, 1, 131-150.

Morse, J. M., \& Field, P. A. (1995). Qualitative research methods for health professionals (2nd ed.). Thousand Oaks, CA: SAGE.

Murphy, V. (2014). Page to stage: The craft of adaptation. Ann Arbor, MI: University of Michigan Press.

Murray-Garcia, J., \& Tervalon, M. (2017). Rethinking intercultural competence: Cultural humility in internationalising higher education. In D.K. Deardorff \& L.A. Aaarasaratnam-Smith (Eds.). Intercultural Competence in Higher Education (pp.19-31). London, UK: Routledge.

Murugesan, S. (2007). Understanding Web 2.0. IT Professional Magazine, 9(4), 34.

NAFSA (2017). Trends in U.S. study abroad. Retrieved from https://www.nafsa.org/Policy_and_Advocacy/Policy_Resources/Policy_Trends_a nd_Data/Trends_in_U_S_Study_Abroad/

National Survey of Student Engagement (2017). NSSE 2017 topical modules U.S. summary: Frequencies by class and sex: Global learning. Retrieved from http://nsse.indiana.edu/2017_institutional_report/pdf/Modules/NSSE17\%20Modu le\%20Summary-Global\%20Learning.pdf

New London Group. (2000). Multiliteracies: Literacy learning and the design of social futures. New York, NY: Routledge. 
Niehaus, E., \& Williams, L. (2016). Faculty transformation in curriculum transformation: The role of faculty development in campus internationalization. Innovative Higher Education, 41(1), 59-74. https://doi.org/10.1007/s10755-015-9334-7

Nilsson, B. (2003). Internationalisation at home from a Swedish perspective: The case of Malmö. Journal of Studies in International Education, 7(1), 27-40. https://doi.org/10.1177/1028315302250178

Nomikoudis, M., \& Starr, M. (2016). Cultural humility in education and work: A valuable approach for teachers, learners and professionals. In J. Arvanitakis \& D. Hornsby (Eds.), Universities, the citizen Scholar and the future of higher education (pp. 69-85). London, UK: Palgrave Macmillan.

Nyangau, J.Z. (2020). Faculty engagement in internationalization: The role of personal agency beliefs. International Journal of Research in Education and Science, 6(1), 74-85.

O’Dowd, R. (2007). Online intercultural exchange: An introduction for foreign language teachers. Languages for intercultural communication and education, Vol. 15. Tonawanda, NY: Multilingual Matters.

O'Dowd, R. (2018). From telecollaboration to virtual exchange: State-of-the-art and the role of UNICollaboration in moving forward. Journal of Virtual Exchange, 1(1), 1-23. https://doi.org/10.14705/rpnet.2018.jve.1

O’Dowd, R., \& Lewis, T. (Eds.). (2016). Online intercultural exchange: Policy, pedagogy, practice. New York, NY: Routledge. 
O'Reilly, T. (2005). What is Web 2.0: Design patterns and business models for the next generation of software. Retrieved from http://www.oreillynet.com/pub/a/oreilly/tim/news/2005/09/30/what-is-web20.html

O'Rourke, B. (2007). Models of telecollaboration (1): eTandem. In R. O'Dowd (Ed.), Online intercultural exchange: An introduction for foreign language teachers. Languages for intercultural communication and education, Vol. 15. Tonawanda, NY: Multilingual Matters.

OECD. (1996). Internationalizing the curriculum in higher education. Paris, France: Organisation for Economic Co-operation and Development.

OED (2019). Oxford English dictionary. Oxford, England: Oxford University Press. Retrieved from https://www.oed.com/

Olson, C., \& Peacock, J. (2012). Globalism and interculturalism: Where global and local meet. In D. Deardorff \& H. De Wit (Eds.), The SAGE handbook of international higher education (pp. 305-322). Thousand Oaks, CA: SAGE. https://doi.org/10.4135/9781452218397.n17

Paige, R. M., \& Mestenhauser, J. A. (1999). Internationalizing educational administration. Educational Administration Quarterly, 35(4), 500-517. https://doi.org/10.1177/0013161X99354005

Paige, R. M., Fry, G. W., Stallman, E. M., Josić, J., \& Jon, J. (2009). Study abroad for global engagement: the long-term impact of mobility experiences. Intercultural Education, 20(1), S29-S44. https://doi.org/10.1080/14675980903370847 
Palinkas, L. A., Horwitz, S. M., Green, C. A., Wisdom, J. P., Duan, N., \& Hoagwood, K. (2015). Purposeful sampling for qualitative data collection and analysis in mixed method implementation research. Administration and Policy in Mental Health and Mental Health Services Research, 42(5), 533-544.

Panteli, N., \& Tucker, R. (2009). Power and trust in global virtual teams. Communications of the ACM, 52(12), 113-115.

Pashby, K., \& de Oliveira Andreotti, V. (2016). Ethical internationalisation in higher education: Interfaces with international development and sustainability. Environmental Education Research, 22(6), 771-787. https://doi.org/10.1080/13504622.2016.1201789

Patterson, L. M., Carrillo, P. B., \& Salinas, R. S. (2012). Lessons from a global learning virtual classroom. Journal of Studies in International Education, 16(2), 182-197. https://doi.org/10.1177/1028315311398665

Patton, M. Q. (1990). Qualitative evaluation and research methods. Thousand Oaks, CA: SAGE

Patton, M. Q. (2014). Qualitative research and evaluation methods: Integrating theory and practice. Thousand Oaks, CA: SAGE.

Pettigrew, T. F., \& Tropp, L. R. (2006). A meta-analytic test of intergroup contact theory. Journal of personality and social psychology, 90(5), 751.

Ping, C. J. (1999). An expanded international role for student affairs. New Directions for Student Services, (86), 13-21. 
Pink, D.H. (2009). Drive: The surprising truth about what motivates us. New York, NY: Riverhead Books.

Prasad, A., DeRosa, D., \& Beyerlein, M. (2017). Dispersion beyond miles: Configuration and performance in virtual teams. Team Performance Management: An International Journal, 23(3), 186-204.

Qu, S., \& Dumay, J. (2011). The qualitative research interview. Qualitative Research in Accounting \& Management, 8(3), 238-264. https://doi.org/10.1108/11766091111162070

Rabionet, S. (2011). How I learned to design and conduct semi-structured interviews: An ongoing and continuous journey. Qualitative Report, 16(2), 563-566.

Richey, R. C., Silber, K. H., \& Ely, D. P. (2008). Reflections on the 2008 AECT Definitions of the Field. TechTrends, 52(1), 24-25.

Ritchhart, R., Church, M. \& Morrison, K. (2011). Making thinking visible. San Francisco, CA: Jossey-Bass.

Rizvi, F. (2007). Internationalization of curriculum: A critical perspective. In M. Hayden, J. Levy, \& J. Thompson (Eds.), The SAGE handbook of research in international education(pp. 390-403). London, England: SAGE.

Robson, S. (2011). Internationalization: A transformative agenda for higher education? Teachers and Teaching, 17(6), 619-630. https://doi.org/10.1080/13540602.2011.625116

Robson, S., Almeida, J., \& Schartner, A. (2018). Internationalization at home: time for review and development? European Journal of Higher Education, 8(1), 19-35. 
Robson, C., \& McCartan, K. (2016). Real world research. Chichester, UK: John Wiley \& Sons.

Rubin, J. (2016). The collaborative online international learning network. In. R. O’Dowd \& T. Lewis (Eds.), Online intercultural exchange: Policy, pedagogy, practice (pp. 263-272). New York, NY: Routledge.

Rubin, J. (2017). Embedding collaborative online international learning (COIL) at higher education institutions: An evolutionary overview with exemplars. Internationalisation of Higher Education, 2, 27-44. Retrieved from www.handbook-internationalisation.com

Rubin, J., \& Guth, S. (2015). Collaborative online international learning: An emerging format for internationalizing curricula. In A. S. Moore \& S. Simon (Eds.), Globally networked teaching in the humanities: Theories and practices (pp. 1527). New York, NY: Routledge.

Rumbley, L. E., Altbach, P. G., \& Reisberg, L. (2012). Internationalization within the higher education context. In D. Deardorff \& H. De Wit (Eds.), The SAGE handbook of international higher education (pp. 3-26). Thousand Oaks, CA: SAGE. https://doi.org/10.4135/9781452218397.n1

Sachs, J. (2015). Achieving the Sustainable Development Goals. Journal of Business Ethics 8(2), pp. 53-62.

Sandelowski, M. (2000). Whatever happened to qualitative description?. Research in Nursing \& Health, 23(4), 334-340. 
Schnickel, J. (2019, March). Virtual internationalization: What and why [newsletter]. Faculty of Letters, Jissen Women's University, Osaka, Japan. Retrieved from https://jissen.repo.nii.ac.jp/?action=pages_view_main\&active_action=repository_ view_main_item_detail\&item_id=2067\&item_no=1\&page_id=13\&block_id=30

Schuerholz-Lehr, S. Caws, C., Van Gyn, G. \& Preece, A. (2007). Internationalizing the higher education curriculum: An emerging model for transforming faculty perspectives. Canadian Journal of Higher Education, 37(1), 67-94.

Seidman, I. (2013). Interviewing as qualitative research: A guide for researchers in education and the social sciences. New York, NY: Teachers College Press.

Sennett, R. (2003). Respect in a world of inequality. New York, NY: WW Norton \& Company.

Shea, T. P., Sherer, P. D., Quilling, R. D., \& Blewett, C. N. (2011). Managing global virtual teams across classrooms, students and faculty. Journal of Teaching in International Business, 22(4), 300-313. https://doi.org/10.1080/08975930.2011.653911

Simcock, B. (1989, January). United States-Japanese trade negotiations. Lecture presented at Purdue University, West Lafayette, IN.

Skagen, D., McCollum, B., Morsch, L., \& Shokoples, B. (2018). Developing communication confidence and professional identity in chemistry through international online collaborative learning. Chemistry Education Research and Practice, 19(2), 567-582. https://doi.org/10.1039/C7RP00220C 
So, H. J., \& Kim, B. (2009). Learning about problem based learning: Student teachers integrating technology, pedagogy and content knowledge. Australasian Journal of Educational Technology, 25(1), 101-116.

Soliya (2019, May 8). Soliya receives grant from the Stevens Initiative to connect students in the US, Middle East, and North Africa through virtual exchange. Retrieved from https://www.soliya.net/news/soliya-receives-grant-stevensinitiative-connect-students-us-middle-east-and-north-africa

Soria, K. M., \& Troisi, J. (2014). Internationalization at Home alternatives to study abroad. Journal of Studies in International Education, 18(3), 261-280. https://doi.org/10.1177/1028315313496572

Standley, H. J. (2015). International mobility placements enable students and staff in Higher Education to enhance transversal and employability-related skills. FEMS Microbiology Letters, 362(19). https://doi.org/10.1093/femsle/fnv157

Starke-Meyerring, D. (2010). Globally networked learning environments: Reshaping the intersections of globalization and e-learning in higher education. E-Learning and Digital Media, 5(4), 127-132. https://doi.org/10.2304/elea.2008.5.4.418

Starke-Meyerring, D., \& Wilson, Melanie. (2008). Designing globally networked learning environments: Visionary partnerships, policies, and pedagogies. Educational futures, Vol. 20. Rotterdam, the Netherlands: Sense Publishers. 
Stein, S. (2016). Rethinking the ethics of internationalization: Five challenges for higher education. InterActions: UCLA Journal of Education and Information Studies, 12(2). Retrieved from https://escholarship.org/uc/item/2nb2b9b4.

Steiner, V. (2018, March). The Potential of COIL in Entrepreneurship Education: Global Venture Incubator as a Joint Initiative in COIL. In 2018 COIL Conference ( $p$. 182). New York, NY: SUNY.

Steinert, Y. (2010). Faculty development: From workshops to communities of practice. Medical Teacher, 32(5), 425-428.

Stohl, M. (2007). We have met the enemy and he is us: The role of the faculty in the internationalization of higher education in the coming decade. Journal of Studies in International Education, 11(3-4), 359-372. https://doi.org/10.1177/1028315307303923

Streitwieser, B. (2014). Internationalisation of higher education and global mobility. In D. Philips (Ed.) Oxford studies in comparative education. Oxford, England: Symposium Books.

SUNY COIL (2018). COIL conference: Global learning for all. Retrieved from https://sunycoilconference2018.sched.com/

SUNY COIL Center (2014). Faculty guide for COIL course development (version 1.4). New York, NY: SUNY Global Center.

Sutton, S.B.(2018). Collaborative learning through international partnerships. Peer Review, 20(1), 16-20. 
Taras, V., Caprar, D. V., Rottig, D., Sarala, R. M., Zakaria, N., Zhao, F., Huang, V. Z. (2013). A global classroom? Evaluating the effectiveness of global virtual collaboration as a teaching tool in management education. Academy of Management Learning \& Education, 12(3), 414-435. https://doi.org/10.5465/amle.2012.0195

Teekens, H. (2013). Student mobility revisited. Higher Education Forum, 10, 23-34. Hiroshima, Japan: Hiroshima University RIHE.

Teekens, H. (2015). The freedom to be: International education and crossing borders. Mestenhauser Lecture on Internationalizing Higher Education, presented at the Global Programs and Strategy Alliance at the University of Minnesota, Minneapolis, MN.

Teijlingen, E. (2014) Semi-structured interviews. Retrieved from https://intranetsp.bournemouth.ac.uk/documentsrep/PGR\%20Workshop\%20\%20Interviews\%20Dec\%202014.pdf

Tervalon, M., \& Murray-Garcia, J. (1998). Cultural humility versus cultural competence: A critical distinction in defining physician training outcomes in multicultural education. Journal of Health Care for the Poor and Underserved, 9(2), 117-125.

Tuke, G. (2019, May). COIL course planning and design. Presentation at the Portland State University Faculty Scholars COIL Workshop, Portland, Oregon. Retrieved from https://www.tukeinternationalconsulting.com/resources.html 
UNESCO IBE. (2013). UNESCO International Bureau of Education glossary of curriculum terminology. Retrieved from: http://www.ibe.unesco.org/fileadmin/user_upload/Publications/IBE_GlossaryCurr iculumTerminology2013_eng.pdf

UNESCO Office Bangkok. (2014). UNESCO Asia-Pacific education policy brief, volume 2: Skills for holistic human development. Retrieved from: http://www.unescobkk.org/fileadmin/user_upload/epr/PDF/Policy_Brief_Vol228_Nov.pdf

United Nations (2015). Transforming our world: The 2030 agenda for sustainable development. Retrieved from https://sustainabledevelopment.un.org/content/documents/21252030\%20Agenda \%20for\%20Sustainable\%20Development\%20web.pdf

Urban, E. L., \& Palmer, L. B. (2014). International students as a resource for internationalization of higher education. Journal of Studies in International Education, 18(4), 305-324. https://doi.org/10.1177/1028315313511642

Van der Wende, M. (2007). Internationalization of higher education in the OECD countries: Challenges and opportunities for the coming decade. Journal of Studies in International Education, 11(3-4), 274-289.

Van Gaalen, A., \& Gielesen, R. (2014). Internationalizing students in the home countryDutch policies. International Higher Education, 78, 10-12. 
Van Gaalen, A., \& Gielesen, R. (2016). Internationalisation at home. In E. Jones, R. Coelen, J. Beelen, \& H. De Wit (Eds.), Global and local internationalization (pp. 149-154). Rotterdam, the Netherlands: Sense Publishers.

Vavrus, F. \& Pekol, A. (2015). Critical internationalization: Moving from theory to practice. FIRE: Forum for International Research, 2(2), 5-21. Retrieved from http://preserve.lehigh.edu/fire/vol2/iss2/2

Virtual Exchange Coalition (2019). What is virtual exchange? Retrieved from http://virtualexchangecoalition.org/

Wächter, B. (2003). An introduction: Internationalisation at home in context. Journal of Studies in International Education, 7(1), 5-11. https://doi.org/10.1177/1028315302250176

Ward, H. (2016). Internationalizing the co-curriculum: Global and intercultural education in the co-curriculum. Internationalization in Action. Washington, D.C.: American Council on Education. Retrieved from https://www.acenet.edu/Documents/IntlzIn-Action-Intlz-Co-Curriculum-Part-2.pdf

Warschauer, M. (1996). Motivational aspects of using computers for writing and communication. In M. Warschauer (Ed.), Telecollaboration in foreign language learning (pp. 29-46). Honolulu, HI: University of Hawaii at Manoa.

Waseda University (2012). Waseda Vision 150: A commitment to the world as Asia's leading university. Retrieved from http://www.waseda.jp/keiei/vision150/pdf/vision150_en.pdf 
Watkins, H., \& Smith, R. (2018). Thinking globally, working locally: Employability and Internationalization at Home. Journal of Studies in International Education, 22(3), 210-224. Retrieved from https://doi.org/10.1177/1028315317751686

Webster-Wright, A. (2009). Reframing professional development through understanding authentic professional learning. Review of Educational Research, 79(2), 702-739.

Weiss, R. S. (1994). Learning from strangers: The art and method of qualitative interview studies. New York, NY: The Free Press

Whatley, M. (2017). Financing study abroad: An exploration of the influence of financial factors on student study abroad patterns. Journal of Studies in International Education, 21(5), 431-449. https://doi.org/10.1177/1028315317697798

Whitehead, D. M. (2015). Global learning: Key to making excellence inclusive. Liberal Education, 101(3), 6-13. Retrieved from https://www.aacu.org/liberaleducation/2015/summer/whitehead

Whittemore, R., Chase, S. K., \& Mandle, C. L. (2001). Validity in qualitative research. Qualitative Health Research, 11(4), 522-537. https://doi.org/10.1177/104973201129119299

Wihlborg, M., \& Robson, S. (2018). Internationalisation of higher education: Drivers, rationales, priorities, values and impacts. European Journal of Higher Education, 8(1), 8-18. https://doi.org/10.1080/21568235.2017.1376696

Williams, D., Berger, J. \& McClendon, S. (2005). Toward a model of inclusive excellence and change in postsecondary institutions. Retrieved from https://www.aacu.org/sites/default/files/files/mei/williams_et_al.pdf 
FACULTY USE OF COIL FOR INTERNATIONALIZATION AT HOME

Wojcicki, E., Izumi, L.T., \& Chang, A. (2015). Moonshots in education: Launching blended learning in the classroom. San Francisco, CA: Pacific Research Institute.

Wolcott, H. (1994). Transforming qualitative data: Description, analysis, and interpretation. Thousand Oaks, CA: SAGE.

World Economic Forum (2016). The future of jobs: Employment, skills and workforce strategy for the fourth industrial revolution. Geneva, Switzerland: WEF.

World Economic Forum (2020). Schools of the future: Defining new models of education for the fourth industrial revolution. Geneva, Switzerland: WEF.

Zakaria, N., Amelinckx, A., \& Wilemon, D. (2004). Working together apart? Building a knowledge-sharing culture for global virtual teams. Creativity and Innovation Management, 13(1), 15-29.

Zha, Q. (2003). Internationalization of higher education: Towards a conceptual framework. Policy Futures in Education, 1(2), 248-270. https://doi.org/10.2304/pfie.2003.1.2.5 


\section{Appendix A: Interview Questions \& Protocol}

1. Tell me about your experience teaching a COIL course.

2. Tell me about why you are teaching a COIL course; what motivates you?

3. What have been the challenges in designing and teaching a COIL course?

4. What have been the rewards in designing and teaching a COIL course?

5. How has teaching COIL changed/informed how you teach your non-COIL courses?

6. How has teaching a COIL course influenced your views on team teaching?

7. How have you used global virtual teams in your COIL course?

8. Have you gained any new personal insights on your own identity, sense of self, and communication style as you have engaged (with faculty and students) in your COIL course? [faculty? students?]

9. What keeps you coming back to teaching with COIL?

\section{Pre-Interview Script}

Interview \#

\section{Interview Protocol}

Date $\quad 1$

Welcome and thank you for your participation today. My name is Sally Mudiamu and I am a doctoral student at Portland State University. This interview will take about 60 minutes and I will ask nine questions about your experience in preparing and teaching a Collaborative Online International Learning course, also known as "COIL". I request your permission to record this interview so that I may accurately document the information you convey. The recording will be destroyed when my study is completed. If at any time during the interview you wish to discontinue use of the digital recorder, please don't hesitate to let me know. All of your responses are confidential and will be scrubbed of any information that identifies you or your institution. The purpose of this study is to increase our understanding of COIL as a faculty-driven Internationalization at Home strategy to inform and improve its adoption and implementation in higher education.

We have each signed and dated a consent form, certifying that we agree to continue with this interview. You will receive one copy and I will keep the other in a locked cabinet, separate from your recorded responses. Your participation in this interview is completely voluntary and if at any time you need to pause or cut it short, please let me know. You may also withdraw your participation at any time without consequence.

Do you have any questions or concerns before we begin? Then, with your permission, we will start the interview. 
Interview Script

\begin{tabular}{|c|c|}
\hline $\begin{array}{l}\text { Introduction } \\
\text { ( } 5 \text { minutes })\end{array}$ & $\begin{array}{l}\text { Before asking my first interview question, I'd like to find out a } \\
\text { little more about you. Would you share how long you have been } \\
\text { teaching at }[\mathrm{x}] \text { ? What is your academic discipline? What courses } \\
\text { do you teach? What is your instructional ranking or role at }[\mathrm{x}] \text { ? }\end{array}$ \\
\hline Question 1 & $\begin{array}{l}\text { Tell me about your experience teaching a COIL course. } \\
\text { PROMPT: What is the process like? }\end{array}$ \\
\hline Question 2 & $\begin{array}{l}\text { Tell me about why you are teaching a COIL course; what } \\
\text { motivates you? } \\
\text { PROMPT: Whose idea was it? } \\
\text { PROMPT: How would you describe your motivation? }\end{array}$ \\
\hline Question 3 & $\begin{array}{l}\text { What have been the challenges in designing and teaching a COIL } \\
\text { course? } \\
\text { PROMPT: What challenges did you expect? } \\
\text { PROMPT: What challenges did you not expect? }\end{array}$ \\
\hline Question 4 & $\begin{array}{l}\text { What have been the rewards in designing and teaching a COIL } \\
\text { course? } \\
\text { PROMPT: What rewards did you anticipate? } \\
\text { PROMPT: What rewards were unexpected? }\end{array}$ \\
\hline Question 5 & $\begin{array}{l}\text { How has teaching COIL changed/informed how you teach your } \\
\text { non-COIL courses? }\end{array}$ \\
\hline Question 6 & $\begin{array}{l}\text { How has teaching a COIL course influenced your views on team } \\
\text { teaching? }\end{array}$ \\
\hline Question 7 & How have you used global virtual teams in your COIL course? \\
\hline Question 8 & $\begin{array}{l}\text { Have you gained any new personal insights on your own identity, } \\
\text { sense of self, and communication style as you have engaged with } \\
\text { [faculty][students] in your COIL course? }\end{array}$ \\
\hline $\begin{array}{l}\text { Wrap up and } \\
\text { Question } 9 \\
\text { (10 minutes) }\end{array}$ & $\begin{array}{l}\text { I want to be respectful of your time and see that we are coming to } \\
\text { the } 50 \text {-minute mark of our interview. I want to conclude with this } \\
\text { question: } \\
\text { What keeps you coming back to teaching with COIL? }\end{array}$ \\
\hline
\end{tabular}




\section{Post-Interview Script}

Thank you for sharing your experiences and observations today. I deeply appreciate the time you have given to take part in this study. Two weeks from now I will send you a follow-up email with several questions. One will ask whether any additional insights or recollections have emerged since the interview. Another will ask whether there is anything you wish to add about preparing for and teaching a COIL course or ask me from the interview. Lastly, I will ask a clarifying question from the interview based on my researcher notes. Reading and responding to the follow-up email will take 10 to 15 minutes maximum. Your email response will be de-identified from you individually and from your institution, kept in a password protected file, and destroyed after the study is completed.

The email address I have down for you is [email address]. Is this the one you prefer me to use or do you have another one you'd like to me to send the follow up email to? 


\section{Appendix B: A Priori Codes}

Internationalization

1. Internationalization of higher education

2. Globalization and international higher education

3. Internationalization of teaching

4. Institutional commitment

5. Comprehensive internationalization

6. Globalization

7. Cosmopolitanism

8. Social mobility

Internationalization at Home

1. Preparation for global work

2. Preparation for global citizenship

3. Place-bound students

4. Multi-culturalism

5. Internationalized learning

6. Internationalized pedagogy

7. Collaborative Online International Learning (COIL)

8. Student learning

Internationalization of the Curriculum

1. Internationalization of the Curriculum

2. Internationalization of teaching, learning and research

3. Disciplined-based

4. Interdisciplinary

5. Cross-disciplinary

6. learning outcomes

7. Problem-based learning

8. Scholarship of teaching and learning

9. Collaborative Online International Learning (COIL)

\section{Virtual Exchange}

1. Virtual Exchange

2. Mobility of students and faculty

3. Telecollaboration

4. Globally Networked Learning Environments

5. Virtual teams

6. Global virtual teams

7. Swift trust

8. Efficacy

9. Project-based learning 
10. Intercultural Communication

11. Online collaboration

12. Collaborative Online International Learning

13. Professional identity 


\author{
Appendix C: Study Invitation Email
}

Dear [name],

My name is Sally Mudiamu and I am researching faculty experience of teaching COIL for my doctoral dissertation at Portland State University. The working title of my study is Faculty use of COIL for Internationalization at Home. I am interested in how faculty experience the creating and teaching of a COIL course. I care deeply about supporting faculty at open access institutions like ours to help prepare our students for global work and citizenship. Your participation in my study will help shape the discussion of best practices around Internationalization at Home.

[name of gatekeeper] gave me your name. I would like to invite you to interview with me to learn more about your experience of teaching a COIL course. The interview will take just 60 minutes total with one brief email follow up communication two weeks afterwards. I am happy to come to your office on campus or at another campus location. I will schedule interviews with faculty at [name of university] over several days in October before the IVEC Conference.

I hope that you will consider participating in my study as an interviewee. I am also working with Greg Tuke at my home university to launch a COIL program. All information relating to this study will be kept both anonymous and confidential.

I thank you in advance for considering participation in my COIL study.

Sincerely yours,

Sally S. Mudiamu

Educational Leadership \& Policy Ed.D. Candidate

Director, Office of International Partnerships \& Initiatives

Portland State University 


\section{Appendix D: Informed Consent Form}

You are being asked to participate in a qualitative research study. Please consider the following information before deciding whether or not to join the study. Please feel free ask for additional information or clarification before you decide to take part. Your participation is voluntary, and you can decline to participate, or withdraw consent at any time, with no consequences.

Study Title:

Faculty use of COIL for Internationalization at Home

Researcher:

Sally S. Mudiamu, Doctoral Candidate in Educational Leadership and Policy College of Education, Portland State University, Portland, Oregon

strand@pdx.edu

503-896-6823

\section{Purpose of the Research Study:}

To explore faculty experience in the development and teaching of a Collaborative Online International Learning (COIL) course.

What you will be asked to do in the study:

1. Meet with the researcher for a 60 -minute interview that will be digitally recorded, transcribed and coded.

2. Answer a follow-up email two weeks following the interview. The email will request additional reflection or observations and ask clarifying questions from the face-to-face interview. The follow-up email read and response is designed to take between 10-30 minutes. The email response will be coded.

Total time required:

70 minutes; a 60-minute face-to-face interview and a 10-15 minute follow up email response two weeks after the interview.

Risks and benefits:

There are no risks or discomforts anticipated.

\section{Confidentiality:}

Measures taken to protect your privacy will include separating your personal information from your interview quotations and use of pseudonyms for your interview transcripts and email responses. All information will be scrubbed of any link to your institution being identified. All recordings, transcripts, emails and any other forms of communication will be kept in a secure password-protected electronic location. Any physical documents will be kept in a locked cabinet in the researcher's office. All direct quotations will be de-identified to ensure anonymity in data storage. 


\section{Compensation:}

All participants will receive a $\$ 30$ Starbucks gift card during the face-to-face interview.

Sources of funding for the research:

Not applicable.

May the researcher benefit from the research?

We may benefit professional if the results of the study are presented at meetings or in academic journals.

Withdrawal from the study:

You are free to withdraw your consent and to stop participating in this study at any time without consequence. You can decline to answer any question you don't wish to answer.

Questions about the study:

Please contact Sally Mudiamu at strand@pdx.edu or 503-896-6823 or Karen Haley, Principal Investigator (dissertation advisor) at khaley@pdx.edu

Participant Rights:

The Portland State University Institutional Review Board (IRB) is overseeing this research. The IRB is housed in the Office of Research Integrity at Portland State University. You may contact them at any time with questions at (503) 725-5484, toll free: (877) 480-4400, and/or email hsrrc@pdx.edu.

\section{Consent Statement:}

I have had the opportunity to read and consider the information on this form. I have asked any questions necessary to determine whether or not to take part in this study. I understand that I can ask more questions at any time. I understand that the interview will take 60 minutes of my time and read/response time for the follow up email will take 10 minutes of my time. I understand that the interview will be digitally recorded and that the recordings and follow up email will be destroyed once the study is complete. I understand that all information I share will remain confidential and not be connected back to me or my institution in any identifiable way.

By signing below, I understand that I am taking part in this qualitative research study voluntarily. I understand that I am not waiving any legal rights. I have been provided with a copy of this consent form. I understand that if my ability to consent for myself changes, my legal representative or myself may be asked to provide consent before I continue in this study.

I consent to join this study.

Printed Name of Adult Participant 
FACULTY USE OF COIL FOR INTERNATIONALIZATION AT HOME

Printed Name of Research Team

Signature of Research Team

Date

Member

Member 
Appendix E: Email Follow-Up to Interview

Dear [name],

Thank you again for sharing your time with me on [date] to talk about COIL. As I mentioned at the end of our time together two weeks ago, I am following up with an email to supplement the data I collected from the interview. I have several questions that I would like to ask you, which should not take much of your time:

1. Now that you have had further time to reflect after the interview, is there anything you'd like to add to your comments and observations on the preparing and teaching of a COIL course?

2. I would like to make sure I understood your comment on [x]. Could you tell me more about what you meant when you said $[\mathrm{x}]$ was $[\mathrm{x}]$ ?

3. In addition, I would like to make sure I understood your comment on [x]. Could you tell me more about what you meant when you said $[\mathrm{x}]$ was $[\mathrm{x}]$ ?

Thank you very much for taking the time to respond. I deeply appreciate your participation in this study. Your email response will be de-identified from you individually as well as your institution and kept in a password protected file. It will be destroyed after the study is completed.

If you have any further questions, please don't hesitate to contact me.

Sincerely yours,

Sally S. Mudiamu

Educational Leadership \& Policy Ed.D. Candidate

Director, Office of International Partnerships \& Initiatives

Portland State University 